Sistema de controle multi-robô baseado em colônia de formigas artificiais

Mauro Miazaki 



\title{
Sistema de controle multi-robô baseado em colônia de formigas artificiais ${ }^{1}$
}

\author{
Mauro Miazaki
}

Orientador: Prof. Dr. Eduardo do Valle Simões

Dissertação apresentada ao Instituto de Ciências Matemáticas e de Computação - ICMC-USP, como parte dos requisitos para obtenção do título de Mestre em Ciências - Ciências de Computação e Matemática Computacional.

\section{“VERSÃO REVISADA APÓS A DEFESA"}

Data da Defesa:

$18 / 04 / 2007$

Visto do Orientador:

\section{USP - São Carlos \\ Junho/ 2007}

Trabalho realizado com auxílio financeiro do CNPq. 

à minha família e aos meus amigos 



\section{Agradecimentos}

Agradeço aos meus pais, Yuzo e Luzia, pelo valioso apoio e suporte emocional e financeiro.

Ao meu amigo e orientador Eduardo Simões, pela valiosa amizade e orientação.

Ao meu amigo Danilo Costa pela valiosa amizade e ajuda neste trabalho.

Aos meus amigos Leizza Rodrigues e Marcos Quiles pelas contribuições neste trabalho.

Ao CNPq pelo suporte financeiro.

Aos meus irmãos Luciana e Marcio pelo apoio.

Aos meus amigos Alex Miura, Daniel Honorato, Edson Matsubara, Luziana Sant' Ana, Marcio Morinishi, Marcio Crocomo, Ronaldo Prati, Sayuri Matsubara, Sidney Sato, Valter Inácio e Wellington Kanno por tantos anos compartilhados de apoio, amizade e alegria em São Carlos. 



\section{Resumo}

Visando contribuir com o estado-da-arte de sistemas bioinspirados na robótica, neste trabalho é abordado o problema do controle de um grupo de robôs para a solução coletiva das tarefas de exploração do ambiente e localização de objetos. Para isso, são utilizados algoritmos inspirados em colônias de formigas. O objetivo deste trabalho, portanto, é o desenvolvimento de um sistema de controle de navegação baseado em colônia de formigas para um time de robôs, de maneira que os robôs resolvam esses problemas utilizando estratégias de controle individuais e simples. Esse sistema tem como base a utilização de marcadores ou feromônios artificiais, que podem ser depositados pelos robôs para marcar determinadas posições do ambiente. 



\section{Abstract}

To advance the state-of-the-art of bioinspired systems in robotics, this work studies the problem of controling a group of robots for solving colective tasks in environment exploration and object localization. To achieve this, we used algorithms inspired in ant colonies. Therefore, the objective of this work is the development of a navigation control system based on ant colony that can solve the problems using simple control strategies. This system uses marks or artificial pheromones that can be released by the robots to mark specific positions in the environment. 



\section{Sumário}

Sumário $\quad$ ix

Lista de Figuras $\quad$ xi

Lista de Tabelas $\quad$ xiii

1 Introdução 1

1.1 Objetivo . . . . . . . . . . . . . . . . . 8

1.2 Estrutura da Dissertação . . . . . . . . . . . . . . . . . . . . . . 10

2 Colônias de formigas $\quad 11$

2.1 Formigas biológicas . . . . . . . . . . . . . . . . . . . . 12

2.2 Formigas artificiais . . . . . . . . . . . . . . . . 15

3 Feromônios artificiais $\quad 21$

3.1 Trilhas químicas e sensores de odores . . . . . . . . . . . . . . 21

3.2 Cadeia de robôs . . . . . . . . . . . . . . . . . . . . 23

3.3 Proposta de uma grade de feromônios artificiais . . . . . . . . . . . . 25

4 Projeto do sistema $\quad 31$

4.1 Arquitetura física . . . . . . . . . . . . . . . . . . . . . . . . . . . 33

4.2 Módulos lógicos . . . . . . . . . . . . . . . . . . . . . . . . 35

4.2.1 Módulo de Processamento de Imagens . . . . . . . . . . . . . . 35

4.2 .2 Módulo de Simulação . . . . . . . . . . . . . . . . . . . . . . . . 41

4.2 .3 Módulo de Controle . . . . . . . . . . . . . . . . . . . . . . . 42

4.2.4 Módulo de Radiofreqüência . . . . . . . . . . . . . . . . . . . 44

4.2.5 Comunicação entre os módulos . . . . . . . . . . . . . . . . 44

4.2 .6 Ambiente unificado . . . . . . . . . . . . . . . . . 45

$\begin{array}{lll}5 & \text { Experimentos } & 47\end{array}$

5.1 Experimento 1: Simulação para analisar os efeitos da variação na concentração do feromônio depositado . . . . . . . . . . . . . . . . . . 48 
5.2 Experimento 2: Simulação para analisar as configurações do Experimento 1 em uma arena menor . . . . . . . . . . . . . . 50

5.3 Experimento 3: Robôs simulados trabalhando com o robô real . . . . . 59

6 Conclusão $\quad 61$

$\begin{array}{ll}\text { Referências Bibliográficas } & 63\end{array}$

$\begin{array}{ll}\text { A Localização de robôs por padrões de cores } & 71\end{array}$

A.1 Marcadores . . . . . . . . . . . . . . . . . . . 71

A.2 Interface Gráfica . . . . . . . . . . . . . . . . . . . . . . . . . . . . . . . . . . .

A.3 Segmentação de Cores . . . . . . . . . . . . . . . . . . . . . . . . . . . . . . . . . . .

A.4 Captura de Protótipos . . . . . . . . . . . . . . . . 75

A.5 Rastreamento de Objetos . . . . . . . . . . . . . 76 


\section{Lista de Figuras}

3.1 Sensor de odores . . . . . . . . . . . . . . . . . . . 23

3.2 Cadeia de robôs formando uma trilha entre o ninho e a presa . . . . . . 25

3.3 Movimentos válidos para o robô-formiga . . . . . . . . . . . . . 27

3.4 Mapeamento da grade na imagem . . . . . . . . . . . . . . . . . 27

3.5 Exemplos de áreas de sensoreamento do robô-formiga . . . . . . . . . . 29

4.1 Arquitetura física do sistema . . . . . . . . . . . . . . . . . 32

4.2 Módulos lógicos do sistema . . . . . . . . . . . . . . . . . . . . . . . . 32

4.3 Imagem dos LEDs obtida pela câmera de vídeo com o filtro de luz infravermelha ....................... 36

4.4 Vizinhança-de-8 . . . . . . . . . . . . . . . . . . . 38

4.5 Câmera de vídeo CCD equipada com um filtro de luz infravermelha . . 39

4.6 Imagem ampliada do LED de luz infravermelha . . . . . . . . . . . . 39

4.7 Disposição dos LEDs de luz infravermelha sobre o robô . . . . . . . . . 39

4.8 MPI de localização por LEDs . . . . . . . . . . . . . . . . . . . . 39

4.9 Aparelho de radiofreqüência . . . . . . . . . . . . . . . . . . . 40

4.10 Robô utilizado . . . . . . . . . . . . . . . . . . . . . . . . . 40

4.11 Tela do simulador . . . . . . . . . . . . . . . . . . . . 40

4.12 Comunicação entre os módulos . . . . . . . . . . . . . . . . 45

4.13 Exemplo de configuração de ambiente físico e exemplo de visão integrada dos ambientes simulado e real . . . . . . . . . . . . . . . 46

5.1 Área explorada por iteração pelos robôs simulados no Experimento 1, utilizando FF e FCA. . . . . . . . . . . . . . . . . . . . . . 52

5.2 Área explorada por iteração pelos robôs simulados no Experimento 1, utilizando FFT e FCA. . . . . . . . . . . . . . . . . . . . 52

5.3 Número de iterações necessário para se encontrar N objetos no Experimento 1, utilizando FF e FCA. . . . . . . . . . . . . . . 53

5.4 Número de iterações necessário para se encontrar N objetos no Experimento 1, utilizando FFT e FCA. . . . . . . . . . . . . . . 53 
5.5 Área explorada por iteração pelos robôs simulados no Experimento 2, utilizando FF e FCA. . . . . . . . . . . . . . . . . . . . . . . . . 54

5.6 Área explorada por iteração pelos robôs simulados no Experimento 2, utilizando FFT e FCA. . . . . . . . . . . . . . . . . . . 54

5.7 Comparação dos resultados de área explorada em FCA e das médias de FF e de FFT no Experimento 2. . . . . . . . . . . . . . . 55

5.8 Arena simulada e arena real . . . . . . . . . . . . . . 55

5.9 Número de iterações necessário para se encontrar N objetos no Experimento 2, utilizando FF e FCA. . . . . . . . . . . . . . . 56

5.10 Número de iterações necessário para se encontrar N objetos no Experimento 2, utilizando FF e FCA. . . . . . . . . . . . . . . 56

5.11 Comparação da área explorada utilizando somente robôs simulados ou o robô real com os simulados. . . . . . . . . . . . . . . . . 57

5.12 Comparação dos dados sobre localização de objetos utilizando somente robôs simulados ou o robô real com os simulados. . . . . . . . . . . . . 57

A.1 Espaço de cores RGB . . . . . . . . . . . . . . . . . . . 73

A.2 Espaço de cores HSI . . . . . . . . . . . . . . . . . . 73

A.3 Exemplo de consulta à matriz de segmentação de cores . . . . . . . . . 75

A.4 $2^{\text {a }}$ iteração do processo de busca de um protótipo . . . . . . . . . . . 77

A.5 Os três primeiros passos da $3^{\text {a }}$ iteração do processo de busca de um

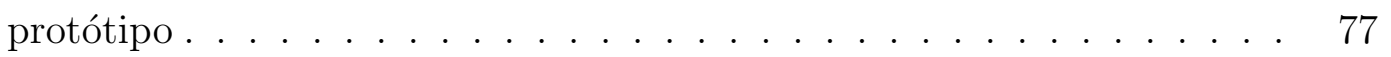

A.6 "Irradiação" da área de busca . . . . . . . . . . . . . . . . . . 78

A.7 Exemplos de marcadores de robôs . . . . . . . . . . . . . . . . . . . . 79

A.8 Tela Principal . . . . . . . . . . . . . . . . . . . . . . . . 79

A.9 Tela de Calibração . . . . . . . . . . . . . . . . . . . . . . . . . 80

A.10 Visualização da segmentação de imagens . . . . . . . . . . . . . . . . . 80

A.11 Seleção do robô para rastreamento . . . . . . . . . . . . . . . . . . . 81

A.12 Exemplo de protótipo e de vetor histograma . . . . . . . . . . . . . . 81

A.13 Exemplo de marcador de robô com as regiões de busca por marcadores de localização e orientação do robô destacadas . . . . . . . . . . . . . . 81 


\section{Lista de Tabelas}

1.1 Exemplos de projetos de robótica inspiradas em colônias de formigas e em inteligência de enxames. . . . . . . . . . . . . . . . 5 5

1.2 Exemplos de projetos de robótica inspiradas em colônias de formigas e em inteligência de enxames (Continuação da Tabela 1.1) . . . . . . . . .

1.3 Exemplos de projetos de robótica inspiradas em colônias de formigas e em inteligência de enxames (Continuação da Tabela 1.2) . . . . . . . . 7 



\section{Capítulo 1}

\section{Introdução}

Ao longo da história evolutiva dos seres vivos, em algumas espécies, os indivíduos começaram a se comunicar e cooperar entre si, proporcionando o desenvolvimento de organizações coletivas. Essa união possibilitou o surgimento de sociedades que se tornaram cada vez mais complexas, auto-suficientes, com castas e divisão de trabalho (Bueno e Campos-Farinha, 1999). Geralmente, a associação a essas características mais imediata que vem à mente são os seres humanos. Porém, também existem outras espécies na natureza que se encaixam perfeitamente nessa descrição. As formigas, legítimos representantes de comunidades sociais, também são um exemplo indicativo de que a cooperação entre indivíduos pode ser um importante fator diferencial de sucesso na batalha pela sobrevivência. Suas colônias existem há milhões de anos (Grimaldi e Agosti, 2000) e continuam se espalhando pelo planeta, apesar das adversidades naturais e dos contínuos esforços humanos para exterminá-las. Isso demonstra sua versatilidade e ca-

pacidade de adaptação às mais variadas dificuldades. É nessa inspiração da natureza que, nos últimos anos, diversos pesquisadores vêm concentrando seus esforços para o desenvolvimento de novas formas de controle de equipes de robôs autônomos.

Diversos trabalhos na literatura apontam as vantagens da utilização de times de robôs de menor capacidade ao invés de apenas um, maior e mais capaz, para a execução de tarefas de difícil planejamento prévio. Um sistema multirobótico é mais maleável e pode se adaptar com maior facilidade às variações no ambiente de trabalho (Nelson 
et al., 2004a; Thakoor et al., 2004). Isso acontece porque quando um time de robôs está disponível, cada agente pode conter sensores e atuadores diferentes e, até mesmo, diferentes capacidades de processamento. Com isso, têm-se indivíduos com diferentes habilidades que podem ser combinadas para produzir uma maior variabilidade de comportamentos do que os obtidos com um único robô. Um sistema multirobótico é também mais tolerante a falhas, pois, se ocorrerem problemas em um dos robôs, os outros ainda poderão completar a tarefa (Barker e Tyrrell, 2005). Se isso ocorresse em uma solução que utilize um único robô, o trabalho não seria concluído. Pode-se também utilizar estratégias inspiradas em colônias de insetos, nas quais vários robôs simples e de baixo custo podem ser combinados para a execução de uma tarefa na qual a complexidade da solução final pode ser maior do que a soma das partes (Martinoli et al., 2004). Para tarefas de alto risco, um robô de alto custo pode ser substituído por um time de robôs mais simples e "descartáveis", capazes de obter a mesma funcionalidade de um robô mais complexo (Terrile et al., 2005).

Apresentadas as vantagens de sistemas multirobóticos, surge a questão: porquê a indústria não tem se voltado para sua produção ao invés de sistemas monorobôs? A resposta pode estar na grande dificuldade de se controlar um sistema multirobótico (Zhang et al., 2004). As técnicas de controle mais utilizadas para sistemas robóticos são sistemas de controle centralizados, nos quais a solução para o problema foi codificada com base no conhecimento de especialistas, gerando soluções rígidas de difícil adaptatividade às variações nas condições do ambiente de trabalho (Michel, 2004; Bekey, 2005). Quando o robô resultante é submetido às condições ruidosas de ambientes reais, esses sistemas possuem dificuldades para controlar corretamente o robô, pois o universo de possibilidades que este pode encontrar geralmente é bem maior do que a capacidade de previsão e antecipação dos projetistas. Quando, ao invés de um único robô, times de robôs são submetidos a esses ambientes ruidosos, a quantidade de efeitos imprevisíveis que o sistema deve tratar cresce rapidamente, pois será maior o número de mecanismos e dispositivos interagindo com o meio (Nelson et al., 2004b). Até mesmo com pequenos números de robôs, sistemas de controle rígidos tornam-se impraticáveis, pois 
o problema já não pode mais ser decomposto e tratado de maneira "top-down" por um especialista.

Além disso, os sistemas de controle centralizados, apesar de serem mais fáceis de projetar, apresentam a desvantagem de necessitar comunicação contínua entre os robôs e o sistema de controle, muitas vezes remotamente situado (Wang, 2002). Se ocorrerem problemas de comunicação, o sistema pode parar de operar. Desta maneira, sistemas de controle descentralizados, que possam ser embarcados no hardware dos robôs, são muito mais tolerantes a falhas de comunicação e provêem maior autonomia ao time de robôs (Korenek e Sekanina, 2005).

Com relação à dificuldade de se controlar sistemas multi-robôs complexos, a natureza nos oferece vários exemplos bem sucedidos. Inspirada nesses exemplos biológicos, a Computação Bioinspirada estuda e desenvolve técnicas para a resolução de problemas complexos (Carvalho et al., 2004). Através da investigação dos processos e mecanismos naturais, são desenvolvidas abordagens alternativas para serem aplicadas aos problemas tradicionais da computação e da engenharia. Entre suas principais áreas, destacam-se: Redes Neurais Artificiais (Quiles et al., 2004), Computação Evolutiva (Bongard e Lipson, 2004) e a Inteligência de Enxames (Swarm Intelligence), nas quais estão incluídos os algoritmos inspirados em formigas (Labella et al., 2004a). Nos últimos anos, técnicas inspiradas no estudo da inteligência emergente da interação entre seres coletivos e sociais têm ganhado destaque na comunidade científica. Assim, o trabalho proposto vem investigar métodos bioinspirados em formigas, que são mais propícios para a implementação de sistemas de controle embarcados descentralizados e independentes de processamento externo (Simões e Dimond, 1999).

A primeira proposta de algoritmo de formigas a aparecer na literatura para resolver problemas de otimização combinatórios difíceis, como o Problema do Caixeiro Viajante e o Problema de Atribuição Quadrática, foi o Ant System (AS), proposto por Dorigo e seus colegas (Dorigo et al., 1991, 1996), no início dos anos 1990. Logo, outras variantes do AS surgiram, adaptados para a resolução de outros problemas de otimização combinatórios. Anos mais tarde, com o intuito de disponibilizar um framework para 
algoritmos de formiga, Dorigo propôs a terminologia Ant Colony Optimization Metaheuristic (ACO) (Dorigo e Di Caro, 1999). AS é considerado o primeiro algoritmo ACO proposto. As outras variantes de AS também foram agrupadas sob o termo ACO. A idéia básica de ACO é a de imitar o comportamento de depositar e seguir trilhas de feromônio das formigas para resolver problemas de otimização. Não se pretende, porém, a construção de um simulador de formigas. As formigas artificiais em ACO apenas são inspiradas e implementam algumas das características das naturais, julgadas relevantes para a solução de problemas, além de possuírem algumas características não existentes em formigas biológicas.

Uma outra proposta de aplicação inspirada em formigas é a de Vittori e Araújo (2001), que aplicou as idéias de trilhas de feromônio em roteamento de telecomunicações. Foram realizados estudos e experimentos sobre o comportamento das formigas argentinas (Linepithema humile), que foram modelados em equações matemáticas. Em seguida, foi construída uma aplicação para simular as formigas em um grafo, no qual se podia bloquear ou liberar a passagem por certos nós.

Relacionado à robótica, há, por exemplo, o projeto Swarm-bots, coordenado por Dorigo, que visa criar um enxame de pequenos robôs com comportamento inspirado em insetos sociais, como as formigas e cupins (Pettinaro et al., 2002). Para a robótica, a característica das colônias de formigas que mais chama a atenção é a capacidade de interação entre indivíduos simples para a realização de tarefas complexas sem liderança global e com comunicação apenas local. A implantação dessa característica em um time de robôs simplificaria seus sistemas e dispensaria a necessidade de estações coordenadoras remotas, reduzindo custos e aumentando a robustez do sistema, que passaria a ter uma maior tolerância a faltas, pois se um robô parar de funcionar, os outros poderiam assumir automaticamente suas tarefas (Cao et al., 1997). A escalabilidade também é outro fator importante, pois a inclusão de um novo robô não necessitaria de alterações no sistema, sendo ele automaticamente detectado e incorporado ao time. Outros exemplos de aplicação em multirobótica de algoritmos inspirados em inteligência de enxames e algoritmos de formigas podem ser vistos nas Tabelas 1.1, 1.2 e 1.3. 
Tabela 1.1: Exemplos de projetos de robótica inspiradas em colônias de formigas e em inteligência de enxames.

\begin{tabular}{|c|c|c|}
\hline $\begin{array}{l}\text { Nome do } \\
\text { Projeto }\end{array}$ & & Informações sobre o Projeto \\
\hline \multirow{4}{*}{$\begin{array}{l}\text { The Ants: } \\
\text { A Community } \\
\text { of Microrobots }\end{array}$} & Instituição & $\begin{array}{l}\text { Artificial Intelligence Lab - AI Lab } \\
\text { (Massachusetts Institute of Technology - MIT) }\end{array}$ \\
\hline & Local & Estados Unidos da América \\
\hline & Homepage & http://www.ai.mit.edu/projects/ants \\
\hline & Descrição & $\begin{array}{l}\text { "The Ants" (As Formigas) são uma comunidade } \\
\text { de microrobôs. A idéia desse projeto foi construir } \\
\text { uma comunidade robótica estruturada através das } \\
\text { interações de muitos indivíduos simples. A ins- } \\
\text { piração vem das colônias de formigas. Cada mi- } \\
\text { crorobô mede aproximadamente } 3,5 \text { x } 3,5 \mathrm{~cm} \text { na } \\
\text { base e } 3,0 \mathrm{~cm} \text { de altura. Seu peso é de aproxima- } \\
\text { damente } 33,5 \mathrm{~g} \text { (McLurkin, 1996). }\end{array}$ \\
\hline \multirow[t]{4}{*}{$\begin{array}{l}\text { Collaborative } \\
\text { Stick Pulling }\end{array}$} & Instituição & $\begin{array}{l}\text { Swarm-Intelligent Systems Group - SWIS } \\
\text { (École Polytechnique Fédérale de Lausanne - } \\
\text { EPFL) }\end{array}$ \\
\hline & Local & Suíça \\
\hline & Homepage & http://www5.epfl.ch/swis/page1353.html \\
\hline & Descrição & $\begin{array}{l}\text { Neste projeto foi desenvolvida uma metodolo- } \\
\text { gia de modelagem de sistemas para manipulação } \\
\text { robótica distribuída baseada em enxames. A me- } \\
\text { todologia proposta não necessita de medições do } \\
\text { ambiente, pois não leva em consideração a tra- } \\
\text { jetória dos robôs ou a distribuição espacial dos } \\
\text { objetos. O modelo foi construído de forma incre- } \\
\text { mental, com validação dos modelos em simulações } \\
\text { e em robôs reais, a cada passo em que aumen- } \\
\text { tava a complexidade do sistema (Ijspeert et al., } \\
2001 \text { ). Dois problemas foram considerados neste } \\
\text { estudo. O primeiro foi o de agregação, que con- } \\
\text { sistiu na manipulação não colaborativa de peque- } \\
\text { nos objetos, inicialmente dispersos em uma arena } \\
\text { fechada, para sua coleta e agrupamento. O outro } \\
\text { problema foi o stick-pulling (puxar o bastão) e en- } \\
\text { volveu estrita manipulação colaborativa. A tarefa } \\
\text { dos robôs foi puxar bastões para fora de buracos } \\
\text { no chão da arena de forma colaborativa. }\end{array}$ \\
\hline
\end{tabular}

Em colônias de formigas biológicas, os problemas de exploração do ambiente e localização de objetos (principalmente comida) são resolvidos com o estabelecimento de trilhas, o que é realizado de forma simples e distribuída. As formigas marcam 
Tabela 1.2: Exemplos de projetos de robótica inspiradas em colônias de formigas e em inteligência de enxames (Continuação da Tabela 1.1).

\begin{tabular}{|c|c|c|}
\hline $\begin{array}{l}\text { Nome do } \\
\text { Projeto }\end{array}$ & & Informações sobre o Projeto \\
\hline \multirow{4}{*}{$\begin{array}{l}\text { Swarm } \\
\text { Project }\end{array}$} & Instituição & iRobot Corporation \\
\hline & Local & Estados Unidos da América \\
\hline & Homepage & http://www. irobot.com/sp.cfm?pageid=149 \\
\hline & Descrição & $\begin{array}{l}\text { O objetivo deste projeto foi construir uma pla- } \\
\text { taforma de desenvolvimento com algoritmos dis- } \\
\text { tribuídos para enxames robóticos compostos por } \\
\text { centenas de robôs. Foram projetados algoritmos } \\
\text { de controle de indivíduos, para serem robustos à } \\
\text { complexidade de ambientes do mundo real, e de } \\
\text { controle do grupo, sendo tolerante à adição ou } \\
\text { falha de qualquer número de indivíduos. Assim, } \\
\text { a plataforma é flexível, podendo funcionar tanto } \\
\text { com grupos de } 10 \text { ou de } 10.000 \text { indivíduos (McLur- } \\
\text { kin e Smith, 2004). Este projeto foi financiado } \\
\text { pela Defense Advanced Research Projects Associ- } \\
\text { ation (DARPA). }\end{array}$ \\
\hline \multirow[t]{4}{*}{ U-bot } & Instituição & $\begin{array}{l}\text { Intelligent Autonomous Systems Laboratory - } \\
\text { IAS Lab } \\
\text { (University of the West of England - UWE) }\end{array}$ \\
\hline & Local & Reino Unido \\
\hline & Homepage & $\begin{array}{l}\text { http://www.ias.uwe.ac.uk/Robots/u-bot. } \\
\text { htm }\end{array}$ \\
\hline & Descrição & $\begin{array}{l}\text { Os U-bots são pequenos robôs simples e com ca- } \\
\text { pacidades limitadas. Foram projetados para in- } \\
\text { vestigar os comportamentos emergentes baseados } \\
\text { em algoritmos de formigas e cupins. Os estudos } \\
\text { concentraram-se em estruturas emergentes, como } \\
\text { construção de paredes e de estruturas complexas } \\
\text { de ninhos, e a classificação e separação coletiva } \\
\text { de diferentes objetos em agrupamentos (Holland } \\
\text { e Melhuish, 1999). }\end{array}$ \\
\hline
\end{tabular}

um caminho depositando feromônio - uma substância química detectável por outras formigas - por onde passam. Deneubourg et al. (1990) demonstrou que o processo de marcar uma trilha de feromônio para que outras formigas possam segui-la é uma boa estratégia para encontrar o menor caminho entre o ninho e a fonte de comida.

Um dos problemas estudados por biólogos foi entender como animais quase cegos como as formigas possuíam a habilidade de estabelecer as menores rotas entre sua 
Tabela 1.3: Exemplos de projetos de robótica inspiradas em colônias de formigas e em inteligência de enxames (Continuação da Tabela 1.2).

\begin{tabular}{|c|c|c|}
\hline $\begin{array}{l}\text { Nome do } \\
\text { Projeto }\end{array}$ & \multicolumn{2}{|r|}{ Informações sobre o Projeto } \\
\hline \multirow{4}{*}{ UltraSwarm } & Instituição & University of Essex \\
\hline & Local & Reino Unido \\
\hline & Homepage & http://gridswarms.essex.ac.uk \\
\hline & Descrição & $\begin{array}{l}\text { O propósito do projeto UltraSwarm (Holland } \\
\text { et al., 2005) é o desenvolvimento de um sistema de } \\
\text { controle de um grande grupo de pequenos veículos } \\
\text { aéreos autônomos que possam voar de forma ágil } \\
\text { e que possuam computadores a bordo interco- } \\
\text { nectados através de uma rede sem fio (wireless } \\
\text { network) de curto alcance, formando um enorme } \\
\text { computador distribuído. Essa grande quantidade } \\
\text { de recursos computacionais poderia ser utilizada } \\
\text { para processar os dados coletados pelos senso- } \\
\text { res do enxame e para direcionar as ações cole- } \\
\text { tivas. A sua inspiração biológica são os ban- } \\
\text { dos de pássaros, que são formados por indivíduos } \\
\text { que agem de forma independente uns dos ou- } \\
\text { tros. Porém, apesar de não haver coordenação } \\
\text { centralizada, o grupo se move de maneira coor- } \\
\text { denada (cada indivíduo voando aproximadamente } \\
\text { na mesma velocidade e mantendo certa distância } \\
\text { entre agentes). Atualmente, um simulador está } \\
\text { sendo utilizado para desenvolver o sistema. Mas } \\
\text { uma arena já se encontra em construção para a } \\
\text { utilização de pequenos helicópteros. Este trabalho } \\
\text { é uma continuação do projeto Gridswarms, que in- } \\
\text { vestigou a mesma idéia, mas com aeromodelos. }\end{array}$ \\
\hline
\end{tabular}

colônia e a fonte de alimentos. Foi descoberto que o meio empregado de comunicar informações entre indivíduos sobre caminhos são as trilhas de feromônio. Uma formiga em movimento deposita feromônio (em quantidades variadas) no solo, marcando o caminho com uma trilha dessa substância. Enquanto uma formiga isolada se move essencialmente de forma aleatória, uma formiga próxima a uma trilha previamente depositada pode detectá-la e decidir, com alta probabilidade, segui-la, reforçando a trilha com seu próprio feromônio. O comportamento coletivo que emerge é uma forma de comportamento autocatalítico, no qual quanto mais formigas seguem uma trilha, 
mais ela fica atrativa a ser seguida. Assim, o processo é caracterizado por um laço de realimentação positiva (positive-feedback loop), em que a probabilidade de uma formiga escolher um caminho aumenta com o número de formigas que previamente escolheram o mesmo caminho.

\subsection{Objetivo}

Este trabalho foi inspirado em pesquisas no comportamento de formigas biológicas (Dorigo et al., 1996; Vittori e Araújo, 2001; Pettinaro et al., 2002; Vargas et al., 2004; Vargas e Simões, 2004), sugerindo uma abordagem em que as atividades de busca são distribuídas entre os agentes que possuem capacidades muito simples e limitadas e que imitam o comportamento de formigas biológicas. Visando contribuir com o estado-da-arte de sistemas bioinspirados em formigas na robótica, é abordado neste trabalho o problema do controle de um grupo de robôs para a solução coletiva das tarefas de exploração do ambiente e localização de objetos. Para isso, são utilizados algoritmos inspirados em colônias de formigas para fazer com que os robôs resolvam esses problemas utilizando estratégias de controle individuais e simples.

O objetivo deste trabalho, portanto, é o desenvolvimento de um sistema de controle de navegação baseado em colônia de formigas para um time de robôs com as tarefas de exploração e busca de objetos. Esse sistema tem como base a utilização de marcadores ou feromônios artificiais, que podem ser depositados pelos robôs para marcar determinadas posições do ambiente. Esses marcadores devem ser percebidos pelos sensores dos robôs, que precisam poder distinguir suas diferentes concentrações. Com base nessas diferenças de concentração, os robôs podem calcular seus deslocamentos no ambiente. Os robôs devem percorrer o ambiente, trabalhando cooperativamente para cobrir a maior área possível na busca por objetos específicos. Para atingir o objetivo proposto, faz-se necessário a implementação de um time de robôs; o desenvolvimento de uma forma eficiente para possibilitar a marcação do ambiente com feromônios artificiais; e a realização de experimentos de exploração e busca de objetos para validação do sistema.

Devido à indisponibilidade de um grande número de equipamentos robóticos sufi- 
cientes para se formar uma colônia para este trabalho e os altos custos de aquisição ou desenvolvimento de robôs e sensores, o sistema será implementado segundo uma abordagem mista. Serão combinados elementos do ambiente real com um ambiente simulado. Desta forma, os robôs reais disponíveis podem interagir com robôs simulados, aumentando artificialmente o número de indivíduos na colônia.

O sistema proposto neste trabalho será projetado de forma modular para facilitar a integração ou substituição de componentes no sistema. Outro ponto que deve ser levado em consideração é a escalabilidade. O usuário deve poder utilizar somente robôs reais, somente robôs simulados ou uma combinação dos dois. O próprio sistema irá gerenciar esses elementos, de forma unificada e independente do tipo. Dessa forma, não será necessário implementar algoritmos de controle diferenciados para se utilizar robôs reais, robôs simulados ou uma combinação dos dois. Um único algoritmo de controle será suficiente para navegar todos os robôs disponíveis, simulados ou reais. A diferenciação será tratada de maneira transparente pelo sistema. Essa abordagem torna-se necessária para viabilizar experimentos com grandes colônias de robôs que irão validar o modelo de controle proposto. O sistema deve gerenciar os robôs simulados de maneira a tornar transparente para o modelo de controle que alguns robôs não são reais.

Para a detecção da trilha de feromônio, devido à dificuldade de adquirir ou desenvolver um sensor para essa tarefa, serão utilizados feromônios virtuais. Cada robô possuirá na memória interna uma tabela de localização dos feromônios depositados por todos os agentes, atualizada a cada iteração. Cada vez que um robô (simulado ou real) deposita um feromônio, ele informa os outros robôs via rádio das respectivas coordenadas do depósito. Assim, todos os robôs podem atualizar suas tabelas internas de feromônio. Para sensoriar o ambiente, cada robô conterá um par de "antenas" virtuais capazes de perceberem as concentrações de feromônio em sua vizinhança. Essa abordagem facilitará a utilização das marcações com feromônios e possibilitará a validação dos algoritmos, que poderão, futuramente, sem qualquer modificação, ser utilizados com sensores químicos, logo que estejam disponíveis a baixo custo e com tamanho reduzido. 


\subsection{Estrutura da Dissertação}

A seguir, no Capítulo 2 são abordadas as colônias de formigas, tanto as biológicas quanto as artificiais. No Capítulo 3, são revisadas algumas das formas de implementação de feromônios encontradas na literatura e apresentada a abordagem proposta por este trabalho para essa questão. O desenvolvimento do projeto do sistema proposto encontra-se no Capítulo 4. Em seguida, no Capítulo 5, são relatados e comentados os experimentos e seus resultados. Para finalizar este trabalho, no Capítulo 6, são discutidas as conclusões, dificuldades e os trabalhos futuros. 


\section{Capítulo 2}

\section{Colônias de formigas}

A formiga é considerada um inseto social, pois vive em comunidade com outras formigas e possui comportamentos mais direcionados à preservação da sobrevivência da colônia como um todo do que a sua própria existência. Os insetos sociais, como formigas, cupins, abelhas e vespas, chamaram a atenção de muitos cientistas devido ao alto nível estrutural que suas colônias conseguem atingir, especialmente quando comparado com a relativa simplicidade dos indivíduos componentes da colônia (Roulston e Silverman, 2002).

Os insetos sociais possuem uma das estratégias de sobrevivência mais bem sucedidas da natureza, o que pode ser comprovado pela sua imensa quantidade e variedade. Segundo Wilson (2000), existem mais espécies de formigas em um quilômetro quadrado de uma floresta brasileira do que todas as espécies de primatas existentes no mundo. Uma simples colônia de formigas pode conter mais habitantes do que todos os elefantes

e leões da África somados. A organização social desses insetos se apresenta aos biólogos como um tópico instigante de estudo e comparação. Entretanto, a riqueza e diversidade dos insetos sociais são tão grandes que, apesar do grande estudo sobre essas criaturas, ainda há muitas espécies pouco investigadas ou completamente desconhecidas. 


\subsection{Formigas biológicas}

As formigas pertencem a uma única família, a Formicidae, que faz parte da ordem Hymenoptera, a qual também inclui abelhas, vespas, e outras formas similares. O nome formiga deriva-se do ácido fórmico, que é uma substância produzida por uma glândula nas formigas, particularmente daquelas pertencentes à subfamília Formicinae. Entretanto, a maioria das espécies de formigas não tem ácido fórmico e pertence à subfamília Myrmicinae. Assim, passou-se a chamar de Mirmecologia o campo da Entomologia dedicado ao estudo das formigas (Hölldobler e Wilson, 1990).

As formigas constituem o grupo de insetos sociais mais amplamente distribuído e numericamente abundante na natureza. Possuem um extensivo registro fóssil que começa no médio Cretáceo e torna-se abundante nos depósitos de âmbar de acúmulos terrestres do Oligoceno e Mioceno. Atualmente, sua presença é verificada em praticamente todos os ambientes terrestres, exceto nos pólos, e estima-se que no mundo existam aproximadamente 15.000 espécies de formigas (Hölldobler e Wilson, 1990). Embora alguns de seus gêneros sejam pragas agrícolas, provocando prejuízos consideráveis à agricultura, as formigas desempenham um papel importante nos ecossistemas terrestres por controlarem as populações de diversos outros grupos animais (Hölldobler e Wilson, 1994). Todas as formigas, junto com os cupins e algumas vespas e abelhas, são altamente sociais (eussociais), sendo conhecidas como insetos sociais. As características que definem um comportamento eussocial são: divisão do trabalho, com indivíduos responsáveis pela reprodução e indivíduos estéreis responsáveis pelos outros trabalhos, como forrageamento (localização e transporte de comida para o ninho) e defesa do ninho (em algumas espécies ocorre diferenciação morfológica entre as castas que cuidam de cada função); cuidados com a prole, alimentação e proteção das crias; sobreposição de gerações, com pelo menos duas gerações coabitando o ninho ao mesmo tempo (Daly et al., 1979).

As formigas apresentam uma grande diversidade de formas e comportamentos, chegando a apresentar diferenças extremas de tamanho, cor, pilosidade e agressividade 
dentro de um mesmo gênero. O tamanho do corpo costuma variar entre $1 \mathrm{~mm}$ e $4 \mathrm{~cm}$ de comprimento e o tamanho da população das colônias varia entre uma dezena a alguns milhões de indivíduos. Ocupam quase todos os nichos disponíveis nos ambientes terrestres e nidificam desde a copa das árvores a alguns metros de profundidade no solo (Hölldobler e Wilson, 1990). Acredita-se que nas florestas tropicais da Amazônia, formigas e cupins compreenderiam juntos cerca de 1/3 da biomassa animal (Hölldobler e Wilson, 1994).

Tal como nos bandos de aves ou cardumes de peixes, nas colônias de formigas não existe um líder (ou mesmo uma hierarquia de líderes) que determine o comportamento individual de cada elemento da população com um fim comum bem determinado. Pelo contrário, esse fim comum resulta da conjugação e interação entre os elementos da população de forma "espontânea". No entanto, e ao contrário dos bandos de aves e cardumes de peixes, existe nas colônias de formigas uma sofisticação adicional: a realimentação positiva (positive feedback). Considere uma situação em que um organismo ou sistema químico produz uma enzima cuja presença incentiva a produção de mais desta mesma enzima. Isto é um exemplo de um laço de realimentação positiva, ou seja, a presença ou ação de algum indivíduo leva à presença ou ação de um próximo indivíduo. Em química, esse fenômeno é denominado como auto-catálise (Kauffman, 1993).

A comunicação química é um dos principais meios de comunicação entre os insetos (Murlis et al., 1992). Nesse tipo de comunicação, indivíduos de uma mesma espécie podem se comunicar através da emissão de substâncias químicas, denominadas feromônios. Marcação de territórios (Gordon, 1999), procura por parceiros, determinação de trilhas (Wilson, 1962) e alarme (Hölldobler e Wilson, 1990) são algumas das finalidades desse tipo de comunicação. No caso específico da atividade de forrageamento, o feromônio é utilizado para recrutar indivíduos para o local da fonte de alimento. Enquanto caminha da fonte de comida ao ninho e vice-versa, uma formiga deposita no chão uma substância chamada feromônio, formando em seu caminho uma trilha de feromônios, que se dissipa ao longo do tempo. Os feromônios, por sua vez, 
são facilmente identificados via olfato pelas outras formigas, que tomam conhecimento (indireto) da presença de uma formiga que transporta comida. Assim, a trilha de feromônio permite a uma formiga encontrar o caminho de volta à fonte de comida ou ao ninho e, além disso, também permite que outras formigas localizem a fonte de comida encontrada. A intensidade do feromônio (número de moléculas de feromônio) em um local é maior quando alguma formiga passou recentemente por ali ou quando um grande número de formigas passou sobre o local. As formigas quando escolhem seu caminho tendem a escolher, com maior probabilidade, caminhos marcados por fortes concentrações de feromônio. Ao seguir uma trilha existente, as formigas tenderão a se concentrar nela, pelo simples fato de que a densidade de feromônio aumenta a cada formiga adicional que segue a trilha. Através deste mecanismo indireto de informação (realimentação positiva) as formigas conseguem colaborar na coleta de alimentos de uma dada fonte de comida. Experimentos evidenciam que as formigas conseguem através deste mesmo mecanismo selecionar o caminho mais curto entre a fonte de alimentos e o ninho, mesmo na presença de obstáculos variados (Deneubourg et al., 1990).

No Instituto de Santa Fé e no Laboratório Nacional de Los Alamos, Mark Millonas e seus colegas desenvolveram modelos matemáticos da dinâmica de inteligência coletiva e de enxames, baseados na habilidade de depositar e detectar feromônios (Millonas, 1993; Chialvo e Millonas, 1995). Suas pesquisas em formigas naturais demonstraram que:

- Quando se coloca uma fonte de comida a uma certa distância do ninho, com dois caminhos possíveis de comprimentos diferentes, geralmente elas acabam optando pelo menor caminho após algum tempo.

- Se um caminho menor é introduzido quando um obstáculo é removido, por exemplo, as formigas geralmente não mudam do caminho em que estão seguindo para essa nova e melhor alternativa.

- Se ambos os caminhos forem de comprimentos iguais, as formigas optarão apenas por uma delas. 
- Se duas fontes de comida forem oferecidas, sendo que uma contenha mais alimentos que a outra, o enxame de formigas escolherá a mais abundante.

- Se a fonte mais abundante for oferecida após a escolha já tenha sido feita por outra fonte, a maioria das espécies é incapaz de trocar a opção. Mas algumas espécies são capazes de alterar seu padrão para a melhor fonte.

- Se duas fontes iguais são oferecidas, as formigas escolherão uma ou outra arbitrariamente.

- As formigas exploram uma fonte de cada vez. Atualmente, a explicação aceita é que esse comportamento surgiu no processo evolutivo, pois uma trilha composta por muitas formigas é mais resistente a condições adversas e a inimigos.

As formigas e as suas colônias têm despertado o interesse de pesquisadores das mais diversas áreas científicas porque apesar de possuírem comportamentos individuais simples, no entanto, são capazes de evidenciar formas de organização e comportamento coletivos extraordinariamente complexos. Esses comportamentos coletivos emergentes e complexos têm servido de metáfora a explorações em áreas tão distantes da Mirmecologia como a Neurociência, a Física, a Ciência da Computação e Vida Artificial. Essas características de auto-organização presentes em insetos sociais, principalmente nas formigas, são a base de sustentação de vários trabalhos nessas áreas, que estendem suas aplicações a modelos que se valem do conceito de auto-organização para alcançar os fins desejados.

\subsection{Formigas artificiais}

No início dos anos 1990, Dorigo e seus colegas propuseram o algoritmo de formigas - Ant Algorithm (AA) - como uma nova abordagem heurística multi-agente, demonstrando como comportamentos tão simples como o de seguir uma trilha de feromônio poderia ser utilizado para a solução de problemas de otimização combinatória (Dorigo et al., 1991, 1996). O AA, originalmente aplicado no problema do caixeiro viajante, foi 
estendido e modificado por vários pesquisadores para aumentar seu desempenho (Dorigo e Gambardella, 1997; Stützle e Hoos, 1998) e para aplicá-lo a outros problemas de otimização, como alocação quadrática (Maniezzo e Colorni, 1999), roteamento de veículos (Di Caro e Dorigo, 1998), roteamento de redes de comunicações (Di Caro e Dorigo, 1998), coloração de grafos (Costa e Hertz, 1997), ordenação seqüencial (Gambardella e Dorigo, 2000), entre outros.

Motivados pelo surgimento de diversas variantes do AA original e pelos resultados alcançados, Dorigo e Di Caro (1999) propuseram a meta-heurística de otimização por colônia de formigas - Ant Colony Optimization (ACO) -, num esforço de prover uma visão unitária das pesquisas correntes nesse campo e para criar um framework comum para todas as versões de AA, ou seja, para identificar os mais relevantes aspectos desses algoritmos, facilitando, assim, o desenvolvimento de novas aplicações.

Dorigo et al. (1996) basearam seus experimentos no fato de que ao caminhar do ninho para o alimento e vice-versa, as formigas retornarão mais rápido e, assim, passarão pelos mesmos pontos mais freqüentemente, quando seguindo o menor caminho. Passando com maior freqüência, elas depositarão uma trilha de feromônio mais densa. E quanto mais formigas optarem pela trilha densa, mais ela será reforçada. Em sua adaptação computacional desses comportamentos, foi deixada uma população de "formigas" buscar um mapa para o caixeiro viajante, aumentando a probabilidade de seguir uma conexão entre duas cidades como uma função do número de outras formigas simuladas que já seguiram aquela conexão. Pela exploração do efeito da realimentação positiva, ou seja, do reforço da trilha com cada formiga adicional, este algoritmo é capaz de resolver problemas combinatórios complexos, em que o objetivo é encontrar um meio de executar uma tarefa no menor número de passos possível.

Assim, a idéia básica de ACO é a de que um grande número de agentes simples e artificiais é capaz de construir boas soluções para problemas de otimização combinatórios difíceis via comunicações de baixo nível. Se em um dado momento uma formiga tenha que optar por diferentes caminhos, aqueles que foram mais escolhidos previamente por outras formigas (ou seja, aqueles com um alto nível de feromônio) são escolhidos com 
maior probabilidade. As formigas reais cooperam em sua busca por comida depositando trilhas químicas (feromônio) no chão. Uma colônia de formigas artificial simula esse comportamento. Formigas artificiais cooperam utilizando uma memória comum que corresponde ao feromônio depositado por formigas reais. O feromônio artificial é acumulado em tempo de execução através de um mecanismo de aprendizado. As formigas artificiais são implementadas como processos paralelos cujo objetivo é construir soluções de um problema usando um procedimento construtivo guiado por uma combinação de feromônio artificial, dados do problema e uma função heurística para avaliar os sucessivos passos construtivos (Dorigo e Di Caro, 1999).

Relacionado a aplicações em robótica, um interessante projeto é o Swarm-bots² Seu enfoque não é somente em formigas, mas insetos sociais em geral. Participam nesse projeto os pesquisadores das instituições:

- Université Libre de Bruxelles, Bélgica;

- École Polytechnique Fédérale de Lausanne, Suíça;

- Consiglio Nazionale delle Ricerche, Itália;

- Instituto dalle Molle di Studi Sull'Intelligenza Artificiale, Suíça.

Este projeto foi coordenado por Marco Dorigo e financiado pelo FET (Future and Emerging Technologies), um dos programas mantidos pelo IST (Information Society Technologies), uma iniciativa da Comunidade Européia para fomentar a pesquisa e o desenvolvimento tecnológico na Europa. Seu custo foi de aproximadamente 2,17 milhões de euros, foi iniciado em 1 de outubro de 2001 e concluído em 31 de março de 2005 (IST, 2007; CORDIS, 2007). Seu objetivo foi desenvolver uma nova abordagem de projeto, implementação, teste e utilização de sistemas robóticos metamórficos capazes de auto-organização e auto-agregação, inspirada pelos estudos recentes em Inteligência de Enxames (Kennedy e Eberhart, 2001), ou seja, pelos estudos das capacidades de auto-organização e auto-agregação em insetos sociais e outras sociedades de animais.

\footnotetext{
${ }^{2}$ http://www.swarm-bots.org
} 
Foi construído o Swarm-bot (Robô-Enxame), um artefato composto por vários robôs simples (os S-bots), inspirados em insetos, capazes de se auto-organizar para se adaptar ao ambiente (Pettinaro et al., 2002).

Um Swarm-bot não é planejado para ser um robô na forma clássica, ou seja, um grande robô ou um pequeno grupo de robôs especializados para resolver uma determinada tarefa. Ao invés disso, ele é uma entidade gerada pela agregação de muitas unidades simples independentes em um grupo com um objetivo em comum. E uma vez que o objetivo esteja completo, as ligações físicas que os unem são desfeitas, causando uma desagregação entre seus componentes atômicos (S-bots) (Pettinaro et al., 2002).

O Swarm-bot deve ser capaz de realizar as seguintes ações:

- Auto-agregação de S-bots para formação dinâmica de formas, como filas, quadrados e círculos (Trianni et al., 2004b);

- Alteração dinâmica de formas (Sahin et al., 2002);

- Desvio de obstáculos e buracos e passagem sobre buracos (Trianni et al., 2004a);

- Movimentação coordenada (Trianni, 2003);

- Navegação em terrenos acidentados (Mondada et al., 2002);

- Localização e transporte de objetos (Gross e Dorigo, 2004);

- Divisão adaptativa do trabalho (Labella et al., 2004b).

Foram consideradas nesse projeto situações em que apenas um S-bot sozinho não é capaz de realizar a tarefa, sendo necessário o esforço cooperativo através da agregação de S-bots em um Swarm-bot. Além disso, o Swarm-bot deve possuir escalabilidade, ou seja, a possibilidade de se aumentar ou reduzir o número de robôs no enxame de forma transparente. A auto-agregação compreende a capacidade dos S-bots de se conectarem uns aos outros, formando uma única estrutura, chamada de Swarm-bot. O Swarm-bot deve ser funcional para a realização de uma tarefa particular, em qualquer momento que 
as contingências ambientais proibirem um S-bot sozinho de realizar sua tarefa (Trianni et al., 2004b).

Nesses exemplos de experimentos inspirados em comportamentos de insetos, há otimização de vários tipos, como agrupamento de itens ou encontrando o menor caminho, com certas características interessantes. Nenhuma dessas instâncias inclui avaliação global da situação: um inseto só pode detectar seu ambiente adjacente. Os métodos bottom-up dos insetos sociais não necessitam de nenhuma medida de avaliação de aptidão (fitness) de uma solução. Nenhuma formiga sabe o quão bem o enxame está se saindo. Em geral, o método de comunicação por feromônio significa que um caminho mais bem-sucedido será de alguma forma mais atraente, com uma acumulação autocatalítica de feromônio resultando na convergência da população no melhor comportamento (Cazangi et al., 2006). 



\section{Capítulo 3}

\section{Feromônios artificiais}

Feromônios são sinais químicos utilizados por organismos para se comunicar entre membros da mesma espécie. No mundo dos insetos, a comunicação por feromônios é amplamente empregada para coordenar atividades da colônia, como agregação, coleta de comida, reprodução, alarme e defesa (Wyatt, 2003).

As próximas seções apresentam algumas abordagens encontradas na literatura para utilizar feromônios em robôs. A Seção 3.1 aborda a utilização de substâncias químicas para marcar a trilha e sensores de odor para detectá-las. A Seção 3.2 apresenta uma forma alternativa para a marcação da trilha, que os próprios robôs marcam o caminho, como se fossem o feromônio. Na Seção 3.3, é apresentada a proposta de marcação de trilha desenvolvida neste trabalho.

\subsection{Trilhas químicas e sensores de odores}

Embora existam vários trabalhos relacionados a desenvolvimento e aplicação de sensores de odores embarcados, a maioria deles foca na detecção dos odores em correntes de ar ou de água (Russell, 2001). O papel dos robôs nesses trabalhos é o rastreamento e detecção da origem de emissão dos odores. Alguns deles inspiraram-se nos movimentos que mariposas realizam para encontrar a parceira no período reprodutivo (Marques e De Almeida, 2000; Marques et al., 2002; Loutfi e Coradeschi, 2002). Há também 
trabalhos inspirados no odor emitido pela abelha rainha para reunir as operárias na colméia (Purnamadjaja e Russell, 2005). Relacionado à marcação química de trilhas no chão e sua detecção, similar às formigas, destacam-se os trabalhos de Russell (Russell et al., 1994; Russell, 1999).

Russell et al. (1994) desenvolveram um sensor de odores apto a detectar marcas olfativas no chão (trilhas de alguma substância química). A técnica empregada nesse aparelho foi a microbalança gravimétrica, também chamada de microbalança de cristal de quartzo. O sensor gravimétrico possui como seu principal componente um cristal de quartzo com uma cobertura química que tenha afinidade com a substância olfativa a ser detectada. As moléculas do odor são absorvidas por esse revestimento e adicionam massa ao cristal. O aumento de massa reduz a freqüência de ressonância do cristal. Dessa forma, a concentração do odor pode ser calculada em função das alterações na freqüência.

A substância escolhida como marcador olfativo foi a cânfora, pois pode ser manipulada sem riscos à saúde, não danifica os equipamentos, é facilmente encontrada e possui baixo custo. Além disso, ela sublima devagar, o que permite que uma trilha de cânfora mantenha-se por várias horas. Para detectar a cânfora, o cristal de quartzo do sensor foi revestido com silicone OV-17.

Em ambientes não controlados, o fluxo de ar prejudica de forma significativa as medições. Mesmo em ambientes controlados, constatou-se que ocorrem consideráveis variações nas leituras do sensor. Para melhorar seu desempenho, foi utilizado um aspirador a vácuo para puxar o ar próximo do chão até o cristal. Como odores nas proximidades também eram aspirados, foi colocado ao redor da entrada do aspirador um gerador de fluxo de ar, criando uma cortina de ar em volta da região a ser analisada (Figura 3.1).

Segundo Russell (1999), o sistema de controle desenvolvido para seguir a trilha foi inspirado na descrição do comportamento da formiga Lasius fuliginosus, estudada por Hangartner (1967). O comportamento de seguir a trilha dessa formiga é mover-se à direita até a antena esquerda encontrar a trilha. Ao encontrá-la, ela move-se à esquerda 


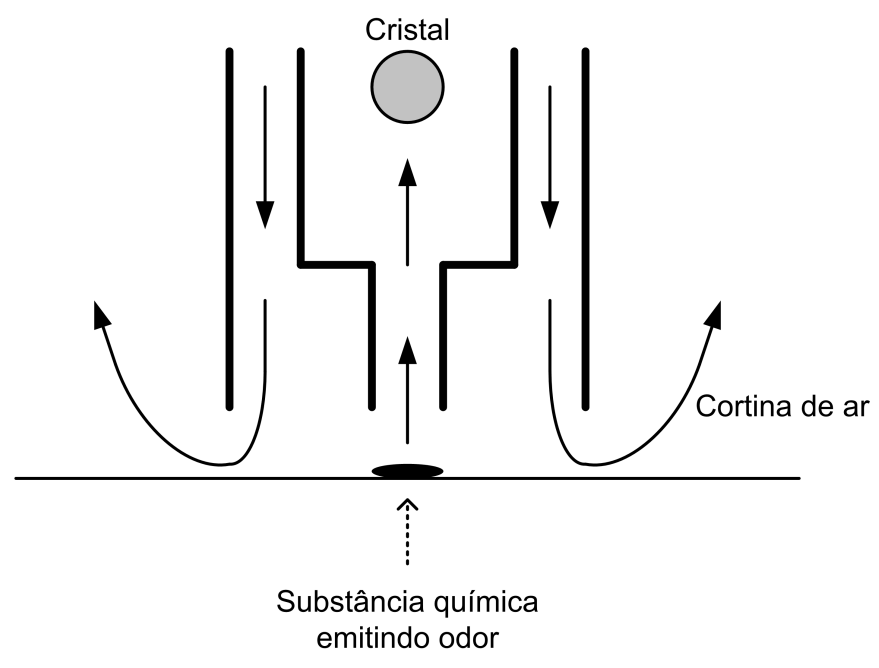

Figura 3.1: Sensor de odores - adaptado de Russell et al. (1994)

até a antena da direita detectar a trilha. Dessa forma, a trilha é mantida entre suas duas antenas.

Experimentos demonstraram que mesmo se a formiga perder uma de suas antenas, ela ainda consegue seguir a trilha, embora menos eficientemente. Por exemplo, se sua antena direita for extirpada, ela se moverá para a direita até sua antena esquerda encontrar a trilha. Em seguida, ela move-se para a esquerda. Como não possui a antena direita para notificá-la da trilha, ela continuará virando, até atingir uma angulação grande. Nesse momento, ela move-se para a direita novamente.

Em seus experimentos, Russell (1999) utilizou um robô com 6 pernas. Dois sensores de odor foram instalados em sua "cabeça", como suas "antenas". O controlador seguiu a descrição acima e mostrou-se robusto, mesmo com descontinuidades na trilha.

\subsection{Cadeia de robôs}

Nouyan e Dorigo (2004) desenvolveram uma solução alternativa para a marcação da trilha. De forma similar às formigas, que usam feromônios para modificar localmente o ambiente e atrair outras formigas para a trilha, os próprios robôs são utilizados para marcar as trilhas. São formadas cadeias de robôs 3.2. Este trabalho foi inicial- 
mente realizado em um simulador do projeto Swarm-bots e posteriormente em robôs reais (Nouyan et al., 2006). O problema considerado para os testes do sistema foi a formação de uma trilha entre dois objetos, o ninho e a presa. Cada indivíduo possui um campo de visão limitado, sendo incapaz de visualizar esses dois objetos ao mesmo tempo. O controlador do robô consiste em quatro comportamentos (Nouyan e Dorigo, 2006), ativados um por vez:

- Busca: o robô anda aleatoriamente em busca do ninho ou de algum robô em uma cadeia.

- Exploração: o robô move-se ao longo da cadeia em direção ao seu final ou, caso ele tenha acabado de deixar a cadeia, em direção ao ninho.

- Cadeia: o robô permanece imóvel, fixando-se na cadeia.

- Finalizado: um caminho foi estabelecido entre o ninho e a presa.

Há também dois importantes parâmetros de configuração:

- Probabilidade de agregação (PA): probabilidade do robô fixar-se no final da cadeia, ou seja, de passar do estado "exploração" para "cadeia".

- Probabilidade de desagregação (PD): probabilidade do robô sair do final da cadeia, ou seja, de alterar seu estado de "cadeia" para "exploração".

Em cada experimento, inicialmente, os robôs são posicionados aleatoriamente no ambiente. Eles começam no estado de "busca". Em seguida, após encontrar o ninho, eles alternam para o modo de "exploração" e procuram por alguma cadeia formada. Caso não haja, há uma probabilidade PA de que o robô inicie sua própria cadeia. E caso encontre, o robô desloca-se até o final da cadeia. Chegando lá, há uma probabilidade PA de que ele passe para o estado "cadeia", permanecendo ali imóvel. Se o indivíduo detectar a presa no final da cadeia, ele passa para o estado "finalizado", fixando a trilha. Durante a formação da cadeia, sempre há o cuidado de não perder em seu campo de sensoriamento o indivíduo anterior na cadeia. Se isso ocorrer, o robô retorna 


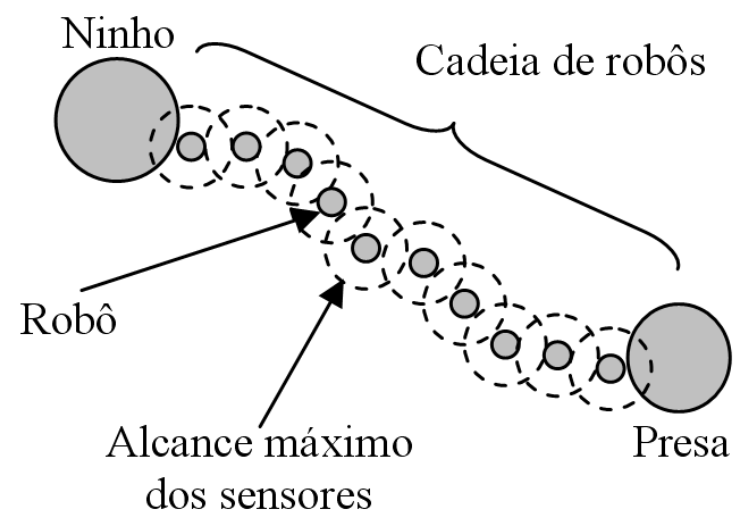

Figura 3.2: Cadeia de robôs formando uma trilha entre o ninho e a presa - adaptado de Nouyan e Dorigo (2006).

ao modo de "busca". Caso o robô localize-se no final da cadeia e não estiver no estado "finalizado", também há uma dada probabilidade PD dele deixar a cadeia. Neste caso, o robô alterna seu estado de "cadeia" para "exploração" e desloca-se pela trilha até o ninho. Foram comparados os dados de experimentos variando-se o número de robôs e a distância entre os objetos a serem conectados. Também foi considerada a variação dos dois parâmetros de configuração PA e PE. Foi constatado que esses dois parâmetros possuem um efeito significativo no comportamento do grupo, influenciando o número de cadeias formadas, o comprimento das cadeias e a taxa de sucesso em encontrar a presa. Em geral, foram obtidas altas taxas de sucesso na formação da trilha entre o ninho e a presa Nouyan e Dorigo (2006).

\subsection{Proposta de uma grade de feromônios artificiais}

O feromônio utilizado pelas formigas naturais é uma substância química depositada por elas no chão para a marcação de trilhas, que pode ser detectada através de suas antenas. Para aplicar essa metodologia na robótica de forma semelhante à abordagem biológica, seria necessário utilizar alguma substância química capaz de evaporar aos poucos. Além disso, também seria preciso um sensor de odores para detectar a substância utilizada. Trabalhos abordando a utilização de marcadores químicos e 
sensores de odores já foram discutidos na Seção 3.1.

Devido às dificuldades em se desenvolver sensores de odores, demonstradas por esses trabalhos, e à dificuldade em se encontrar algum sensor comercial adequado aos propósitos desta pesquisa em termos de custo, tamanho e consumo de energia, optou-se por não utilizar nenhuma forma de marcação real do chão. A abordagem de formação de cadeias, discutida na Seção 3.2, possui limitações no alcance máximo de exploração, limitado pela quantidade de robôs disponíveis na colônia para se situar lado a lado e formar a trilha. Também acaba-se tornando limitado em relação à exploração de regiões muito distantes do ninho, pois é mais difícil a formação de longas trilhas e, quanto mais distante, maiores são as possibilidades de direcionamento da trilha formada. Dessa forma, optou-se por desenvolver uma abordagem diferente baseadas em feromônios virtuais.

Em cada robô é armazenada na forma de tabela na memória uma grade do tamanho do ambiente, para armazenar as coordenadas em que há feromônios. Como o propósito é que o robô perceba apenas o ambiente ao seu redor (percepção local), apesar de toda a grade ser armazenada no robô, ele apenas perceberá os feromônios próximos ao seu redor, em um raio máximo limitado. Isso possibilita simular "antenas" virtuais capazes de "sentir" a concentração de feromônios em uma área determinada na grade.

A cada iteração, os feromônios depositados "evaporam" (são decrementados) e os robôs depositam novos feromônios em sua posição corrente, e depois avançam uma posição na grade. Como cada robô tem conhecimento sobre sua posição, sua própria trilha é facilmente mapeada na grade. Porém, um robô não tem como localizar a posição dos demais. Por isso, torna-se necessário um módulo de processamento de imagem para a localização de todos os robôs e um módulo de comunicação via rádio para transmitir a cada robô suas coordenadas e as dos demais. Apenas com essa informação, ou seja, a localização de todos os robôs no ambiente, cada robô pode processar e completar sua grade embarcada com os novos pontos de depósito de feromônio e decrementar pontos já conhecidos. A forma como essa localização é realizada e como essas coordenadas são transmitidas são abordadas em detalhes no Capítulo 4. 
Cada ponto na grade representa uma posição em que se pode localizar um objeto, um obstáculo ou um robô, além dos pontos das trilhas de feromônios. Assim, os robôsformigas operam como pontos em uma grade. Os possíveis movimentos são limitados para frente, frente-esquerda e frente-direita. Esses movimentos e suas variações em relação à orientação do robô são ilustrados na Figura 3.3. A Figura 3.4 ilustra o mapeamento com um exemplo. Nele, uma grade $3 \times 4$ é mapeada para uma grade 6 x 8. Assim, cada ponto na primeira grade corresponde a um quadrado de 2 x 2 na segunda grade. O procedimento adotado neste trabalho é similar, porém foi utilizada uma grade de $25 \times 19$ pontos, mapeada na tela do ambiente, que possui $640 \times 480$ pixels.
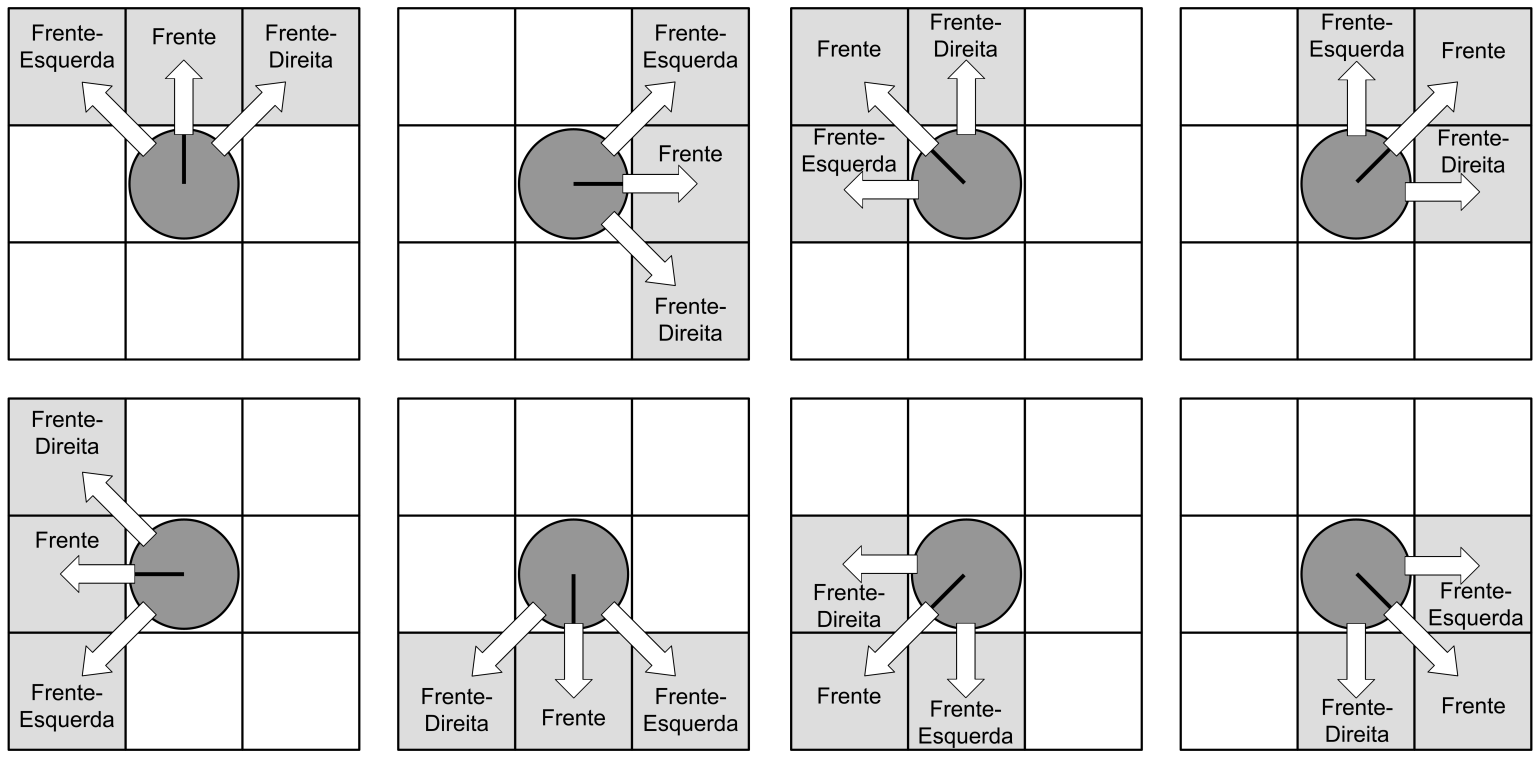

Figura 3.3: Movimentos válidos para o robô-formiga

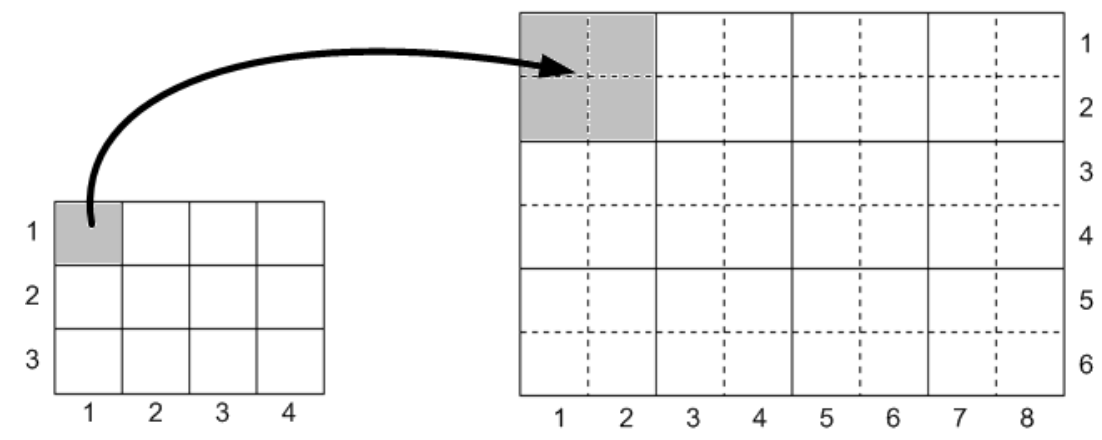

Figura 3.4: Mapeamento da grade na imagem

Para simular as duas antenas das formigas biológicas, que possuem capacidades ol- 
fativas (Hölldobler e Wilson, 1990), os robôs-formigas possuem "antenas" simuladas, ou seja, eles possuem a capacidade de detectar a intensidade de feromônios separadamente, ao seu lado esquerdo e ao seu lado direito. Os feromônios depositados no ambiente são armazenados em uma matriz, que é atualizada a cada iteração. Nas atualizações, os feromônios já depositados "evaporam" (são decrementados) e os robôs-formigas depositam novos pontos de feromônios.

Para este trabalho, foram definidos dois tipos de áreas de alcance do sensoriamento das "antenas" do robô-formiga: área de sensoriamento frente-trás (Figura 3.5, em (a) e (b)) e área de sensoriamento à frente (Figura 3.5, em (c) e (d)). Nessas figuras, o robô-formiga é representado como um ponto preto, conforme destacado em (a), e em duas orientações distintas, $90^{\circ}$ e $45^{\circ}$, destacadas em (b). A área de sensoriamento da "antena" esquerda é a região mais escura, enquanto que a da direita é a região um pouco mais clara. A faixa mais clara entre as áreas esquerda e direita é a região percebida em comum pelos dois lados. O raio de sensoriamento pode ser ajustado pelo usuário. Optou-se por essa forma de área de sensoriamento devido à facilidade em variar seu raio e porque, quando ela é rotacionada em $45^{\circ}$, pode-se obter uma região de mesmo tamanho de área e de raio, conforme pode ser observado nos exemplos da Figura 3.5. Conforme destacado em (c), o robô-formiga permanece com área de sensoriamento com raio igual a dois e área coberta à esquerda igual a seis, apesar de orientações diferentes $\left(90^{\circ}\right.$ e $\left.45^{\circ}\right)$. Em (d), o raio passou a ser quatro e a área tornou-se 20, para as duas orientações. A área da direita é igual a área da esquerda.

Essa solução através de feromônios virtuais localizados em uma tabela na memória é simples de se implementar e resolve o problema de marcação de feromônios a um custo muito baixo. Essa solução permite simular sensores virtuais ("antenas") que não estão fisicamente presentes no robô. Não obstante, este fato não é percebido pelo algoritmo de controle e o sistema multi-agente (a colônia de robôs-formigas) pode operar normalmente. O sistema foi implementado de maneira modular para que em um futuro próximo sensores químicos reais (uma vez disponíveis a baixo custo) possam ser instalados nos robôs sem qualquer necessidade de mudança em seu algoritmo de 
controle.

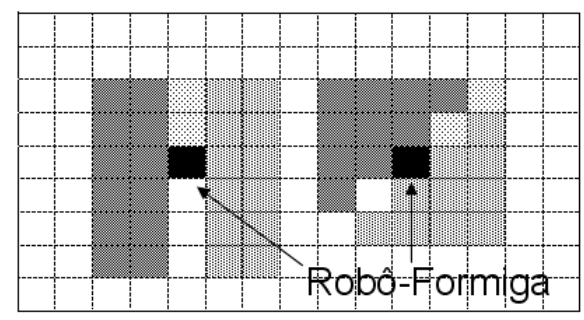

(a)

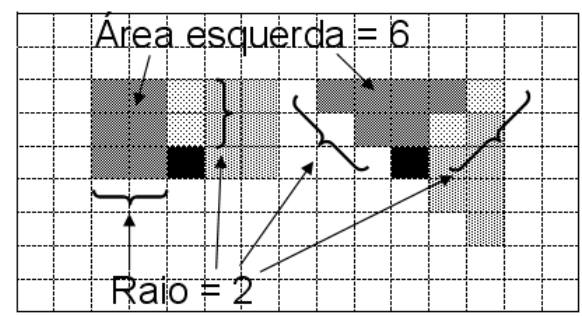

(c)

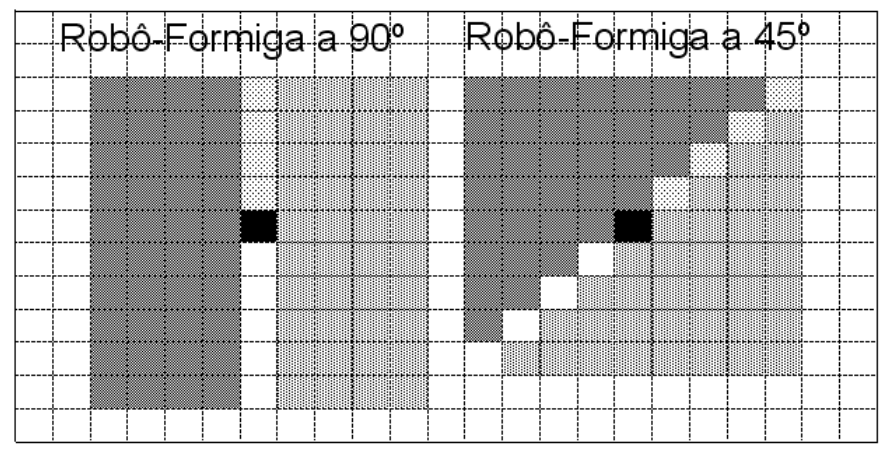

(b)

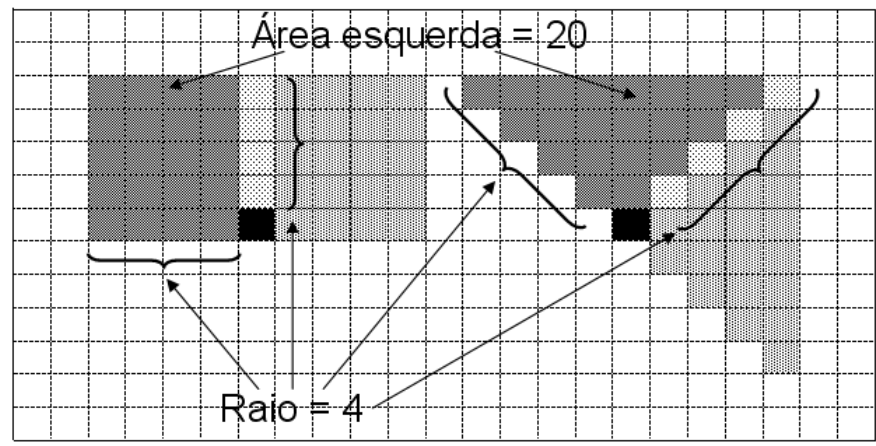

(d)

Figura 3.5: Exemplos de áreas de sensoreamento do robô-formiga: (a) sensoriamento frente-trás com raio 2; (b) sensoriamento frente-trás com raio 4; (c) sensoriamento à frente com raio 2 ; e (d) sensoriamento à frente com raio 4. 



\section{Capítulo 4}

\section{Projeto do sistema}

O projeto escalonável do sistema de controle de colônia de formigas artificiais desenvolvido pode ser analisado em relação aos seus componentes físicos e módulos lógicos. Essas duas abordagens analíticas são sintetizadas pelas Figuras 4.1 e 4.2. Os equipamentos físicos que compõem o sistema (Figura 4.1) consistem de um grupo de robôs, seu ambiente de trabalho, uma câmera de vídeo e dois computadores (PC1 e PC2), um equipado com a placa de captura de imagens e o outro com um rádio-modem. Para a comunicação com os robôs, os módulos lógicos (Figura 4.2) organizam de forma transparente toda a comunicação entre os controladores embarcados dos robôs, sejam simulados ou reais.

A arena é o ambiente de trabalho dos robôs reais e contém o grupo de robôs, os obstáculos, os objetos a serem encontrados e as paredes. Por uma questão de custo de implementação e disponibilidade no momento de realização dos experimentos, somente um robô real foi utilizado. Os demais foram simulados. Para isso, foi construído um simulador para os robôs no qual o robô real é representado e os robôs virtuais podem detectá-lo como se fosse um deles. Devido ao alto custo de sensores olfativos capazes de perceber vestígios de feromônios, estes também foram representados em simulação.

A seguir, os componentes da arquitetura física são descritos em detalhes na Seção 4.1. Os módulos lógicos são o tema da Seção 4.2. 


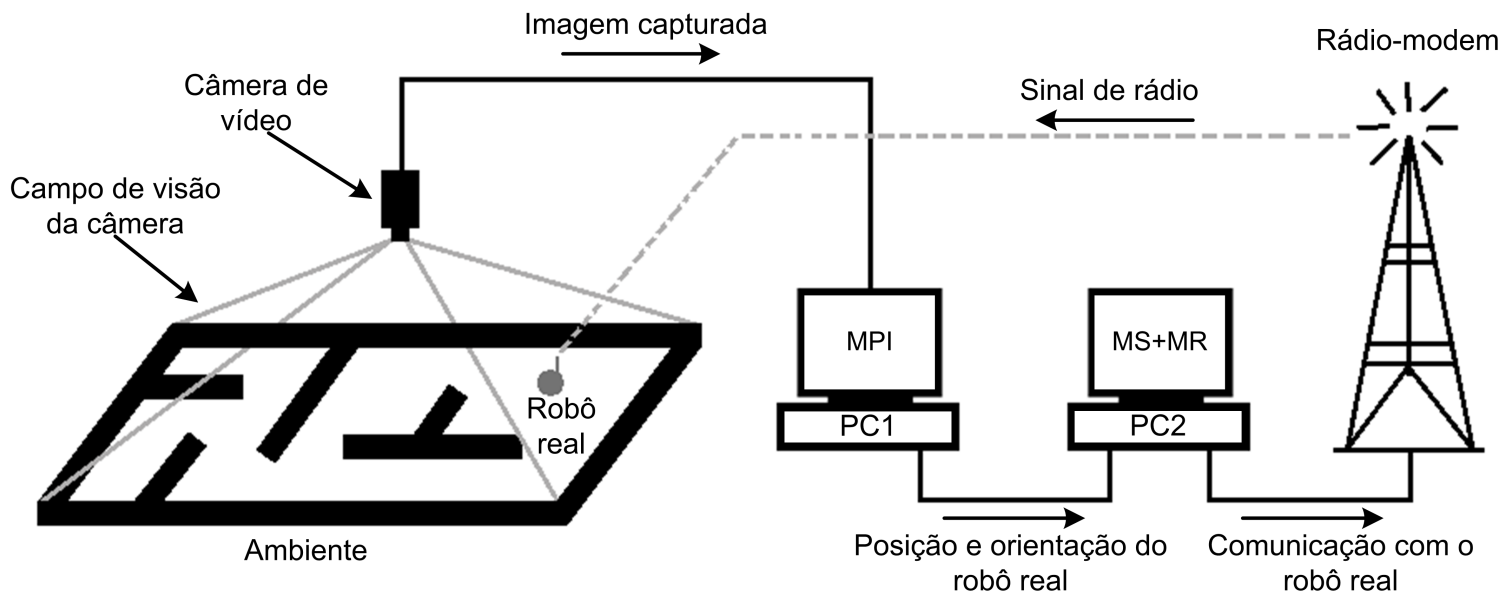

Figura 4.1: Arquitetura física do sistema

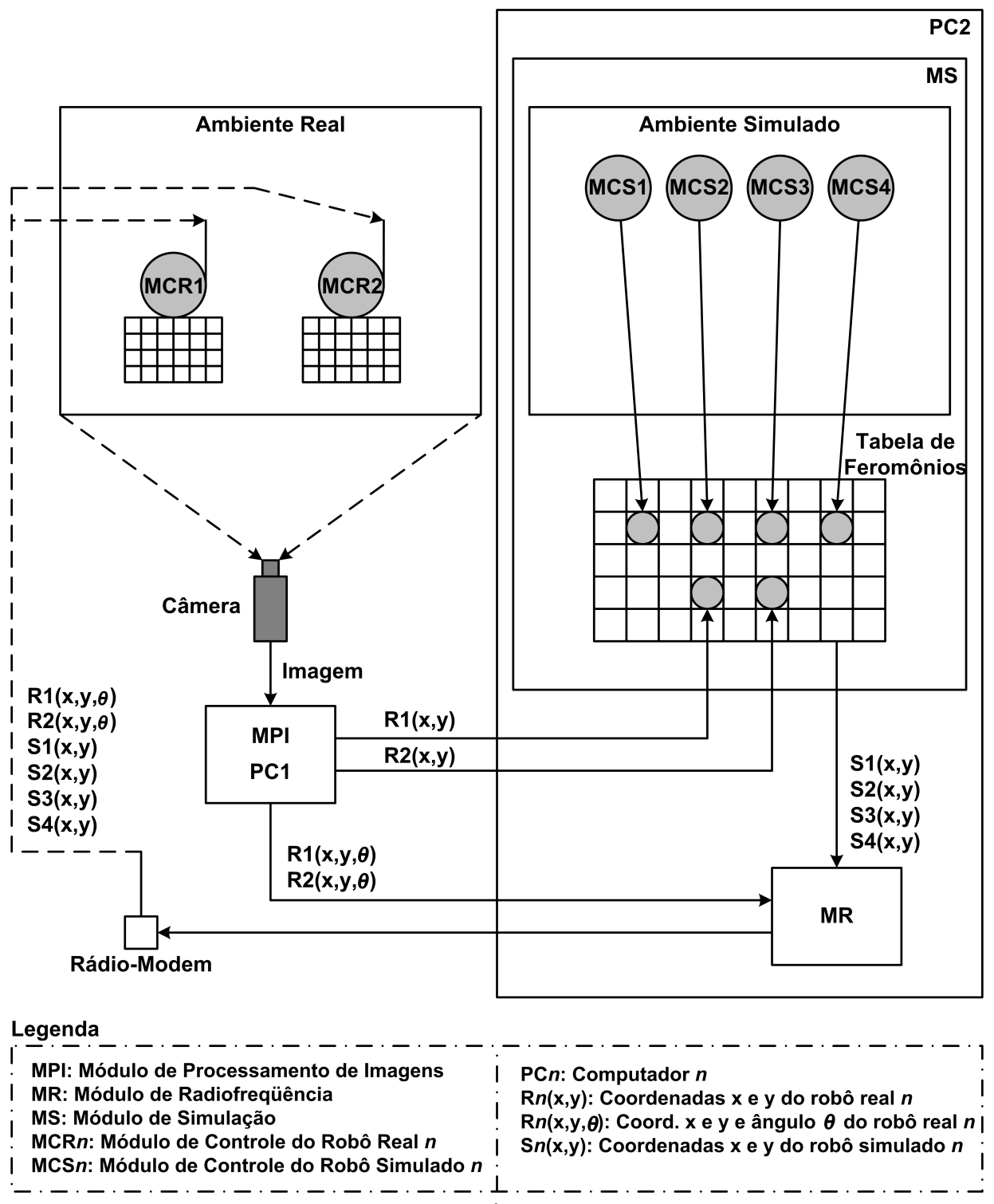

Figura 4.2: Módulos lógicos do sistema 


\subsection{Arquitetura física}

A Figura 4.1 ilustra o ambiente real e a infra-estrutura para realização dos experimentos. A arena com os obstáculos e o robô real está à esquerda da figura. Acima, está a câmera de vídeo, cujo campo de visão cobre toda a arena. A imagem de vídeo é transmitida para o computador PC1, no qual está o Módulo de Processamento de Imagens (MPI), responsável por localizar e determinar a orientação dos robôs reais. Os obstáculos reais também são mapeados pelo usuário no ambiente simulado. As coordenadas e a orientação dos robôs reais são transmitidas para o computador PC2, no qual se encontram o Módulo de Simulação (MS) e o Módulo de Rádio (MR). O MPI processa a imagem capturada pela câmera, extraindo as coordenadas de posição $(x, y)$ e a orientação $(\theta)$ de cada robô real. O MPI monta uma lista com $(x, y, \theta)$ de cada robô e transmite via socket para os outros módulos a cada iteração. O MS recebe a lista e faz uso apenas das coordenadas $(x, y)$ para atualizar a posição dos robôs reais na janela de visualização. O MS também é responsável por atualizar a deposição de feromônio dos robôs reais e simulados na tabela de feromônios do ambiente simulado. O MR também recebe a lista com as coordenadas dos robôs reais do MPI e uma lista com as coordenadas dos robôs virtuais do MS e as transmite pelo rádio-modem para os robôs reais. Estes, atualizam suas tabelas internas de feromônio com os depósitos dos outros robôs reais e dos robôs simulados. Os Módulos de Controle dos robôs reais (MCR1, ... , MCRn) e dos robôs simulados (MCS1, ... , MCSn) calculam as concentrações de feromônio em cada uma das "antenas", com base em suas respectivas tabelas de feromônio, e tomam uma decisão de manobra, segundo o algoritmo de controle. Cada robô se movimenta e, em seguida, o ciclo recomeça.

A câmera de vídeo utilizada é uma câmera CCD da Samsung, modelo SDC-415ND, equipada com uma lente auto-íris varifocal de 2,8-10,0 $\mathrm{mm}$ da Kodo, modelo SCV2810DC. Também foi utilizado um filtro de infravermelho da Hoya, modelo R72, com $52 \mathrm{~mm}$ de diâmetro, que somente permite a passagem de raios infravermelhos acima de $720 \mathrm{~nm}$. Como o diâmetro do filtro é maior que o da lente, para sua conexão à 
câmera, foi confeccionado um suporte em papel cartão (Figura 4.5). A câmera, a lente e o filtro foram escolhidos por possuir a melhor relação entre custo e benefício entre os modelos encontrados disponíveis à venda. Como a câmera seria posicionada sobre o ambiente a uma curta distância da região a ser filmada, foi necessário selecionar uma lente que proporcionasse uma boa abertura nessas condições. A câmera foi posicionada a cerca de 1,70 m acima do ambiente, proporcionando uma área máxima de cobertura retangular de, aproximadamente, 2 x 3 m no solo.

A placa de captura de imagens foi instalada em PC1. Essa é uma placa da PixelView, modelo PlayTV MPEG 2. Sua escolha foi devido ao seu baixo custo, aliada à qualidade satisfatória para este trabalho. Além disso, essa placa possui o chipset bt878, da família Brooktree, o que facilita sua instalação em Linux. Essa família de chipsets é suportada no Linux através do driver bttv, que possui vários anos de amadurecimento e geralmente já vem integrado nas principais distribuições atuais. No PC2, foi instalado o aparelho de radiofreqüência. Esse aparelho utiliza um módulo rádiomodem da RadioMetrix BIN-2 $433 \mathrm{MHz}$, construído especificamente para este projeto (Figura 4.9).

O PC1 deve rodar o MPI em Linux. O PC2 deve rodar os demais módulos MS e MR em Windows. Um dos computadores utilizados (PC1) possui processador Intel Dual Core 3,4 GHz e 2 GB de memória RAM. O outro (PC2) possui processador Athlon XP 1800+ e 512 MB de memória RAM. Ambos possuem Windows XP e Debian Linux instalados e foram preparados para rodar os softwares correspondentes.

O robô utilizado (Figura 4.10) foi desenvolvido por Simões (2000). A arquitetura do robô consiste em uma plataforma de $22 \mathrm{~cm}$ de diâmetro com duas rodas diferenciais. Possui um processador Motorola 68HC11 2 MHz, 64 Kb de RAM, pára-choques arredondados com oito sensores de colisão e oito sensores de proximidade infravermelhos. As rodas estão posicionadas no meio do robô, o que lhe permite realizar rotação em torno de seu eixo central. 


\subsection{Módulos lógicos}

A arquitetura lógica do sistema de controle de colônia de formigas artificiais (Figura 4.2) é composta de quatro módulos:

- Módulo de Processamento de Imagens (MPI);

- Módulo de Simulação (MS);

- Módulos de Controle individuais dos robôs reais (MCRn) e simulados (MCSn) o módulo de controle dos robôs reais é implementado em Assembler e embarcado nos processadores dos robôs;

- Módulo de Rádio-modem (MR).

Esses módulos podem ser classificados em dois tipos. Os responsáveis pelo mapeamento e controle dos objetos no mundo real e os responsáveis pelo mundo simulado. MPI e MR são os mecanismos de interação com o mundo real. MS é onde o mundo simulado é criado e gerenciado. Os MCs são os responsáveis por acompanhar as ações dos robôs reais e simulados. Esses módulos são abordados em maiores detalhes nas próximas seções: MPI na Subseção 4.2.1; MS na Subseção 4.2.2; MCs na Subseção 4.2.3; e MR na Subseção 4.2.4. A comunicação entre os módulos é discutida na Subseção 4.2.5. Na Subseção 4.2.6, é abordado o ambiente unificado dos mundos virtual e real.

\subsubsection{Módulo de Processamento de Imagens}

Para o Módulo de Processamento de Imagens (MPI), o primeiro algoritmo implementado rastreava robôs com base em seu padrão de cores (ver Apêndice A). Porém, um dos principais problemas encontrados nessa abordagem foi a variação de tonalidade das cores devido à iluminação. Isso dificulta a segmentação da imagem e, por conseqüência, a localização dos robôs. Outro problema encontrado foi relacionado à 
precisão na determinação da orientação do robô, essencial para este trabalho. A orientação refere-se à determinação de onde está a frente do robô, calculando-se a sua angulação em relação à base da imagem. Para resolver esse problema, foram utilizados LEDs (Light-Emitting Diodes - Figura 4.6) de emissão de luz infravermelha instalados sobre o robô e um filtro de banda infravermelha encaixado na frente da lente da câmera de vídeo (Figura 4.5). Dessa forma, a imagem obtida foi uma tela preta com alguns círculos brancos (Figura 4.3). Esses círculos brancos são a luz infravermelha emitida pelos LEDs. Assim, pode-se obter uma imagem do ambiente com menos ruído e menos suscetível às variações de iluminação. Essas características permitiram uma melhor precisão na determinação da posição e da orientação do robô. Além disso, este programa exige menos processamento que a implementação anterior. A implementação anterior é apresentada no Apêndice A, com o propósito de que possa ser útil em outras aplicações, nas quais seja possível controlar a iluminação do ambiente.

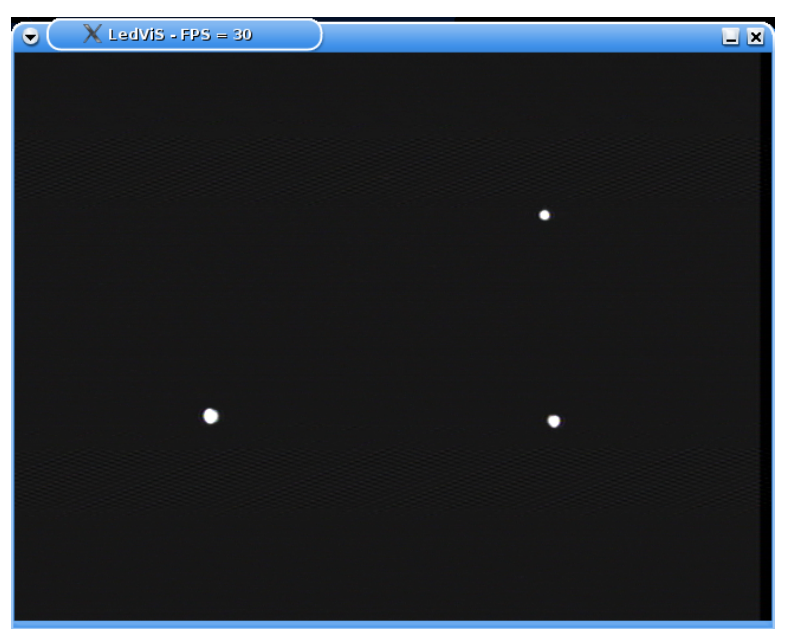

Figura 4.3: Imagem dos LEDs obtida pela câmera de vídeo com o filtro de luz infravermelha (os LEDs foram aproximados à câmera para melhor visualização).

Sua implementação foi realizada na plataforma Linux, com a linguagem de programação C++ e com a utilização da biblioteca $\mathrm{SDL}^{1}$ (Simple DirectMedia Layer) para a implementação da GUI (Graphical User Interface - Interface Gráfica do Usuário). Essa é uma biblioteca desenvolvida para facilitar o acesso de baixo nível a recursos multimídia, como áudio, teclado, mouse, vídeo, entre outros. Para acessar as funcio-

\footnotetext{
${ }^{1}$ http://www.libsdl.org
} 
nalidades e a imagem disponibilizada pela placa de captura, foi utilizada a biblioteca Video4Linux2 2 . O MPI foi implementado como uma biblioteca de software, possibilitando ser utilizado como um módulo de um sistema maior, que possua outros módulos. Essa biblioteca desenvolvida provê uma classe com métodos para obtenção das coordenadas da posição e a orientação dos robôs e uma interface gráfica.

Além da posição $(x, y)$ do robô, também foi necessário identificar sua orientação. Para isso, os LEDs foram dispostos sobre o robô formando um triângulo retângulo (Figura 4.7(a)). Convencionou-se que o menor segmento $(\overline{B C})$ indica a parte de trás do robô. O segmento de tamanho intermediário $(\overline{A B})$ fica alinhado ao centro do robô, no sentido frente-atrás. É através do cálculo da angulação do segmento $\overline{A B}$ em relação à base da imagem obtida que o software localiza a frente do robô.

O fluxograma apresentado na Figura 4.8 ilustra o funcionamento do módulo. Inicialmente, a imagem passa por uma varredura para localizar os agrupamentos de pixels correspondentes aos LEDs e determinar a coordenada de cada um deles. Em seguida, as coordenadas dos LEDs localizados são usadas para identificar cada robô, que possui três LEDs sobre si (Figura 4.7(b)).

Foi realizada uma análise empírica das imagens obtidas pela câmera e constatouse que os níveis de R, G e B captados diretamente de fontes de luz, como um LED, são altos e com valores iguais ou muito próximos. Isso pode ser explicado pelo fato de que a imagem captada de uma fonte de luz aparece como uma "bola" branca na tela. O branco puro é composto com R, G e B em seus valores máximos, ou seja, 255. Pequenas variações nas intensidades do branco geram valores um pouco abaixo de 255 aparecendo na tela também. Com base nessa característica, para reduzir a carga de processamento, optou-se por utilizar somente uma das componentes. Foi escolhido arbitrariamente o $\mathrm{R}$, mas poderia ter sido utilizado o $\mathrm{G}$ ou o $\mathrm{B}$.

A varredura da imagem é realizada utilizando-se a vizinhança-de-8 (Gonzalez e Woods, 2000). Com a aplicação dessa técnica, podem ser determinadas regiões na imagem para posterior classificação. Um pixel $p$ nas coordenadas $(x, y)$ possui 8 pontos

\footnotetext{
${ }^{2}$ http://linuxtv.org/v4lwiki/index.php/Main_Page
} 
vizinhos (Figura 4.4), cujas coordenadas são:

$(x+1, y),(x-1, y),(x, y+1),(x, y-1),(x+1, y+1),(x+1, y-1),(x-1, y+1),(x-1, y-1)$

Esse conjunto de pixels é denominado de vizinhança-de-8 de $p$. Deve-se notar que se $p$ encontrar-se na borda da imagem, ele terá menos vizinhos válidos, pois alguns deles cairão fora da imagem.

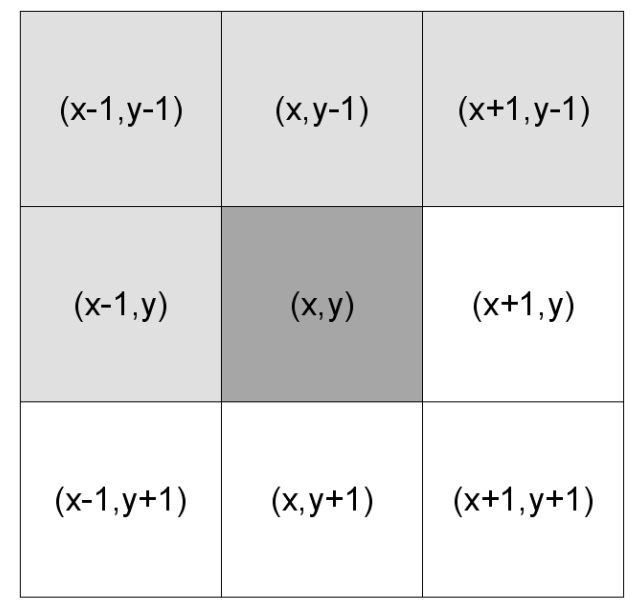

Figura 4.4: Vizinhança-de-8. O ponto $(x, y)$ em cinza escuro é o pixel $p$ sendo analisado. Os outros 8 pontos são seus vizinhos. Os pontos em cinza claro são os vizinhos analisados para determinar se o ponto $p$ é adjacente a algum deles.

Dois pixels estão conectados se forem adjacentes e se satisfizerem algum critério de similaridade. Neste trabalho foi considerado que dois pixels são adjacentes se forem vizinhos-de-8 e são similares se o valor em $\mathrm{R}$ nos dois pixels for maior que um limiar ajustado pelo usuário. Se dois pixels forem adjacentes (vizinhos-de-8) e similares, então eles são conectados-de-8. Portanto, um pixel é adjacente a outro se eles forem conectados. E dois subconjuntos da imagem são adjacentes se algum pixel de um dos subconjuntos for adjacente a algum pixel do outro subconjunto.

Para a rotulação dos componentes conectados-de-8, a imagem é percorrida pixel a pixel, da esquerda para a direita e de cima para baixo. Seja $p$ o pixel em qualquer passo no processo de varredura e considerando-se o valor de $p$ igual a 0 se o seu valor for inferior a um dado limiar e 1 se superior. A forma pela qual os pixels são percorridos garante que quando o procedimento alcançar $p$, o seu vizinho da esquerda e os seus 3 vizinhos superiores já tenham sido processados (Figura 4.4). 


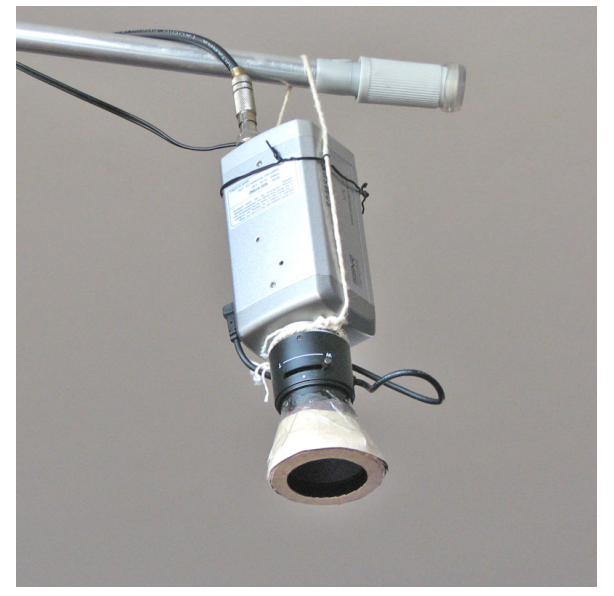

Figura 4.5: Câmera de vídeo CCD equipada com um filtro de luz infravermelha

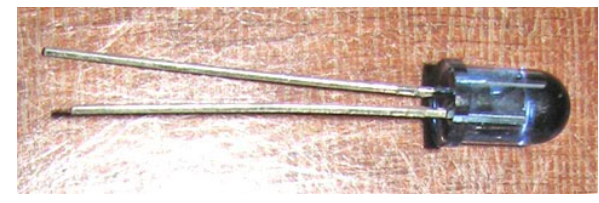

Figura 4.6: Imagem ampliada do LED de luz infravermelha

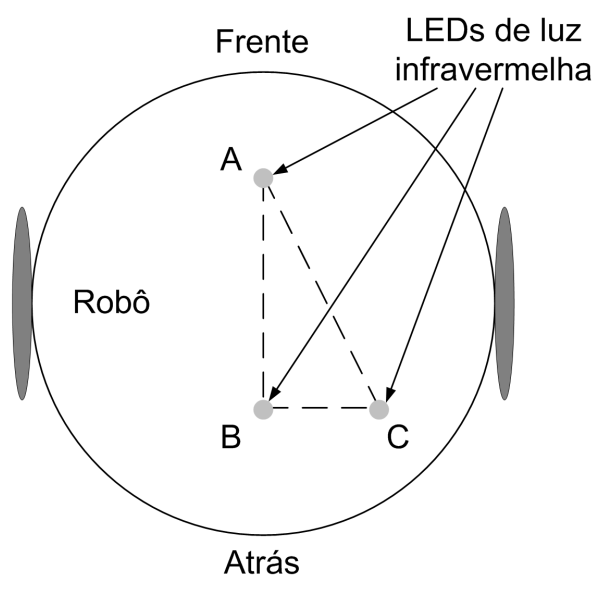

(a)

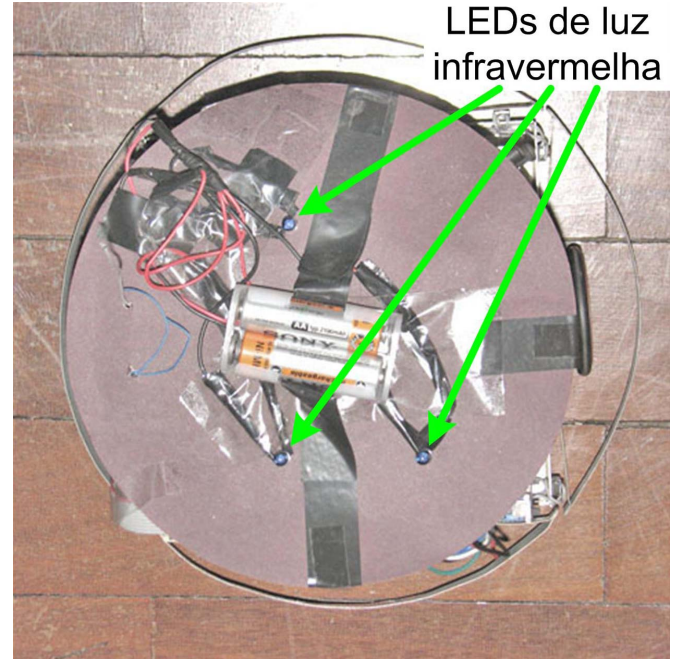

(b)

Figura 4.7: Disposição dos LEDs de luz infravermelha sobre o robô: (a) Triângulo retângulo $\mathrm{ABC}$ formado pelos LEDs e (b) foto dos LEDs sobre o robô.

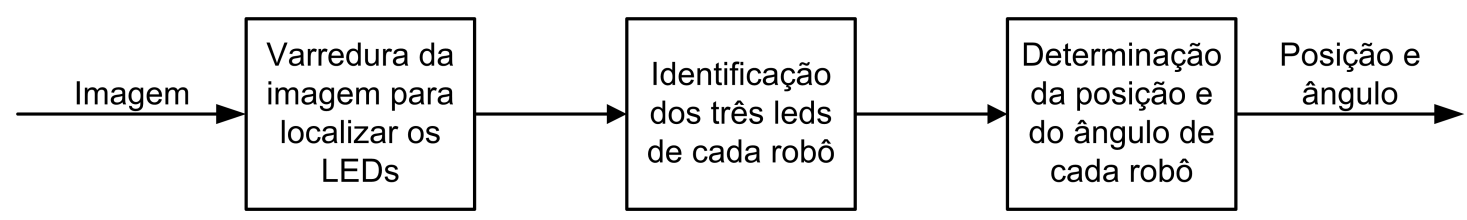

Figura 4.8: MPI de localização por LEDs 


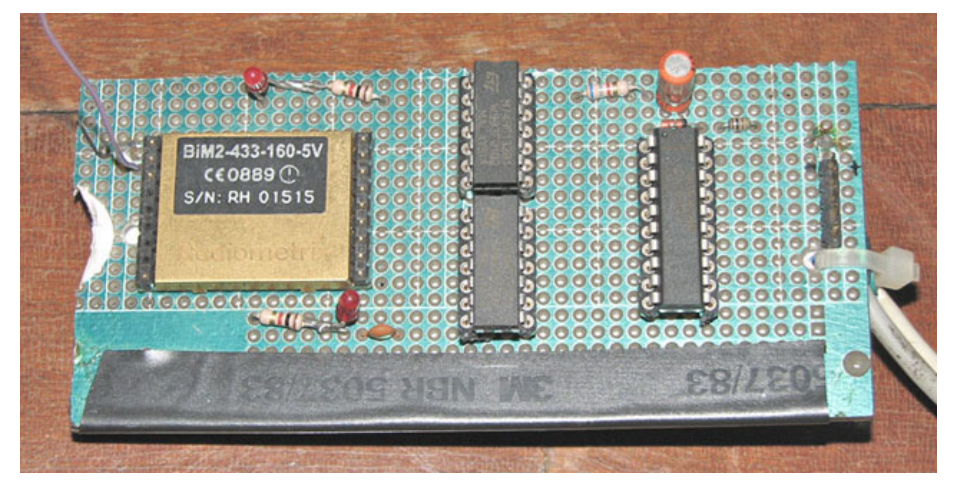

Figura 4.9: Aparelho de radiofreqüência

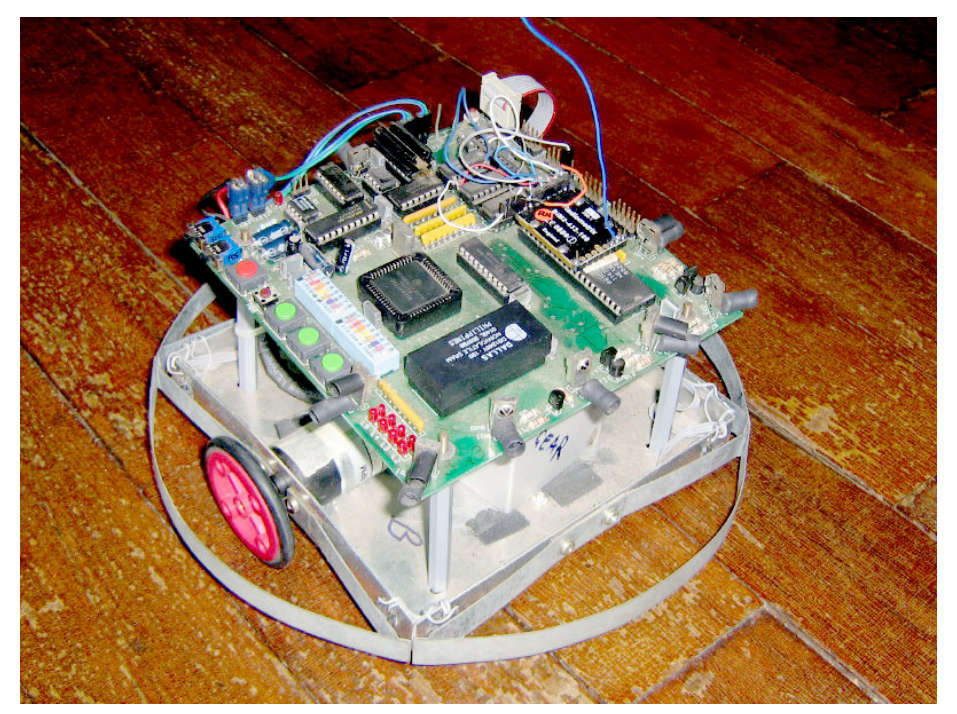

Figura 4.10: Robô utilizado

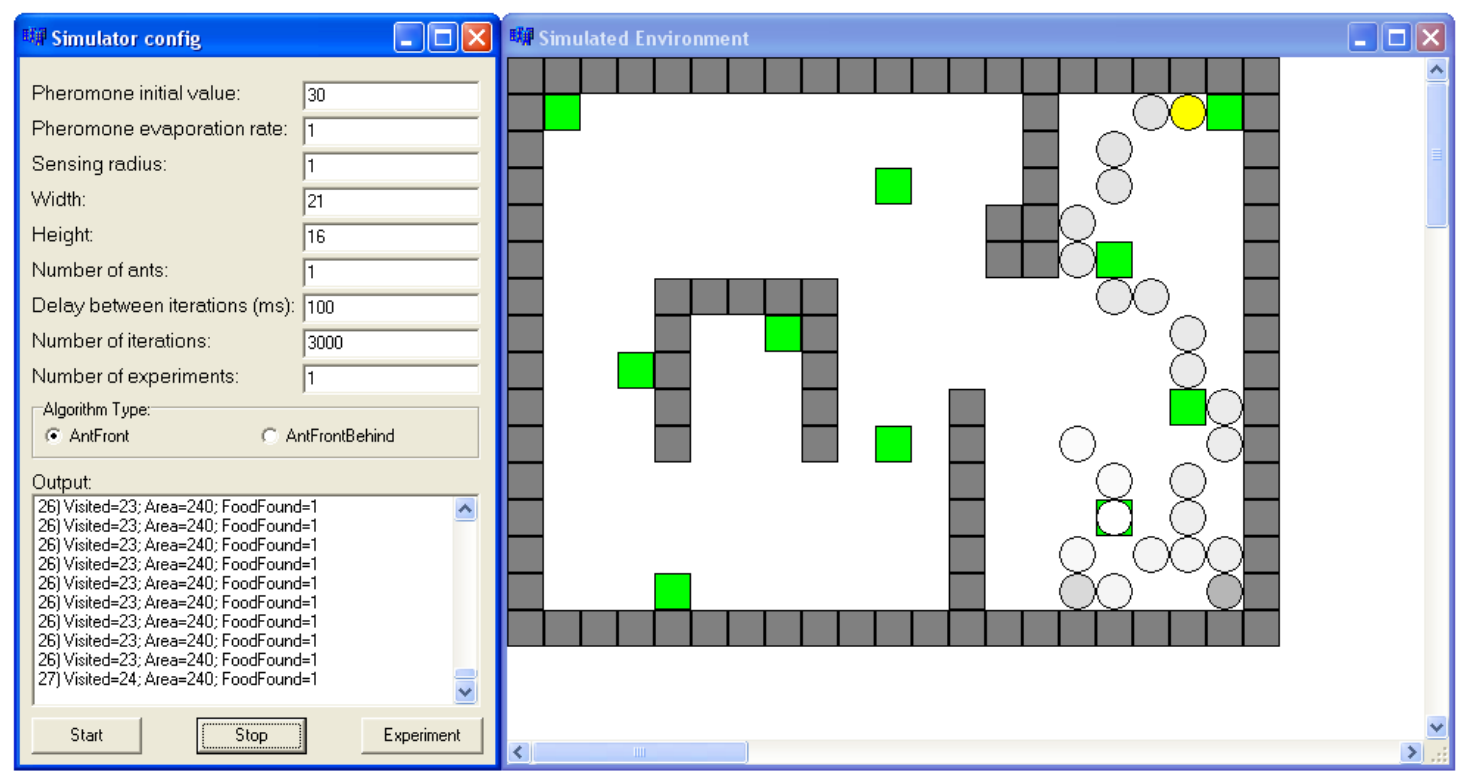

Figura 4.11: Tela do simulador 
Assim, o algoritmo opera da seguinte forma: caso o valor de $p$ seja 0, mova para a próxima posição. Caso $p$ seja 1, os seus vizinhos devem ser examinados. Se o seu vizinho da esquerda e os seus 3 vizinhos superiores forem 0 , atribua a $p$ um novo rótulo. Se um deles for 1 , atribua a $p$ o seu rótulo. Se dois ou mais deles forem 1 , atribua um dos rótulos a $p$ e marque todos esses rótulos como equivalentes. Após terminar de percorrer a imagem, atribua um único rótulo aos equivalentes.

A cada vez que um novo rótulo é atribuído, a coordenada do ponto que gerou esse evento é armazenada. Assim, o primeiro pixel encontrado de cada subconjunto é utilizado para designar a sua posição na imagem. Cada subconjunto encontrado corresponde a um LED. Como os LEDs são muito pequenos na imagem, essa aproximação grosseira não interfere significativamente na precisão do módulo.

Em seguida, o próximo passo é a identificação dos três LEDs de cada robô. O usuário deve informar ao programa a distância aproximada entre os LEDs. Com isso, é possível isolá-los. Deve-se ressaltar que os LEDs devem estar a certa distância da borda do robô, de tal forma que quando dois robôs se aproximam, as distâncias entre os LEDs do mesmo robô sejam pelo menos a metade da distância entre dois LEDs pertencentes a robôs diferentes.

Isolados os três LEDs de cada robô, pode-se determinar a sua posição e a sua angulação. Inicialmente, é identificado o segmento de tamanho intermediário $(\overline{A B})$. Para a posição, basta calcular o ponto médio de $\overline{A B}$. Para a angulação, calcula-se a inclinação de $\overline{A B}$ em relação à base da imagem.

\subsubsection{Módulo de Simulação}

O Módulo de Simulação foi desenvolvido no $\mathrm{C}++$ Builder. Este módulo simula o comportamento do robô real em um ambiente simulado, no qual podem ser adicionados robôs, obstáculos e objetos. A Figura 4.11 mostra a tela do simulador, composta pelo formulário de configuração do algoritmo de formigas (à esquerda) e a arena do ambiente simulado (à direita). O círculo amarelo representa o robô-formiga. Os círculos cinzas, os feromônios depositados. Os quadrados cinzas, os obstáculos. Os quadrados verdes 
são os objetos a serem localizados. O quadrado verde com um círculo branco no meio é um objeto já localizado.

O simulador permite ajustar, através do formulário de configuração, o valor inicial do feromônio (intensidade inicial de depósito), a taxa de evaporação do feromônio, o raio de sensoriamento, a largura e a altura da arena, o número de robôs-formigas simulados e reais e o tipo de área de sensoriamento (sensoriamento à frente ou sensoriamento frente-trás). Além disso, também é possível ajustar um tempo adicional de espera (em ms). O seu propósito é facilitar a visualização do movimento dos robôs-formigas na tela, principalmente quando só há robôs simulados e eles se movimentam rápido. Esse tempo de espera reduz a velocidade de seus movimentos e, assim, é possível visualizar melhor os eventos. Caso haja somente robôs simulados, é possível rodar vários experimentos com a mesma configuração de uma só vez, sem a exibição da interface. Para isso, deve-se especificar o número máximo de iterações e o número de experimentos a serem executados. O programa salva automaticamente em arquivo a média dos resultados.

\subsubsection{Módulo de Controle}

O termo colônia aqui utilizado refere-se a um conjunto de robôs, virtuais ou reais, com características e habilidades semelhantes, que mimetizam comportamentos das formigas biológicas (Cao et al., 1997). Esses robôs são chamados neste trabalho de robôs-formigas. Como o próprio nome sugere, eles são versões de formigas robóticas inspiradas nas biológicas. A exploração de seu ambiente e a localização de objetos foram as atividades abordadas para serem desempenhadas pela colônia.

Deve-se ressaltar que o controle da colônia simula um sistema distribuído, em que cada robô teria o seu próprio módulo de controle, embarcado no caso dos reais e emulado no caso dos simulados. Portanto, os robôs-formigas propostos podem ser considerados um sistema multi-agente com controle distribuído e descentralizado, pois cada um deles é independente de um agente central de controle, podendo tomar suas próprias decisões com base nas informações locais coletadas de sua posição corrente. O grupo de 
robôs é homogêneo, ou seja, as capacidades e habilidades dos indivíduos são idênticas. Outro ponto importante a ser considerado é a comunicação entre os robôs. Neste trabalho não há comunicação explícita direta entre os indivíduos. Eles se comunicam de forma indireta, através do próprio ambiente, utilizando-se de marcações de trilhas de feromônios. Essa forma de comunicação indireta, pela modificação do ambiente, é chamada de estigmergia stigmergy (Dorigo et al., 2000).

Cada robô-formiga possui o seguinte algoritmo, executado a cada iteração:

1. Determinar a direção para o próximo passo:

1.1 Se um obstáculo for encontrado em seu caminho:

1.1.1 Se estiver à sua frente, girar para um dos lados (escolhido aleatoriamente).

1.1.2 Senão (se o obstáculo estiver em um de seus lados), virar para o lado oposto.

\subsection{Senão:}

1.2.1 Verificar a quantidade de feromônio detectada em cada antena.

1.2.2 Se as duas antenas detectarem a mesma quantidade de feromônio, escolher aleatoriamente uma direção.

1.2.3 Senão, escolher a direção onde há a menor concentração de feromônios.

2. Depositar feromônio.

3. Mover-se para a direção escolhida.

Portanto, o comportamento de um robô-formiga pode ser influenciado pelo ambiente ao encontrar:

- Feromônios: o robô-formiga tende a se afastar dos locais de maior concentração;

- Obstáculos, paredes e outros robôs: o robô vira para o lado que não tem obstáculo, com a finalidade de não colidir;

- Fonte de Alimento: quando percebe o objeto a ser encontrado dentro de um raio R, o robô apresenta uma forte tendência de se deslocar em sua direção. 


\subsubsection{Módulo de Radiofreqüência}

O Módulo de Radiofreqüência (MR) é o responsável pela comunicação com os robôs reais. Pelo MR, é possível enviar para cada robô real suas coordenadas e orientação, além das demais coordenadas dos robôs reais e simulados. Cada robô real necessita saber a sua posição $(x, y)$ para acessar a tabela de feromônios. A sua orientação também é necessária para posicionar as "antenas" e calcular as concentrações de feromônio em cada uma. Essa estratégia de comunicação com os robôs reais através de radiofreqüencia, em conjunto com o processamento de imagens para determinar a localização, possibilita a economia de recursos, pois os robôs não necessitam de sensores sofisticados para determinar sua posição e orientação, como, por exemplo, GPS e bússola eletrônica.

\subsubsection{Comunicação entre os módulos}

Os módulos comunicam-se entre si da seguinte forma (Figura 4.12):

- As imagens do mundo real são capturadas através da câmera de vídeo e transmitidas ao MPI.

- MPI no PC1 (cliente) e MS+MR no PC2 (servidor) utilizam conexão TCP/IP por sockets.

- MS e MR estão no mesmo processo, ou seja, estão implementados no mesmo programa, estando apenas separados em termos lógicos. A princípio, pretendiase separá-los em dois programs e conectá-los também através de sockets. Porém, devido a dificuldades de implementação não solucionadas a tempo, optou-se por uni-los.

- A comunicação entre MR e o robô ocorre por rádio-modem, no protocolo RS-232, através da conexão da porta serial COM1 do PC2 com o rádio-modem.

MPI localiza-se no computador PC1 e MS+MR estão localizados em outro computador, PC2. Isso faz-se necessário para manter o software de processamento de imagens 
isolado em um computador, dedicado devido a sua alta demanda de processamento para segmentar os marcadores dos robôs e identificar suas coordenadas e orientação. Essa abordagem de separar o sistema geral em sistemas menores e integrá-los via sockets foi idealizada para posteriormente facilitar a substituição e integração de novas partes. Assim, por exemplo, o MPI poderia ser facilmente substituído por outra implementação, bastando utilizar o protocolo de comunicação estabelecido entre as partes. Além disso, a nova implementação poderia ser executada em qualquer outro sistema operacional e até mesmo em outra máquina. Essa é outra vantagem dessa abordagem. Cada parte do sistema geral poderia ser facilmente distribuído em vários computadores. Devido à essa natureza distribuída, também seria possível executar um tipo de MPI em uma máquina e outro MPI diferente em outra, por exemplo. Dessa forma, o usuário poderia facilmente optar qual MPI utilizar.

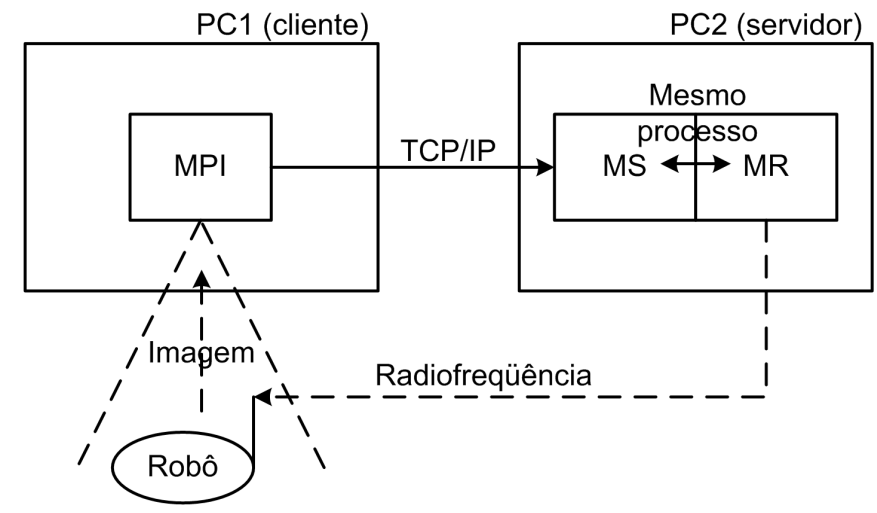

Figura 4.12: Comunicação entre os módulos

\subsubsection{Ambiente unificado}

O ambiente real (físico) onde o robô opera nos experimentos é uma área retangular, podendo haver ou não obstáculos e objetos a serem localizados. A Figura 4.13(a) é um exemplo que ilustra uma possível configuração de ambiente real, visto de cima. A câmera de vídeo fica instalada sobre essa área, para a aquisição das imagens necessárias ao MPI.

Os componentes reais do ambiente físico (o robô e os obstáculos) são mapeados 
no ambiente simulado. Os robôs reais são mapeados através do MPI, que os localiza, determina suas orientações e envia essas informações ao MS. Atualmente, os obstáculos são mapeados manualmente pelo usuário, que deve informar ao sistema a localização dos obstáculos reais. A automatização da identificação dos obstáculos reais será realizada como um trabalho futuro. Além dos elementos reais, também podem haver robôs, obstáculos e objetos simulados. Todos esses elementos, reais e simulados, mais os feromônios depositados, são demarcados em matrizes, armazenadas e gerenciadas pelos Módulos de Controle de cada robô.

Dessa forma, todos esses componentes, reais e simulados, interagem entre si sem distinção. O MS recebe diretamente do MPI as coordenadas dos robôs reais e as mapeia em avatares dos robôs no ambiente simulado. Assim, o MC de cada robô pode receber as coordenadas e a orientação de todos os robôs e determinar os comandos individuais em função das concentrações de feromônio nas tabelas internas. No caso dos robôs reais, esses comandos são utilizados para movimentar os robôs no ambiente real. Já no caso dos simulados, esses comandos vão para o MS, que atualiza as posições dos robôs simulados na janela de visualização. A Figura 4.13(b) exemplifica a visão integrada dos ambientes, na qual o sistema não diferencia os elementos simulados e reais.

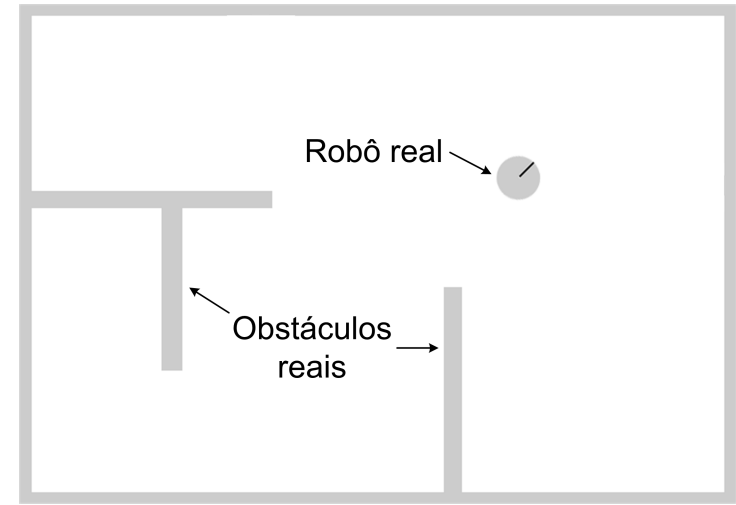

(a)

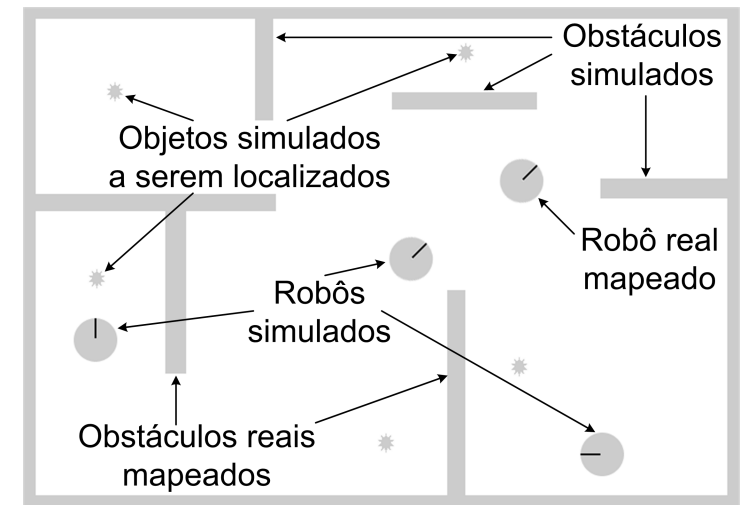

(b)

Figura 4.13: Exemplo de configuração de ambiente físico (a) e exemplo de visão integrada dos ambientes simulado e real (b) 


\section{Capítulo 5}

\section{Experimentos}

Os experimentos realizados tiveram como propósito testar a funcionalidade do sistema desenvolvido neste trabalho. Como experimentos em robôs reais costumam demandar bastante tempo para sua realização, isso dificulta executar um número grande de experimentos que seria necessário para testar o desempenho em função de variações nas configurações dos parâmetros. Dessa forma, optou-se por primeiro realizar essa análise comparativa do sistema no simulador. Após escolhidos os melhores valores de parâmetros, foram realizados experimentos com o robô real considerando esses resultados obtidos em simulação. Como na época em que os experimentos foram realizados havia somente um robô real disponível em funcionamento, isso acabou limitando as possibilidades de experimentos de interação entre robôs reais e mistos. Assim, foram realizados experimentos com cinco robôs simulados e um experimento com um robô real e quatro simulados.

Três configurações do algoritmo de formigas proposto foram testadas:

1. Formiga com sensoriamento à frente $-\mathrm{FF}$;

2. Formiga com sensoriamento frente-trás - FFT;

3. Formiga sem sensoriamento (caminhada aleatória) - FCA.

A configuração 3 é obtida ajustando-se o algoritmo de formigas para não depositar feromônio no ambiente. Assim, somente as capacidades de decisão aleatória da direção 
e de desvio de obstáculos são empregadas. Esse caso foi considerado para demonstrar que o algoritmo proposto é capaz de melhorar o desempenho na realização das tarefas de exploração e busca de objetos no ambiente.

Foram adotadas como medidas de desempenho nos experimentos:

1. Área explorada;

2. Quantidade de objetos localizados.

A área explorada consiste na quantidade de células da grade livre de obstáculos que foram visitadas por algum membro da colônia. Os objetos a serem localizados são dispostos nas células livres e são "coletados" pelos robôs-formigas quando eles passam pela célula em que está o objeto.

A seguir, são descritos os três experimentos e os respectivos resultados alcançados nas Seções 5.1, 5.2 e 5.3. Nos gráficos apresentados neste capítulo, as notações utilizadas nas legendas indicam a configuração utilizada e o valor de concentração do feromônio depositado pelos robôs-formigas no teste correspondente. Por exemplo, FF30 indica a utilização da configuração FF (Formiga com sensoriamento à frente), com valor de concentração de feromônio de 30 .

\subsection{Experimento 1: Simulação para analisar os efeitos da va- riação na concentração do feromônio depositado}

Neste experimento, a arena utilizada possui área total de 100 x 80 células, contendo alguns obstáculos e 22 objetos, o que deixa disponível para navegação e exploração 7168 células livres. O valor de depósito do feromônio define qual valor de concentração de feromônio é depositada pelas formigas na arena a cada iteração. A "evaporação" dos feromônios presentes na arena ocorre a uma taxa de uma unidade por iteração. O raio de sensoriamento por feromônios foi fixado com valor um. Foram testados quatro valores diferentes de configuração da concentração do feromônio depositado pela formiga: 30, 60, 90 e 120. O grupo de robôs possui 10 integrantes. 
Foram realizados 100 testes, com 3000 iterações, para cada configuração:

- FF com valor de depósito de feromônio igual a 15;

- FF com valor de depósito de feromônio igual a 30;

- FF com valor de depósito de feromônio igual a 60;

- FF com valor de depósito de feromônio igual a 120;

- FFT com valor de depósito de feromônio igual a 15;

- FFT com valor de depósito de feromônio igual a 30;

- FFT com valor de depósito de feromônio igual a 60;

- FFT com valor de depósito de feromônio igual a 120;

- FCA.

Os dados apresentados são as médias de 100 execuções do experimento. O gráfico na Figura 5.1 apresenta os dados sobre a utilização de FF. Para efeitos de comparação, os dados de FCA também estão presentes. É possível visualizar que todas as configurações FF apresentam curvas acima da curva FCA. Isso demonstra que nos experimentos realizados a utilização de trilhas de feromônio na exploração apresenta resultados melhores do que a abordagem aleatória. Outra observação que pode ser extraída desse gráfico é que quanto maior a taxa de depósito de feromônio, melhor fica a eficácia do algoritmo. Os resultados obtidos utilizando FFT foram semelhantes aos encontrados usando FF. Portanto, assim como FF, FFT também se mostrou mais eficiente que FCA nos experimentos realizados. As curvas de cada abordagem FFT são apresentada na Figura 5.2 .

Nos próximos dois gráficos discutidos, são apresentadas as curvas do número de iterações que foram necessários para encontrar $\mathrm{N}$ objetos na arena, utilizando-se FF e FCA, respectivamente. Dessa forma, as curvas mais abaixo são as que representam os melhores desempenhos, pois denotam que foram necessárias menos iterações para encontrar o mesmo número de objetos que as curvas mais altas. 
O gráfico da abordagem FF é apresentado na Figura 5.3. Por esse gráfico, pode-se visualizar que até aproximadamente a metade dele, todas as abordagens obtiveram desempenho semelhante. A partir desse ponto, começam a aparecer divergências. Os piores foram FF15 e FF30. A configuração de caminhada aleatória (FCA) apresenta um desempenho semelhante aos dois primeiros durante a maior parte do gráfico. Porém, no final, apresenta desempenho semelhante ao FF60. Considerando-se o desempenho geral, FF60 pode ser considerada a segunda melhor abordagem. FF120 aparece claramente como a melhor opção.

Na Figura 5.4, é apresentado o gráfico sobre o número de iterações necessárias para localizar N objetos utilizando a configuração FFT e FCA. Como pode ser observado, aproximadamente um pouco antes da metade do gráfico, as diferentes configurações começam a se distingüir. FFT15 apresentou o pior desempenho, apresentando desempenho inferior a FCA. FFT30 e FFT60 apresentaram resultados bem próximos, sendo que FFT60 obteve desempenho ligeiramente melhor. Contudo, a melhor configuração é evidenciada no gráfico como sendo FFT120.

Os dados coletados sugerem que quanto maior a concentração de feromônio depositado pelo robô-formiga no ambiente desenvolvido, mais rápido ocorre a exploração e a coleta de objetos. Também é possível visualizar que o algoritmo de formigas proposto apresenta nos experimentos resultados melhores em todas as configurações para exploração e, na maioria dos casos, também melhores que a busca aleatória na localização de objetos.

\subsection{Experimento 2: Simulação para analisar as configurações do Experimento 1 em uma arena menor}

Este experimento foi realizado na arena do ambiente simulado, apresentada na Figura 5.8(a). Essa arena possui como medidas 21 x 16 células. Esse tamanho foi escolhido porque se constatou que o robô mede em torno de 30 pixels de diâmetro quando visualizado pela câmera de vídeo a 1,80 m do solo. Como a imagem do vídeo 
capturada possui dimensões de 640 x 480 pixels, dividindo esses valores por 30, obtêm-se as medidas utilizadas na simulação. Dessa forma, a área máxima obtida pelas imagens da arena real restringe o tamanho máximo da arena simulada. A arena utilizada neste experimento possui área livre de obstáculos igual a 240 células, enquanto que a arena do Experimento 1 possui 7168 células. Portanto, o propósito deste experimento é verificar se os resultados observados no Experimento 1, conduzidos em uma arena quase 30 vezes maior que a deste experimento, também são verificados em uma arena de área pequena.

A taxa de evaporação utilizada foi fixada em uma unidade por iteração, o raio de sensoriamento por feromônios possui valor um e foram distribuídos na arena 10 objetos para coleta. Foram testadas em FF e em FFT, quatro variações de concentração de feromônio: 30, 60, 90 e 120. Para comparação, os resultados de FCA também são exibidos nos gráficos. O grupo utilizado nos testes possui 5 robôs. Este experimento foi executado 100 vezes para poder realizar o cálculo das médias dos resultados.

A Figura 5.5 apresenta o gráfico da área visitada pelas formigas ao longo do tempo (iterações) utilizando FF e FCA. Pode-se perceber pelo gráfico que não há diferenças significativas entre as quatro configurações de FF. Apenas FF15 apresenta um desempenho ligeiramente inferior aos demais. Mas todas elas apresentaram um desempenho melhor que a configuração de caminha aleatória do robô-formiga (FCA), considerando que suas curvas demonstram uma exploração mais rápida do terreno. Isso é percebido pela primeira metade do gráfico, no qual suas curvas claramente crescem mais rápidas e se destacam sobre a curva de FCA. Na segunda metade do gráfico, todas as curvas se unem. Isso acontece porque a área máxima de exploração é 240. Assim, quando a área já explorada chega próximo a esse valor, a quantidade de pontos ainda não explorados é tão pequena que as diferentes abordagens não são muito diferentes entre si. Portanto, como o Experimento 1, este experimento também demonstra empiricamente a eficácia na utilização de trilhas de feromônio na exploração. A indiferença nos resultados com a variação da concentração de feromônios depositada pode ser explicada considerando-se o tamanho da arena. 


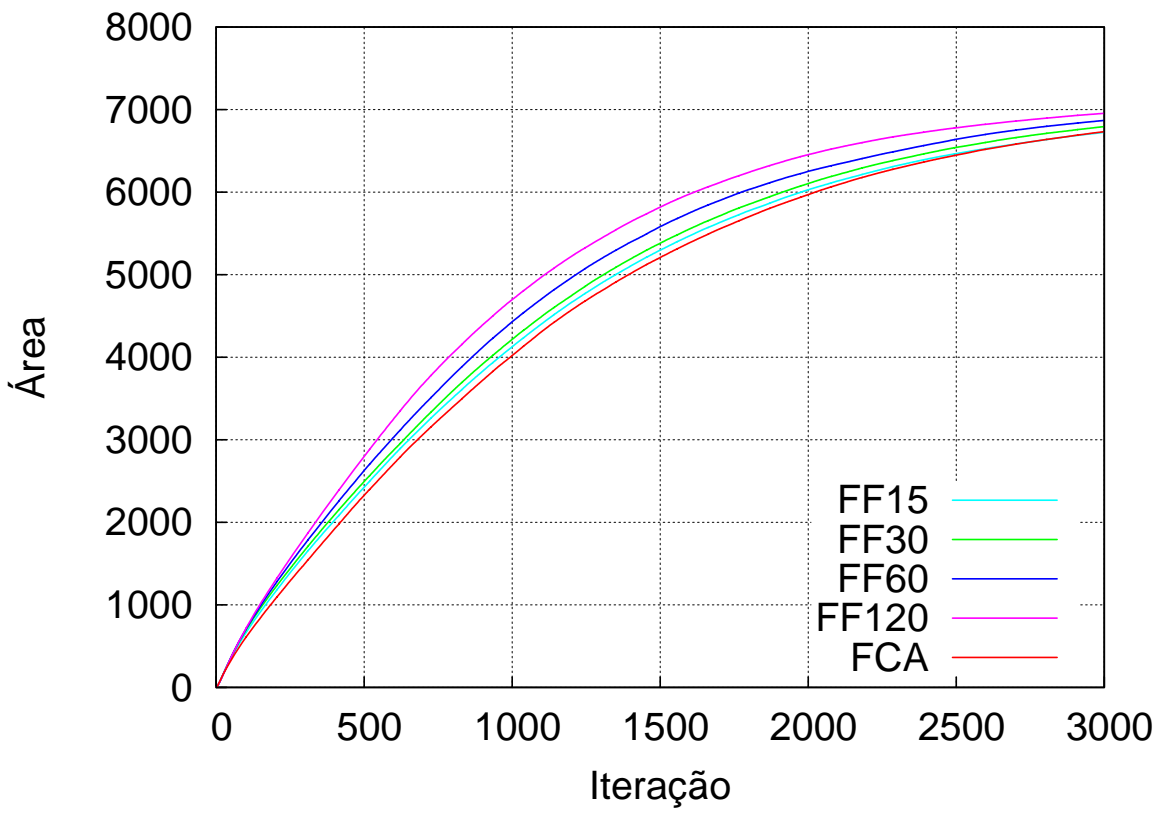

Figura 5.1: Área explorada por iteração pelos robôs simulados no Experimento 1, utilizando FF e FCA.

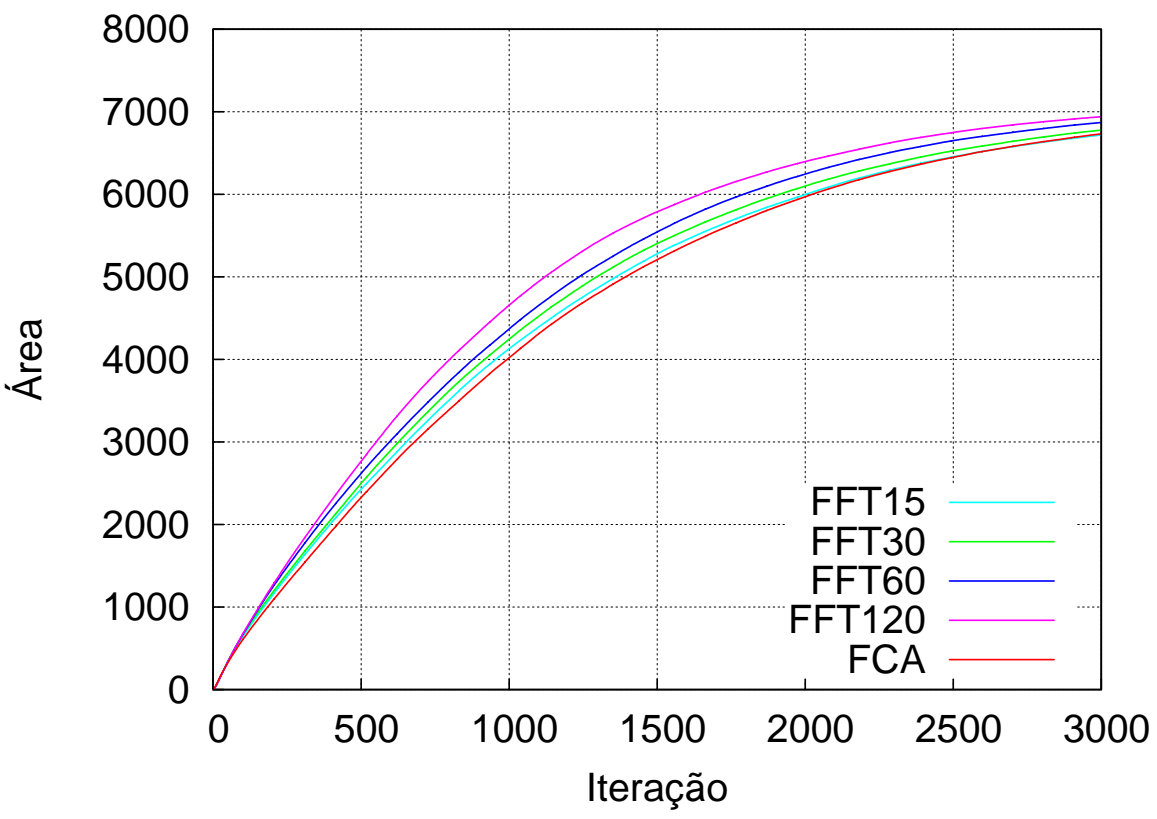

Figura 5.2: Área explorada por iteração pelos robôs simulados no Experimento 1, utilizando FFT e FCA. 


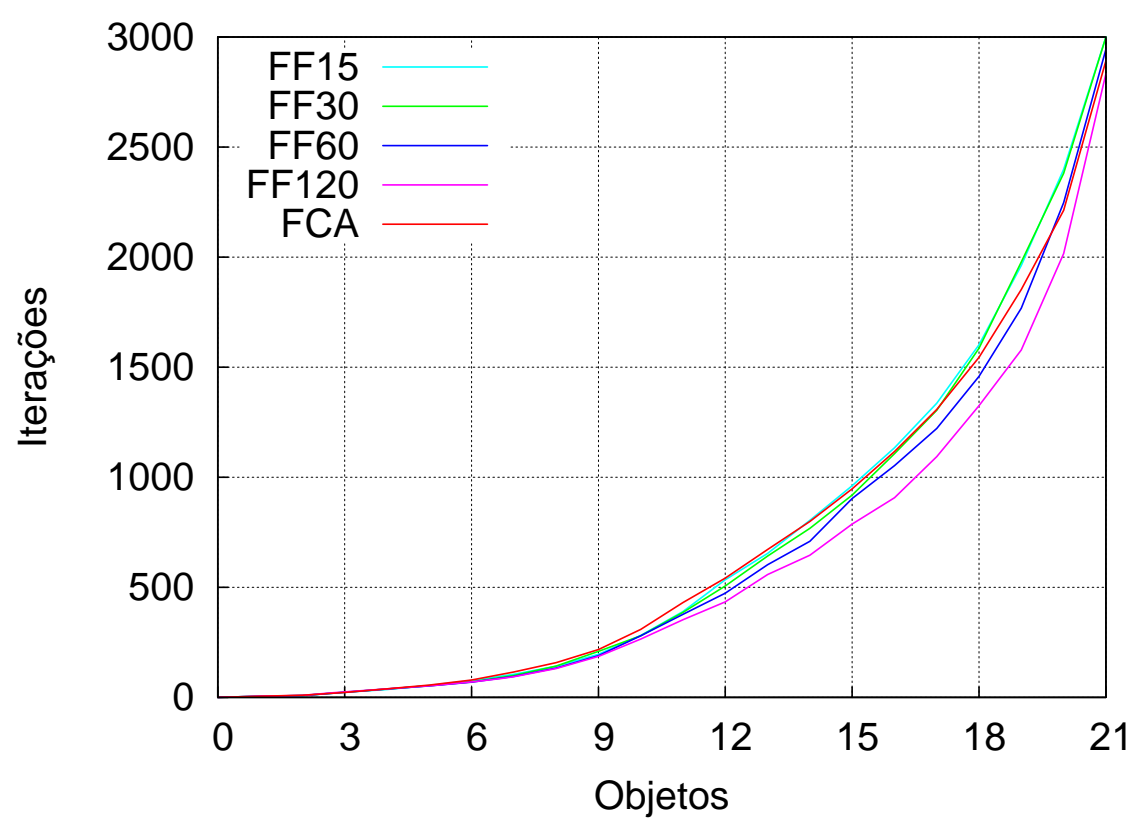

Figura 5.3: Número de iterações necessário para se encontrar N objetos no Experimento 1, utilizando FF e FCA.

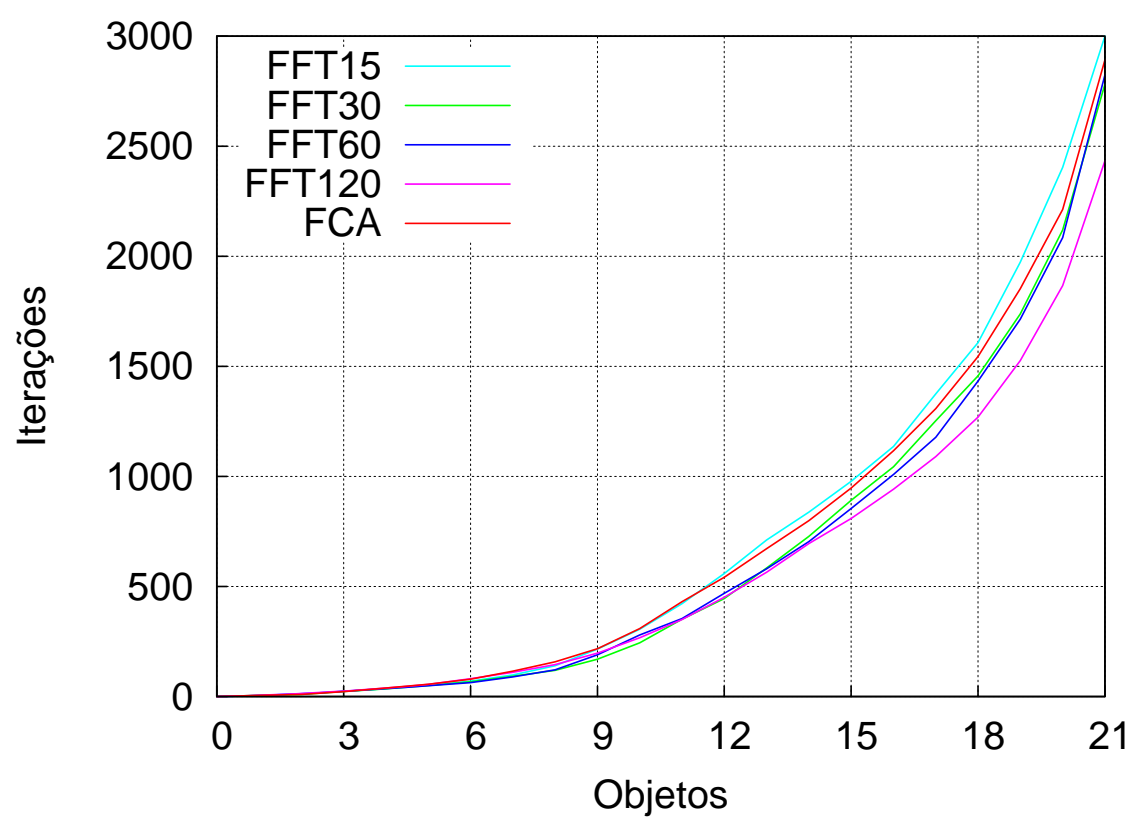

Figura 5.4: Número de iterações necessário para se encontrar N objetos no Experimento 1, utilizando FFT e FCA. 


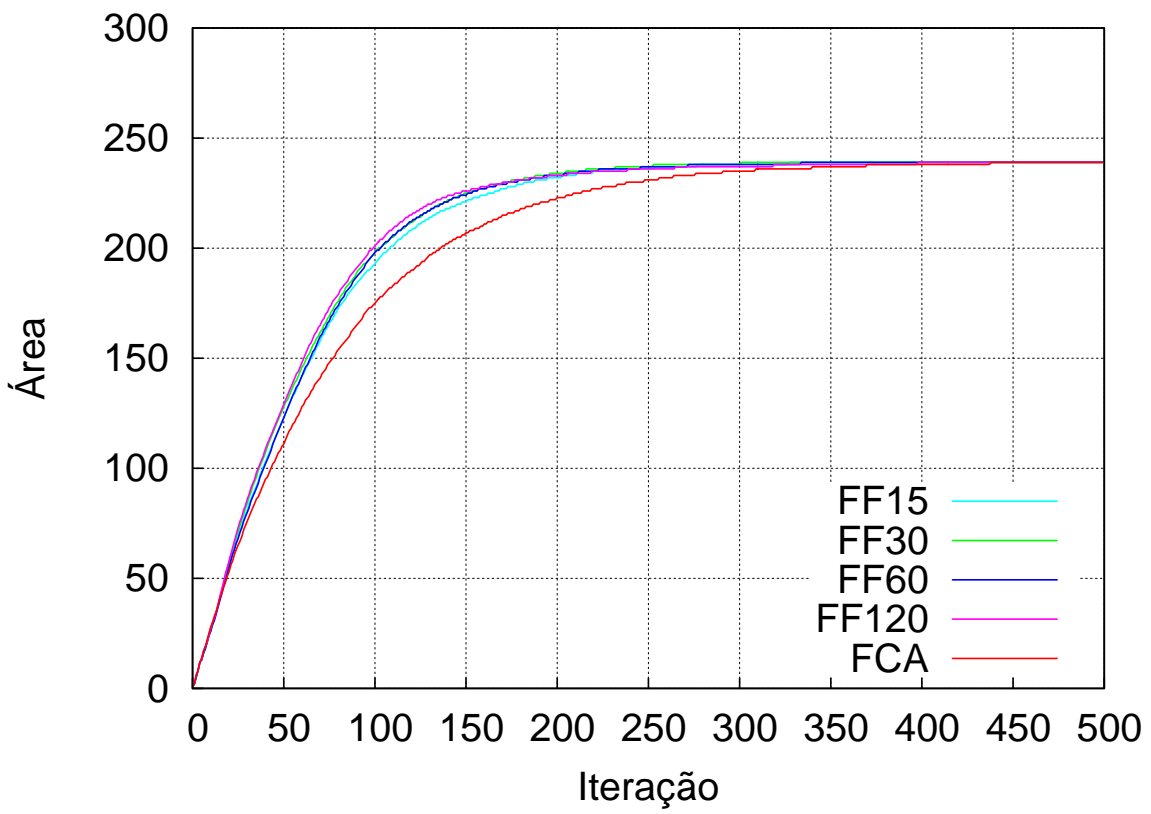

Figura 5.5: Área explorada por iteração pelos robôs simulados no Experimento 2, utilizando FF e FCA.

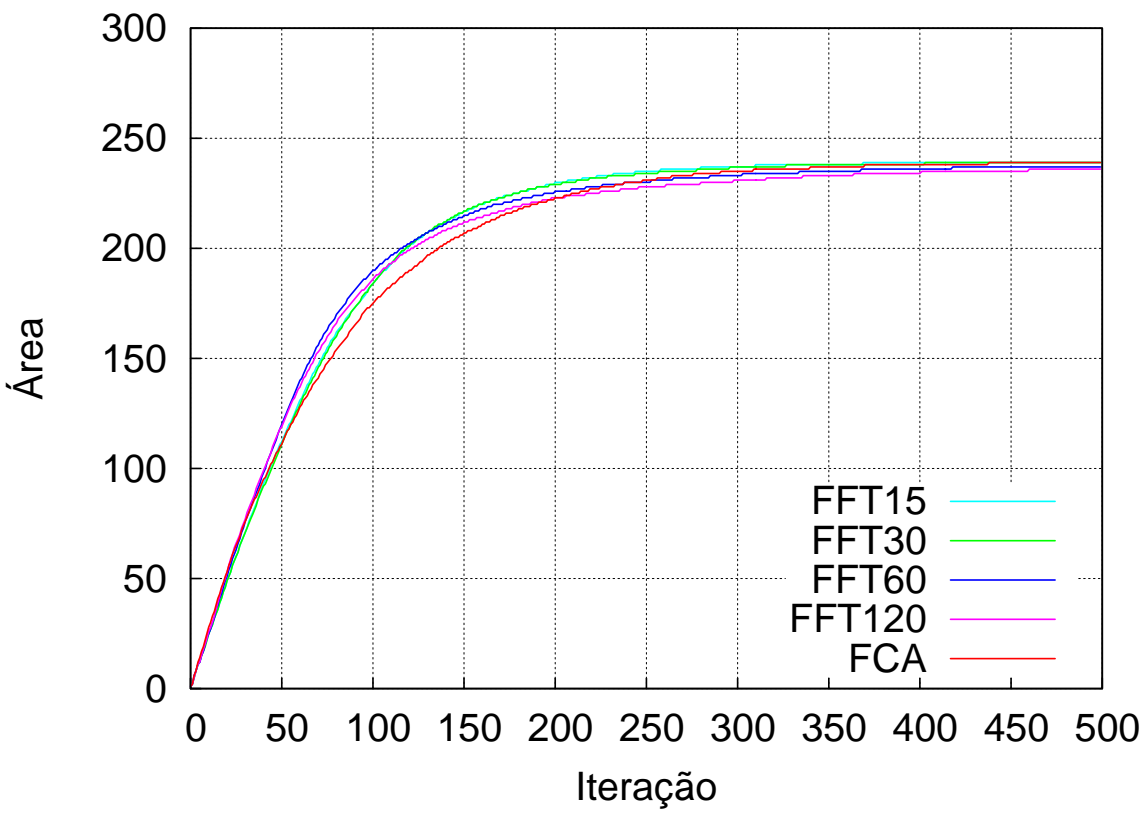

Figura 5.6: Área explorada por iteração pelos robôs simulados no Experimento 2, utilizando FFT e FCA. 


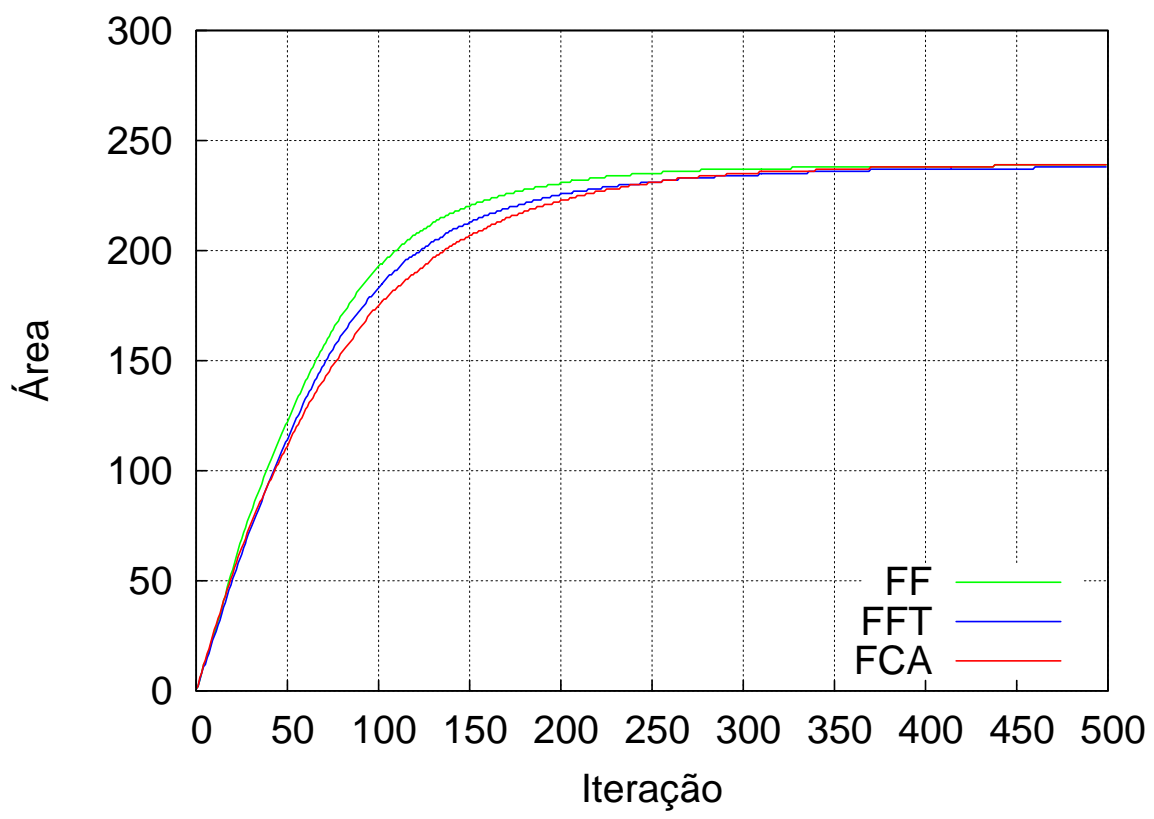

Figura 5.7: Comparação dos resultados de área explorada em FCA e das médias de FF e de FFT no Experimento 2.

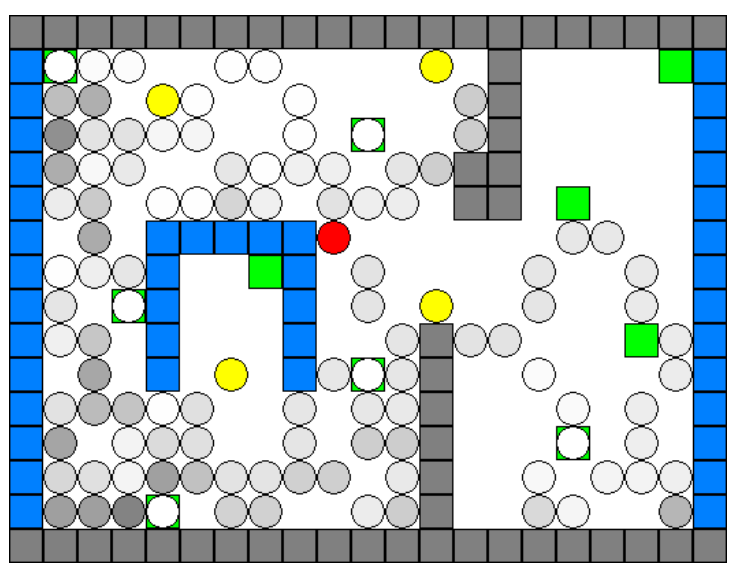

(a)

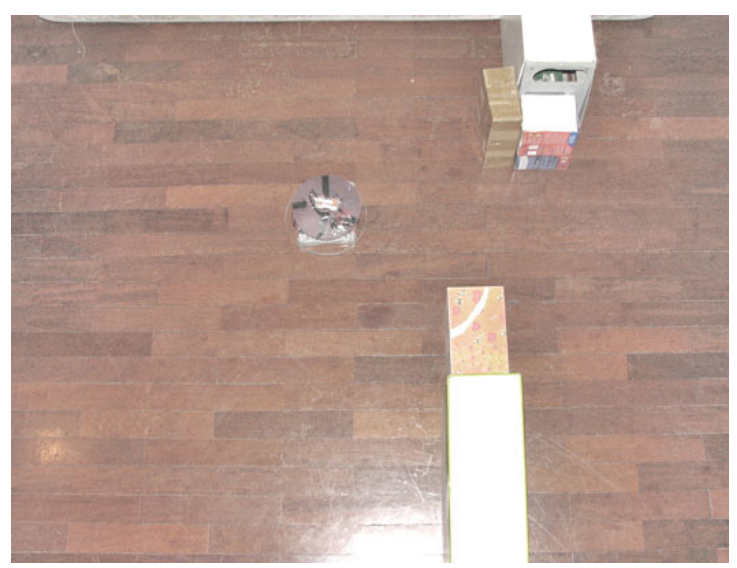

(b)

Figura 5.8: Arena simulada (a) e arena real (b) 


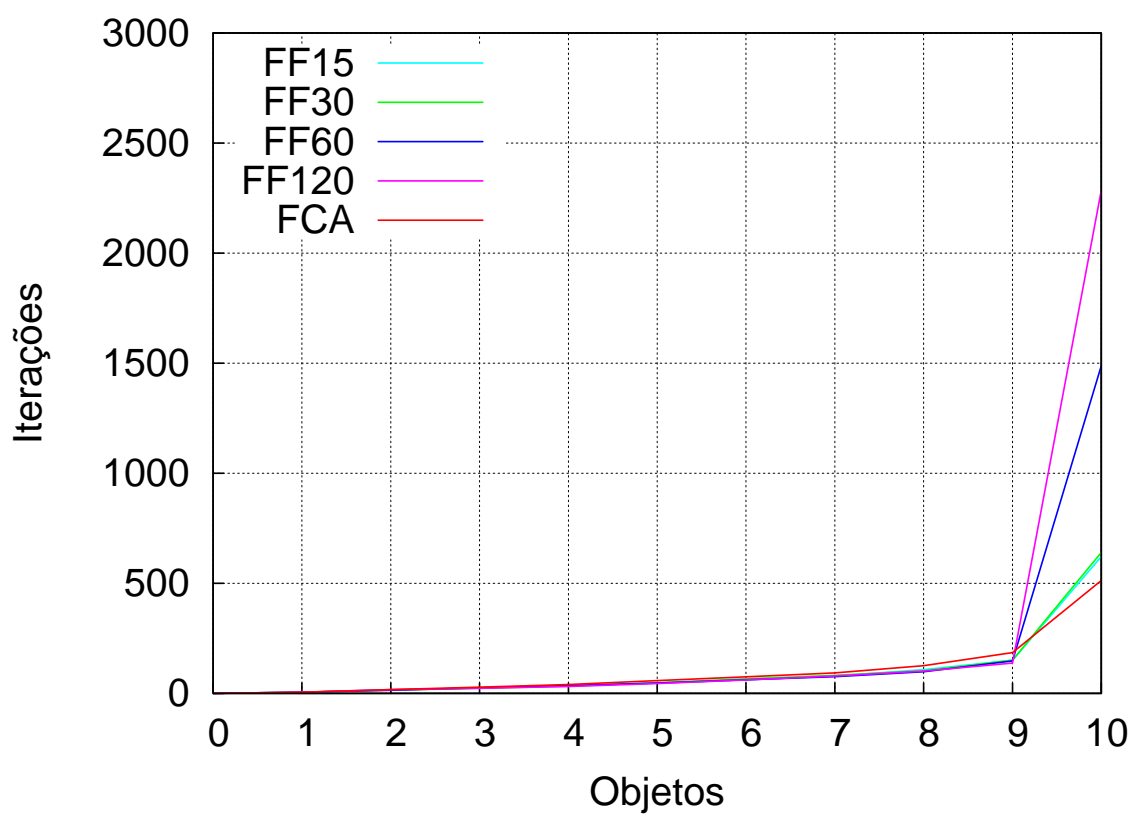

Figura 5.9: Número de iterações necessário para se encontrar N objetos no Experimento 2, utilizando FF e FCA.

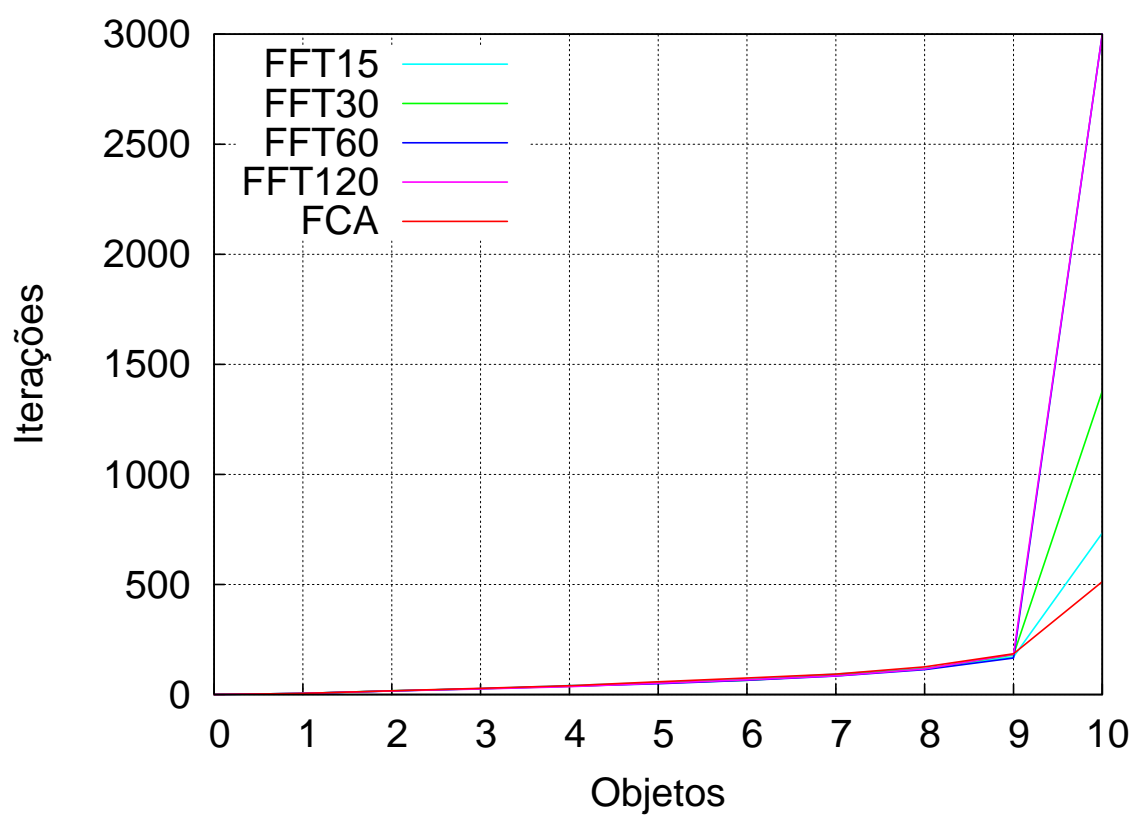

Figura 5.10: Número de iterações necessário para se encontrar N objetos no Experimento 2, utilizando FF e FCA. 


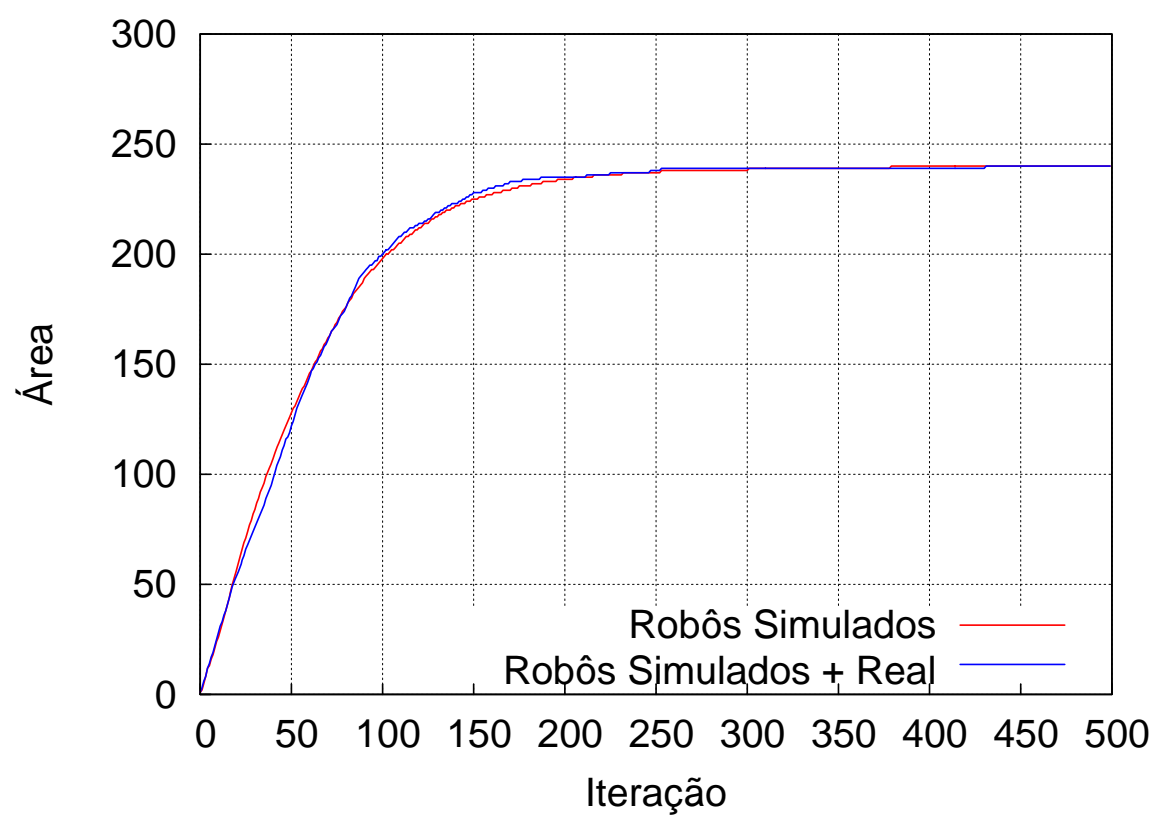

Figura 5.11: Comparação da área explorada utilizando somente robôs simulados ou o robô real com os simulados.

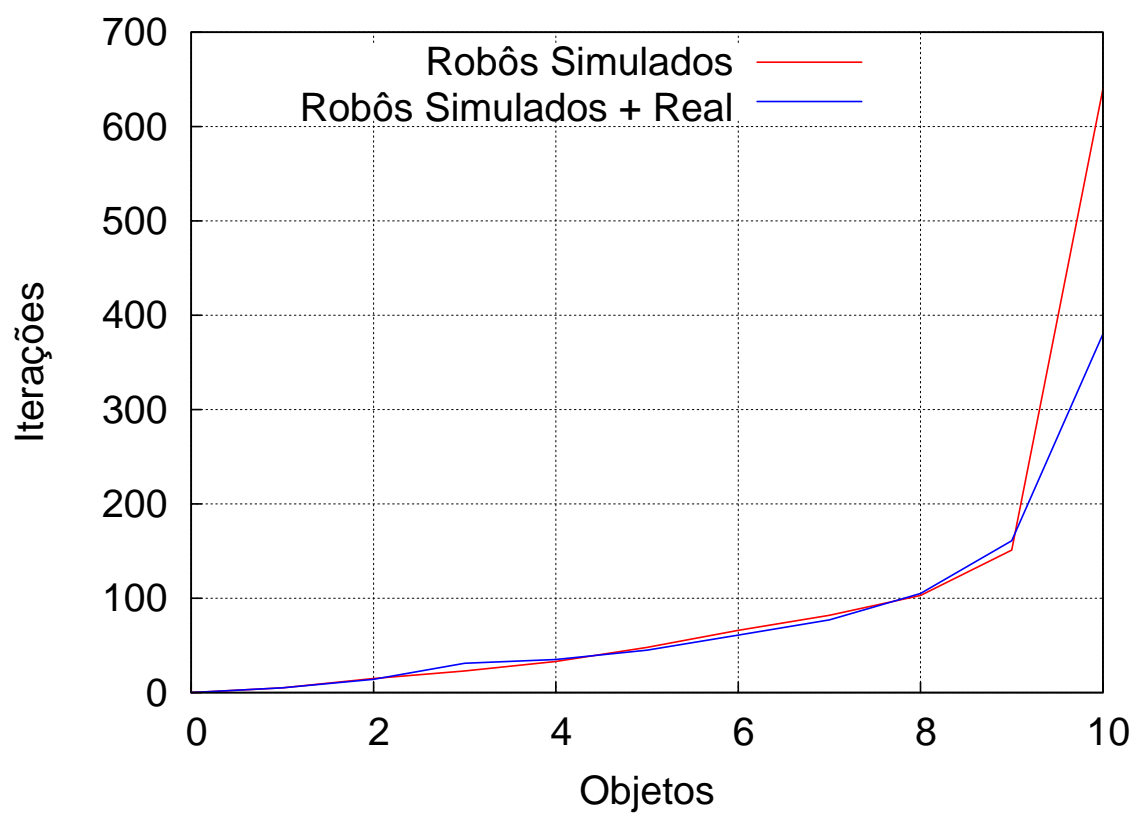

Figura 5.12: Comparação dos dados sobre localização de objetos utilizando somente robôs simulados ou o robô real com os simulados. 
Quando a arena possui um tamanho relativamente grande, esse valor passa a ser importante, pois quanto menor for a concentração de feromônio depositada, mais rápido a marcação desaparecerá da arena. Dessa forma, se o ambiente for muito esparso em relação ao número de robôs-formigas ali presente, pode ocorrer do feromônio depositado por um robô-formiga "evaporar" freqüentemente antes que outros integrantes do grupo possam passar pela região marcada. Com isso, o feromônio passa a não ter muito efeito no desempenho da exploração, tendendo à abordagem sem feromônios ou aleatória (FCA). Assim, em arenas como a do Experimento 1, as variações na concentração de feromônio passam a fazer diferença. Porém, em uma arena relativamente pequena como a deste experimento, os robôs-formigas têm a oportunidade de percorrer as regiões com depósitos das companheiras mais facilmente. Por isso, as variações não causam muita diferença nos resultados. Deve-se ressaltar que apesar do efeito da variação no tamanho da arena afetar os resultados com FF, ainda assim, tanto neste experimento quanto no Experimento 1, o algoritmo de formigas utilizando feromônios apresentou-se melhor que FCA, no qual não é empregado feromônio, somente caminhada aleatória.

A Figura 5.6 demonstra os resultados obtidos com a mesma configuração que o teste anterior, porém com FFT. Mais uma vez, os resultados obtidos entre as diferentes intensidades não demonstrou diferenças significativas e todos foram superiores a FCA, embora um pouco menos. A análise anterior também se aplica a estes resultados. Na Figura 5.7, a média dos resultados em FF, a média em FFT e os resultados em FFC são comparados. Pode-se observar que FF obteve o melhor desempenho.

Nas Figuras 5.9 e 5.10, são mostrados graficamente os resultados da coleta de objetos comparando-se, no primeiro gráfico, FCA e variações em FF e, no segundo, FCA e variações em FFT. Considerando-se que havia dez objetos dispersos na arena, como pode ser observado em ambos os gráficos, até o nono objeto, o desempenho foi similar para todas as configurações. Porém, na coleta do último objeto, foi necessário um número de iterações consideravelmente maior que do penúltimo. Isso pode ter ocorrido devido ao tamanho da arena e possivelmente devido à dificuldade em se encontrar o último objeto, que se encontrava em uma região pouco visitada pelos robôs. 
Neste experimento, foi possível observar empiricamente que a utilização de feromônios apresenta resultados melhores na exploração, como também constatado no Experimento 1. Porém, o efeito na variação da concentração de feromônio depositada não foi observado neste experimento, provavelmente devido ao tamanho reduzido da arena. Os resultados com a coleta de objetos também divergiram dos encontrados no Experimento 1, demonstrando que feromônios são mais efetivos em arenas maiores. Uma possível explicação para esse resultado é que em uma arena relativamente pequena, os robôs possuem maiores chances de encontrar os objetos rapidamente.

\subsection{Experimento 3: Robôs simulados trabalhando com o robô real}

Para testar a integração do ambiente simulado com o real, foi conduzido este experimento utilizando um robô real e quatro simulados. A configuração do ambiente foi a mesma do Experimento 2: área de 21 x 16 células, taxa de evaporação igual a 1, raio de sensoriamento igual a 1 e 10 objetos para localização. O experimento foi repetido 5 vezes e os dados apresentados nos gráficos são as suas médias. Com base no Experimento 2, a melhor configuração de formiga foi a FF. Entre suas quatro variações em termos de concentração de feromônio, na exploração todos obtiveram resultados bastante próximos, com exceção de FF15, que obteve um desempenho ligeiramente inferior. Desconsiderando FF15 pelas razões apresentadas, na tarefa de localização de objetos, o melhor desempenho foi de FF30. Portanto, essa foi a configuração selecionada para este experimento.

A Figura 5.8(a) exibe o ambiente simulado com os objetos simulados e os objetos reais mapeados. Os objetos simulados que aparecem nessa figura são: os quatro robôs simulados (círculos amarelos), os obstáculos simulados (quadrados azuis) e os objetos simulados a serem coletados (quadrados verdes). Os objetos reais mapeados são: o robô real (círulo vermelho) e os obstáculos reais (quadrados cinzas) mapeados. Também são exibidas as posições dos objetos já coletados pelos robôs (quadrados verdes com um 
círculo branco no meio) e as trilhas de feromônios (círculos cinzas). Quanto mais forte o tom de cinza no círculo da trilha, maior a concentração de feromônio naquele ponto. Os círculos brancos indicam a ausência de feromônio e marcam pontos já visitados pelo robô no ambiente. As regiões em branco, sem círculos, são locais ainda não visitados. Em (b), é mostrado o ambiente real, cujos objetos reais foram mapeados no ambiente simulado em (a).

As Figuras 5.11 e 5.12 apresentam os resultados obtidos com o grupo misto (robô real+ simulados) e com o grupo simulado, cujos resultados utilizados são os coletados no Experimento 2. Na tarefa de exploração, os resultados obtidos entre as duas abordagens são próximos. Já na tarefa de localização de objetos, os resultados até o nono objeto também foram próximos. Porém, na localização do último objeto, houve uma grande diferença. Isso pode ser atribuído às variações na movimentação dos robôs e na possível dificuldade de se encontrar o último objeto. Às vezes, os robôs podem, por "sorte", optar por um caminho que leve ao objeto em menos iterações em uma rodada do experimento do que na outra. Como os experimentos com o robô real são dispendiosos em termos de tempo, só foi possível executar 5 vezes este experimento, por limitações no tempo de execução deste projeto. Isso pode ter favorecido o desempenho do time. No entanto, analisando-se todo o resultado obtido, pode-se afirmar que as duas abordagens obtiveram resultados parecidos, o que indica o funcionamento transparente e robusto do sistema que mantém resultados compatíveis, usando grupos mistos ou simulados. 


\section{Capítulo 6}

\section{Conclusão}

O desenvolvimento deste trabalho demandou esforços em processamento de imagens, robótica, simulação, comunicação via rede e computação bioinspirada. Unindo-se tudo isso, foi possível desenvolver um sistema de controle multi-robô para a realização de experimentos de controle distribuído inspirado em colônias de formigas, utilizandose robôs reais e simulados simultaneamente. Isso possibilitou superar o problema da falta de robôs reais disponíveis para a formação de uma colônia para os experimentos. Além disso, também foi possível tornar transparente o processo de inserir e retirar robôs reais e simulados. O próprio sistema gerencia automaticamente de onde e para onde as informações devem ser enviadas, seja para o ambiente simulado ou via rádio para um robô real. Dessa forma, torna-se indiferente ao sistema se há somente robôs reais, somente robôs simulados ou uma mistura de ambos. É importante ressaltar que a fuga dos feromônios não advém de funções complexas para se implementar em hardware. Para obter esse comportamento, é necessário apenas a comparação entre as concentrações de feromônios nas duas "antenas" (dois sensores). Isso torna o modelo tão simples quanto possível para implementações em robótica.

Para testar a integração do ambiente simulado com o real, foram conduzidos experimentos utilizando um grupo com um robô real e quatro simulados e outro grupo com cinco robôs simulados. Foram testadas três configurações do algoritmo de formigas proposto: FF, FFT e FCA. A abordagem inspirada na utilização de marcadores 
temporários no próprio ambiente, como fazem as formigas, mostrou-se promissora na tarefa de exploração.

Deste trabalho, podem-se mencionar como contribuições ao grupo de pesquisas e à comunidade científica:

- Sistema de localização de robôs através de LEDs de cor infravermelha.

- Sistema de localização de robôs através de segmentação do padrão de cores (possui problemas devido à variação de iluminação, mas pode ser usado em ambientes com iluminação bem controlada e homogênea).

- Um algoritmo inspirado em formigas para a exploração de ambientes.

- Solução para feromônios virtuais: grade em memória + processamento de imagens.

- Sistema misto: robôs reais e virtuais que interagem de forma transparente.

- Sistema de fácil integração e modificação: divisão em módulos, conectados por sockets (flexibilidade para implementar e integrar novos módulos, mesmo em diferentes sistemas operacionais).

Como trabalhos futuros, podem-se citar:

- Realizar experimentos com um número maior de robôs reais.

- Automatizar a detecção dos obstáculos reais.

- Considerar formas alternativas para a marcação da trilha, como a utilização de marcadores químicos.

- Investigar a possibilidade de utilização de dispositivos GPS e ZigBee para monitorar a posição dos robôs em ambientes maiores e externos.

- Instalação deste sistema como plataforma de apoio ao desenvolvimento de novos trabalhos no grupo de pesquisas.

- Continuar o aperfeiçoamento do algoritmo de controle inspirado em formigas. 


\section{Referências Bibliográficas}

Barker, W. e Tyrrell, M. (2005). Hardware fault-tolerance within the POEtic system. In Evolvable Systems: From Biology to Hardware, LNCS 3637, pag. 25-36. Springer Verlag.

Bekey, G. A. (2005). Autonomous robots: from biological inspiration to implementation and control. MIT Press. ISBN 0-262-02578-7.

Bongard, J. C. e Lipson, H. (2004). Once more unto the breach: co-evolving a robot and its simulator. In Proceedings of the 9th International Conference on the Simulation and Synthesis of Living Systems (ALIFE9), Boston, MA.

Bueno, O. C. e Campos-Farinha, A. E. d. C. (1999). Insetos e outros invasores de residências, volume 6, chapter As formigas domésticas, pag. 135-180. Editora FEALQ, Piracicaba, SP.

Cao, Y., Fukunaga, A. S., e Kahng, A. B. (1997). Cooperative mobile robotics: antecedents and directions. In Autonomous Robots, volume 4, pag. 1-23, Boston. Kluwer Academic Publishers.

Carvalho, A. C. P. L. F., Delbem, A. C. B., Simões, E. D. V., et al. (2004). Computação bioinspirada. Apostila de minicurso XXIII JAI - Jornada de Atualização em Informática - Congresso da Sociedade Brasileira de Computação 2004, Salvador, Bahia.

Cazangi, R. R., von Zuben, F. J., e Figueiredo, M. F. (2006). Evolutionary stigmergy in multipurpose navigation systems. In IEEE Congress on Evolutionary Computation (CEC 2006), pag. 370-377.

Chialvo, D. R. e Millonas, M. M. (1995). How swarms buid cognitive maps. In Computer and System Sciencies, The NATO ASI Series, Series F, pag. 1-10.

CORDIS (2007). Information about the Swarm-bots Project at the Community Research \& Development Information Service's web site. Disponível em: http://cordis.europa.eu/search/index.cfm?fuseaction=proj. 
simpledocumentlucene\&HD_ID $=5200234 \& C F I D=870557 \& C F T O K E N=28769447$. Acessado em: 06/02/2007.

Costa, D. e Hertz, A. (1997). Ants can colour graphs. Journal of the Operational Research Society, 48(3):295-305.

Daly, H. V., Doyen, J. T., e Purcell, A. H. (1979). Introduction to insect biology and diversity. McGraw-Hill, New York.

Deneubourg, J.-L., Aron, S., Goss, S., e Pasteels, J. M. (1990). The self-organizing exploratory pattern of the Argentine ant. Journal of Insect Behavior, 9:159-168.

Di Caro, G. e Dorigo, M. (1998). AntNet: distributed stigmergetic control for communications networks. Journal of Artificial Intelligence Research (JAIR), 9:317-365.

Dorigo, M., Bonabeau, E., e Theraulaz, G. (2000). Ant algorithms and stigmergy. Future Generation Computer Systems, 16:851-871.

Dorigo, M. e Di Caro, G. (1999). Ant Colony Optimization: a new meta-heuristic. In Angeline, P. J., Michalewicz, Z., Schoenauer, M., Yao, X., e Zalzala, A., editors, Proceedings of the Congress on Evolutionary Computation, volume 2, pag. 14701477, Washington, DC. IEEE Press.

Dorigo, M. e Gambardella, L. M. (1997). Ant Colony System: a cooperative learning approach to the traveling salesman problem. IEEE Transactions on Evolutionary Computation, 1(1):53-66.

Dorigo, M., Maniezzo, V., e Colorni, A. (1991). Positive feedback as a search strategy. Relatório Técnico 91-016, Dipartimento di Elettronica, Politecnico di Milano, Italy.

Dorigo, M., Maniezzo, V., e Colorni, A. (1996). The Ant System: optimization by a colony of cooperating agents. IEEE Transactions on Systems, Man, and Cybernetics - Part B, 26(1):1-13.

Gambardella, L. M. e Dorigo, M. (2000). An ant colony system hybridized with a new local search for the sequential ordering problem. INFORMS Journal on Computing, $12(3): 237-255$.

Gonzalez, R. C. e Woods, R. E. (2000). Processamento de imagens digitais. Editora Edgard Blücher. Translated by Cesar Jr., Roberto Marcondes and Costa, Luciano da Fontoura. ISBN 85-212-0264-4.

Gordon, D. M. (1999). Ants at work: how an insect society is organized. The Free Press. ISBN 978-0684857336. 
Grimaldi, D. e Agosti, D. (2000). A formicine in New Jersey Cretaceous amber (Hymenoptera: Formicidae) and early evolution of the ants. Proceedings of the National Academy of Sciences of the United States of America, 97(25):13678-13683.

Gross, R. e Dorigo, M. (2004). Coperative transport of objects of different shapes and sizes. In Dorigo, M., Birattari, M., Blum, C., Gambardella, L. M., Mondada, F., e Stützle, T., editors, Ant Colony Optimization and Swarm Intelligence, 4th International Workshop, ANTS 2004, volume 3172 of Lecture Notes in Computer Science, pag. 107-118, Berlin, Germany. Springer Verlag.

Hangartner, W. (1967). Spezifität und inaktivierung des spurpheromons von Lasius fuliginosus latr. und orientierung der arbeiterinnen im duftfeld. Zeitschrift für Physiology, 57:103-136.

Holland, O. e Melhuish, C. (1999). Stigmergy, self-organisation, and sorting in collective robotics. Artificial Life, 5(2):173-202.

Holland, O., Woods, J., De Nardi, R., e Clark, A. (2005). Beyond swarm intelligence: The ultraswarm. In Proceedings of the IEEE Swarm Intelligence Symposium (SIS2005), pag. 34-41.

Hölldobler, B. e Wilson, E. O. (1990). The ants. Belknap/Harvard University Press, Cambridge, Massachusetts, USA.

Hölldobler, B. e Wilson, E. O. (1994). Journey to the ants. Belknap/Harvard University Press, Cambridge, Massachusetts, USA.

Ijspeert, A. J., Martinoli, A., Billard, A., e Gambardella, L. M. (2001). Collaboration through the exploitation of local interactions in autonomous collective robotics: The stick pulling experiment. Autonomous Robots, 11(2):149-171.

IST (2007). Information about the Swarm-bots project at the Information Society Technologies' web site. Disponível em: http://cordis . europa.eu/fetch?CALLER=IST_ UNIFIEDSRCH\&ACTION=D\&DOC=8\&CAT=PROJ\&QUERY=1170787078965\&RCN=57869.

Acessado em: 06/02/2007.

Kauffman, S. A. (1993). Origins of order: self-organization and selection in evolution. Oxford University Press, New York.

Kennedy, J. e Eberhart, R. (2001). Swarm intelligence. Morgan Kaufmann. ISBN: 1-55860-595-9.

Korenek, J. e Sekanina, L. (2005). Intrinsic evolution of sorting networks: a novel complete hardware implementation for FPGAs. In Evolvable Systems: From Biology to Hardware, LNCS 3637, pag. 46-55. Springer Verlag. 
Labella, T. H., Dorigo, M., e Deneubourg, J.-L. (2004a). Efficiency and task allocation in prey retrieval. In Ijspeert, A., Mange, D., Murata, M., e Nishio, S., editors, Proceedings of the First International Workshop on Biologically Inspired Approaches to Advanced Information Technology (Bio-ADIT2004), Lecture Notes in Computer Science, pag. 32-47, Heidelberg, Germany. Springer Verlag.

Labella, T. H., Dorigo, M., e Deneubourg, J.-L. (2004b). Self-organised task allocation in a group of robots. In Alami, R., editor, Proceedings of the 7th International Symposium on Distributed Autonomous Robotic Systems (DARS04), pag. 23-25, Toulouse, France.

Loutfi, A. e Coradeschi, S. (2002). Relying on an electronic nose for odor localization. In Proceedings of the International Symposium on Virtual and Intelligent Measurement Systems (VIMS2002), pag. 46-50.

Maniezzo, V. e Colorni, A. (1999). The Ant System applied to the quadratic assignment problem. IEEE Transactions on Data and Knowledge Engineering, 11(5):769-778.

Marques, L. e De Almeida, A. (2000). Electronic nose-based odour source localization. In Proceedings of the 6th International Workshop on Advanced Motion Control, pag. 36-40, Japão.

Marques, L., Nunes, U., e De Almeida, A. T. (2002). Olfaction-based mobile robot navigation. Thin Solid Films, 418:51-58.

Martinoli, A., Easton, K., e Agassounon, W. (2004). Modeling swarm robotic systems: a case study in collaborative distributed manipulation. International Journal of Robotics Research, 23(4):415-436.

McLurkin, J. e Smith, J. (2004). Distributed algorithms for dispersion in indoor environments using a swarm of autonomous mobile robots. In Distributed Autonomous Robotic Systems Conference.

McLurkin, J. D. (1996). Using cooperative robots for explosive ordnance disposal. Relatório técnico, Massachusetts Institute of Technology.

Michel, O. (2004). Webot: Professional mobile robot simulation. Journal of Advanced Robotic Systems, 1(1):39-42.

Millonas, M. M. (1993). Swarms, phase transitions, and collective intelligence. In Langton, C. G., editor, Artificial Life III: Proceedings of the Workshop on Artificial Life, Santa Fe Institute Studies in the Sciences of Complexity, pag. 417-445, Reading, MA. Addison-Wesley. 
Mondada, F., Guignard, A., Colot, A., Floreano, D., Deneubourg, J.-L., Gambardella, L. M., Nolfi, S., e Dorigo, M. (2002). SWARM-BOT: a new concept of robust all-terrain mobile robotic system. Relatório Técnico LSA2-I2S-STI, Swiss Federal Institute of Technology, Lausanne, Switzerland.

Murlis, J., Elkinton, J. S., e Card, R. T. (1992). Odor plumes and how insects use them. Annual Review of Entomology, 37:505-532.

Nelson, A. L., Grant, E., Galeotti, J., e Rhody, S. (2004a). Maze exploration behaviors using an integrated evolutionary robotics environment. Robotics and Autonomous Systems, 46(3):159-173.

Nelson, A. L., Grant, E., e Henderson, T. C. (2004b). Evolution of neural controllers for competitive game playing with teams of mobile robots. Robotics and Autonomous Systems, 46:135-150.

Nouyan, S. e Dorigo, M. (2004). Chain formation in a swarm of robots. Relatório Técnico TR/IRIDIA/2004-18, IRIDIA, Université Libre de Bruxelles, Belgium.

Nouyan, S. e Dorigo, M. (2006). Chain based path formation in swarms of robots. In Dorigo, M., Gambardella, L. M., Birattari, M., Martinoli, A., Poli, R., e Stutzle, T., editors, Proceedings of ANTS2006, pag. 120-131, Berlin, Germany. Springer Verlag.

Nouyan, S., Grob, R., Dorigo, M., Bonani, M., e Mondada, F. (2006). Group transport along a robot chain in a self-organized robot colony. In Proceedings of the 9th International Conference on Intelligent Autonomous Systems (IAS-9), pag. 433-442, Tokyo, Japan. IOS Press.

Pettinaro, G. C., Kwee, I., Gambardella, L. M., Mondada, F., Floreano, D., Nolfi, S., Deneubourg, J.-L., e Dorigo, M. (2002). SWARM Robotics: a different approach to service robotics. In Proceedings of the 33rd International Symposium on Robotics, pag. 7-11, Stockholm, Sweden. International Federation of Robotics.

Purnamadjaja, A. H. e Russell, R. A. (2005). Congregation behaviour in a robot swarm using pheromone communication. In Sammut, C., editor, Proceedings of the 2005 Australasian Conference on Robotics and Automation (ACRA2005), Australia.

Quiles, M. G., Miazaki, M., Romero, R. A. F., e Simões, E. D. V. (2004). Configuração de topologia para redes neurais multi-camadas com algoritmo evolutivo aplicado ao controle de robôs móveis. In Anais do SBC 2004 - XXIV Congresso da Sociedade Brasileira de Computação - Encontro de Robótica Inteligente, Salvador, Bahia. 
Roulston, T. H. e Silverman, J. (2002). The effect of food size and dispersion pattern on retrieval rate by the argentine ant, Linepithema humile (Hymenoptera: Formicidae). Journal of Insect Behaviour, 15(5):633-648.

Russell, R. A. (1999). Ant trails - an example for robots to follow? In Proceedings of the IEEE International Conference on Robotics and Automation, volume 4, pag. 2698-2703, USA.

Russell, R. A. (2001). Survey of robotic applications for odor-sensing technology. The International Journal of Robotics Research, 20(2):144-162.

Russell, R. A., Thiel, D., e Mackay-Sim, A. (1994). Sensing odour trails for mobile robot navigation. In Proceedings of the IEEE International Conference on Robotics and Automation, volume 3, pag. 2672-2677, USA.

Sahin, E., Labella, T. H., Trianni, V., Deneubourg, J.-L., Rasse, P., Floreano, D., Gambardella, L. M., Mondada, F., Nolfi, S., e Dorigo, M. (2002). SWARM-BOT: pattern formation in a swarm of self-assembling mobile robots. In Kamel, A. E., Mellouli, K., e Borne, P., editors, Proceedings of the IEEE International Conference on Systems, Man and Cybernetics, pag. 6-9, Piscataway, NJ. IEEE Press.

Simões, E. V. (2000). Development of an embedded evolutionary controller to enable collision-free navigation of a population of autonomous mobile robots. Tese de doutorado, The University of Kent at Canterbury, United Kingdom.

Simões, E. V. e Dimond, K. R. (1999). An evolutionary controller for autonomous multi-robot systems. In Proceedings of the IEEE International Conference on Systems, Man and Cybernetics, volume 6, pag. 596-601, Japan.

Stützle, T. e Hoos, H. (1998). Improvements on the Ant System: introducing the MAX-MIN Ant System. In Albrecht, R. F., Smith, G. D., e Steele, N. C., editors, Artificial Neural Networks and Genetic Algorithms, pag. 245-249. Springer Verlag.

Terrile, R. J., Adami, C., Aghazarian, H., Chau, S. N., Dang, V. T., Ferguson, M. I., Fink, W., Huntsberger, T. L., Klimeck, G., Kordon, M. A., Lee, S., von Allmen, P., e Xu, J. (2005). Evolutionary computation technologies for space systems. In Proceedings of the IEEE Aerospace Conference, pag. 4284-4295.

Thakoor, S., Morookian, J. M., Chahl, J., Hine, B., e Zormetzer, S. (2004). Bees: Exploring mars with bioinspired technologies. Computer, 37(9):38-47.

Trianni, V. (2003). Evolution of coordinated motion behaviors in a group of selfassembled robots. DEA Thesis TR/IRIDIA/2003-25, IRIDIA - Université Libre de Bruxelles, Belgium. 
Trianni, V., Nolfi, S., e Dorigo, M. (2004a). Hole avoidance: experiments in coordinated motion on rough terrain. In Groen, F., Amato, N., Bonarini, A., Yoshida, E., e Krose, B., editors, Proceedings of the 8th Conference on Intelligent Autonomous Systems (IAS8), pag. 29-36, Amsterdam, Netherlands. IOS Press.

Trianni, V., Tuci, E., e Dorigo, M. (2004b). Evolving functional self-assembling in a swarm of autonomous robots. In Schaal, S., Ijspeert, A., Billard, A., Vijayakumar, S., Hallam, J., e Meyer, J.-A., editors, From Animals to Animats VIII - Proceedings of the 8th International Conference on Simulation of Adaptive Behavior, pag. 405-414, Cambridge, MA. MIT Press.

Vargas, D. V., Miazaki, M., Simões, E. V., e Delbem, A. C. B. (2004). Uma colônia artificial de formigas modelada por sistema evolutivo. In SBRN 2004 - VIII Brazilian Symposium on Neural Networks, São Luís, Maranhão.

Vargas, D. V. e Simões, E. V. (2004). Implementação de formigas robóticas com características físicas das formigas biológicas. In Macêdo, R. J. d. A. et al., editors, Anais do SBC 2004 - XXIV Congresso da Sociedade Brasileira de Computação Encontro de Robótica Inteligente, volume 1, pag. 1-10, Salvador, Bahia. Sociedade Brasileira de Computação.

Vittori, K. e Araújo, A. F. R. (2001). Agent-oriented routing in telecommunications networks. IEICE Transactions On Communications, E84-B(11):3006-3013.

Wang, L. (2002). Computational intelligence in autonomous mobile robotics - a review. In Proceedings of the International Symposium on Micromechatronics and Human Science, pag. 227-235.

Wilson, E. O. (1962). Chemical communication in the Fire Ant Solenopsis saevissima. Animal Behavior, 10:134-164.

Wilson, E. O. (2000). Sociobiology: the new synthesis. Harvard University Press.

Wyatt, T. D. (2003). Pheromones and animal behaviour: communication by smell and taste. Cambridge University Press, Cambridge, United Kingdom.

Zhang, Y., Antonsson, E. K., e Martinoli, A. (2004). Evolving neural controllers for collective robotic inspection. In Proceedings of the 9th Online World Conference on Soft Computing in Industrial Applications, pag. 1-10. 



\section{Apêndice A}

\section{Localização de robôs por padrões de cores}

Este módulo de processamento de imagens foi desenvolvido em colaboração com Marcos Gonçalves Quiles, doutorando do ICMC-USP. O seu propósito foi desenvolvêlo para o rastreamento dos robôs e em tempo real. O módulo deve prover a localização, ou seja, as coordenadas $x$ e $y$, de até dez robôs. Também deve ser fornecida a orientação (em graus) dos robôs, que deverão estar com as marcações de orientação apropriadas. A orientação refere-se à posição da frente do robô.

\section{A.1 Marcadores}

Deve haver um marcador circular de $5 \mathrm{~cm}$ de diâmetro da cor azul sobre cada robô, em seu centro. As cores preta e branca podem ser utilizadas sem restrições sobre os robôs. Também podem ser utilizados marcadores de cor verde claro, rosa claro e ciano. E o ambiente do fundo deve ser verde (para distinguir de verde claro, neste texto, a cor do campo será denominada de verde escuro).

Assim, para possibilitar a distinção entre os robôs e a determinação de suas orientações, foi desenvolvido o padrão de marcadores mostrado na Figura A.7. Portanto, cada robô deve possuir um círculo preto de $18 \mathrm{~cm}$ de diâmetro, com um círculo amarelo ou azul de $5 \mathrm{~cm}$ de diâmetro em seu centro. Ao redor do círculo amarelo ou azul, há uma borda de aproximadamente $1,5 \mathrm{~cm}$ de espessura, que pode possuir as cores: verde claro, rosa claro e ciano. Essa borda pode possuir uma única cor (Figura A.7-a) ou combinações das cores citadas (Figura A.7-b). Cada robô deve possuir um padrão de cores único nessa borda para possibilitar sua identificação. Deve haver também sobre o robô um setor circular rosa de aproximadamente $22,5^{\circ}$, utilizado pelo módulo para localizar a frente do robô (orientação). O tamanho do marcador de orientação foi definido em $22,5^{\circ}$ porque o módulo de visão procura-o em 16 posições ao redor do marcador central $\left(360^{\circ} \div 16=22,5^{\circ}\right)$. 


\section{A.2 Interface Gráfica}

O propósito da interface gráfica é prover ao usuário uma forma amigável de interação com o módulo de processamento de imagens. Através da interface gráfica, o usuário pode visualizar os objetos a serem rastreados nas imagens adquiridas pela câmera de vídeo e selecioná-los nessa mesma tela utilizando o mouse e o teclado. Também pode ser realizada na interface a calibração de cores, permitindo, assim, um melhor ajuste e funcionamento do rastreamento de objetos. Além disso, o usuário também pode visualizar o rastreamento dos objetos no vídeo através da interface.

A interface gráfica utiliza resolução de tela de 800 x 600 pixels. O vídeo adquirido e exibido na interface possui resolução de 640 x 480 pixels. As duas telas mais importantes são:

- Tela Principal (Figura A.8): exibe o vídeo adquirido, os objetos rastreados, informações sobre estes objetos e botões de acesso às funcionalidades do módulo.

- Tela de Calibração (Figura A.9): além de apresentar o vídeo adquirido, os objetos rastreados, e as informações sobre estes objetos, permite ajustar os limiares de segmentação de cores.

Ambas as telas também permitem visualizar as imagens segmentadas (Figura A.10).

\section{A.3 Segmentação de Cores}

A segmentação de cores permite calibrar o módulo, ou seja, refinar o rastreamento através do ajuste dos valores limiares entre as cores consideradas. Esse ajuste destinase a dividir o espectro de cores em faixas, ou seja, segmentá-lo. Dessa forma, todas as cores dentro de uma faixa delimitada são consideradas como sendo iguais. O módulo de visão considera nove faixas de cores: vermelho, amarelo, verde claro, verde escuro, ciano, azul, rosa, preto e branco.

Mas antes da segmentação, é necessário converter cada pixel de RGB - Red (Vermelho), Green (Verde) e Blue (Azul) - para HSI - Hue (Cor), Saturation (Saturação) e Intensity (Intensidade) -, pois embora a câmera de vídeo CCD utilizada forneça as imagens diretamente no espaço de cores RGB, optou-se por utilizar o HSI, apesar dos custos de conversão, pela maior facilidade em se segmentar as cores nesse espaço. Para segmentar as cores no espaço RGB seria necessário delimitar regiões tridimensionais, enquanto que no espaço HSI, basta delimitar ângulos em sua circunferência, que corresponde a H (Gonzalez e Woods, 2000). Ambos os módulos de cores citados estão representados nas Figuras A.1 e A.2. Além do H, o módulo de visão também utiliza o I 


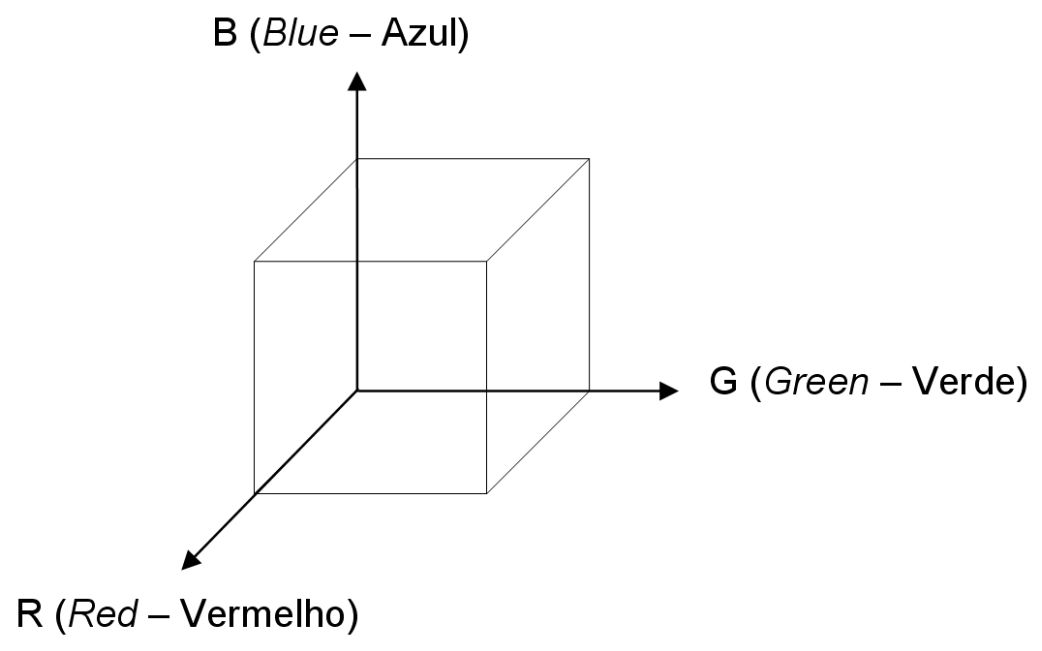

Figura A.1: Espaço de cores RGB (Gonzalez e Woods, 2000)

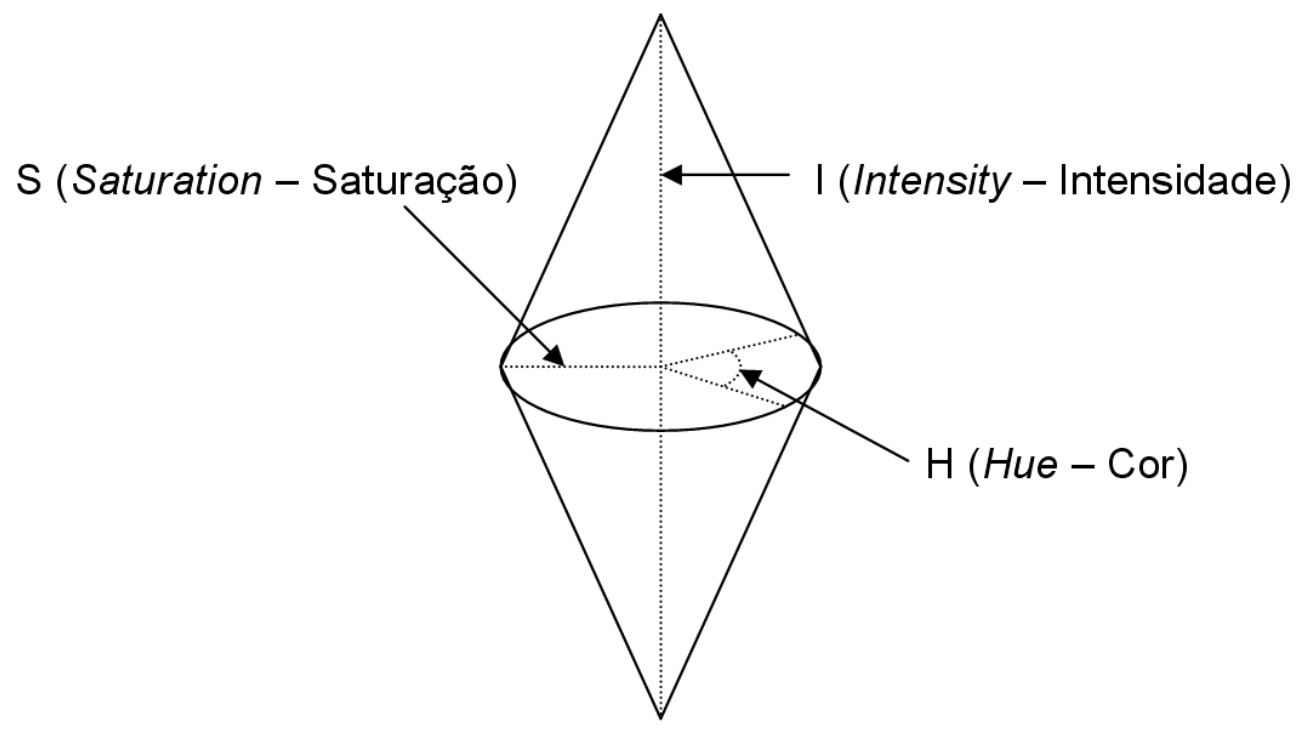

Figura A.2: Espaço de cores HSI (Gonzalez e Woods, 2000) 
para poder diferenciar o branco e o preto das outras cores, além de permitir distinguir o verde em claro e escuro. O S não é necessário.

O H e o I são obtidos do RGB através das Fórmulas A.1 e A.2:

$$
H= \begin{cases}\theta & \text { se } B \leq G \\ 2 \pi-\theta & \text { se } B>G\end{cases}
$$

onde

$$
\begin{gathered}
\theta=\cos ^{-1}\left\{\frac{\frac{1}{2}[(R-G)+(R-B)]}{\sqrt{(R-G)^{2}+(R-B)(G-B)}}\right\} \\
I=\frac{R+G+B}{3}
\end{gathered}
$$

Após a conversão, cada pixel deve ser segmentado, ou seja, classificado em uma das nove faixas de cores consideradas. As cores possuem valores entre 0 e 360 (ângulos na circunferência H). Cada faixa de cor deve possuir seus limiares definidos pelo usuário através da Tela de Calibração (Figura A.9).

Como a operação de conversão é realizada em cada quadro (frame) adquirido, ela é uma operação que demanda uma quantidade significativa de tempo de processamento. Para reduzir esse tempo, ao invés de se utilizar diretamente as equações, optou-se por criar uma matriz de segmentação de cores. Assim, para cada pixel RGB obtido, basta realizar uma consulta na matriz para obter a cor segmentada correspondente sem necessitar realizar cálculos.

A matriz de segmentação de cores destina-se a armazenar a cor segmentada correspondente ao pixel RGB que se deseje segmentar. Assim, R, G e B como sendo os eixos $x, y$ e $z$ da matriz (em forma de cubo). Para cada valor de R, G e B obtêm-se a cor correspondente, já convertida para HSI e segmentada com os valores de limiar.

Para o preenchimento da matriz, inicialmente, cada um dos três componentes do padrão de cores RGB (vermelho, verde e azul), que possui valores entre 0 e 255, é dividido por quatro. Com isso, ao invés de ser armazenada uma matriz com 256 x 256 x 256 posições, é armazenada uma matriz menor, com 64 x 64 x 64 posições. Cada valor RGB sendo considerado na matriz é convertido para I, que é inicialmente utilizado para verificar se o pixel encontra-se na faixa de cor preta ou branca. Em seguida, cada valor RGB restante é convertido para H, que é empregado para classificar cada pixel em vermelho, amarelo, verde, ciano, azul ou rosa. Caso o pixel seja classificado como verde, utiliza-se o seu I para distingui-lo em verde claro (marcador) ou verde escuro. E caso seja classificado como azul, utiliza-se o seu I para melhor diferenciá-lo de preto. Esta diferenciação tornou-se necessária devido a um problema encontrado durante os testes. Alguns tipos de papéis pretos utilizados acabavam sendo classificados como azul, o que comprometia a segmentação. O aumento do limiar da cor preta não se mostrou 
uma boa solução, já que isso influenciava também as outras cores. Assim, optou-se por utilizar um valor de limiar exclusivo para separar azul e preto. E, finalmente, a cor segmentada é armazenada na matriz, na posição correspondente ao valor RGB.

Na Figura A.3, é apresentado um exemplo de uma consulta à matriz de segmentação de cores para determinar a cor segmentada de um pixel em RGB, com os valores $\mathrm{R}=255$, $\mathrm{G}=255$ e $\mathrm{B}=0$. Deve-se ressaltar que estes valores devem ser divididos por quatro antes de se consultar a matriz. Assim, tem-se $\mathrm{R}=63, \mathrm{G}=63$ e $\mathrm{B}=0$. A cor correspondente, neste exemplo, é a amarela.

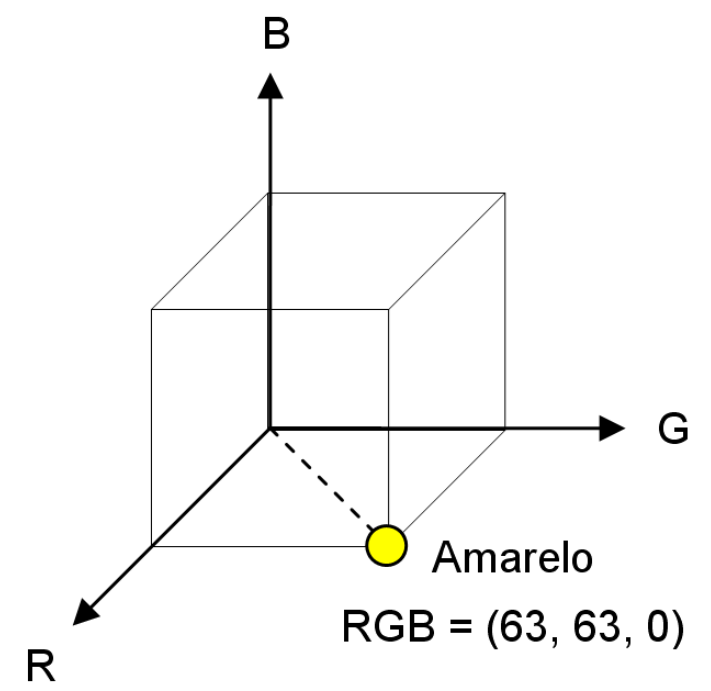

Figura A.3: Exemplo de consulta à matriz de segmentação de cores

\section{A.4 Captura de Protótipos}

O protótipo (objeto a ser rastreado) deve ser especificado na interface do módulo, delimitando-se com um quadrado a região na imagem em que se encontra o marcador do robô (Figura A.11). Em seguida, essa região é segmentada através da matriz de segmentação de cores. Os componentes de cada pixel são divididos por quatro (R/4, $\mathrm{G} / 4, \mathrm{~B} / 4$ ) e, com os resultados, realiza-se uma consulta à matriz para obter a faixa de cor a qual o pixel se classifica. Após a segmentação, efetua-se a contagem dos pixels classificados em cada uma das nove faixas de cores, originando o vetor histograma do protótipo. O vetor histograma de cada objeto é construído e armazenado para ser utilizado no processo de rastreamento.

A Figura A.12 apresenta um exemplo de protótipo e de vetor histograma resultante. Conforme pode ser visualizado, nesse exemplo, o protótipo é um quadrado de 3 x 3 pixels. O protótipo já se apresenta segmentado, possuindo um pixel amarelo, um rosa claro, um ciano, três pretos e três verdes escuros. Esta contagem é registrada no vetor histograma. As demais cores, que não aparecem no protótipo, recebem contagem zero. 


\section{A.5 Rastreamento de Objetos}

O processo de rastreamento de objetos destina-se à obtenção da localização dos robôs e da orientação dos robôs em tempo real. Antes de iniciar o rastreamento, os protótipos dos objetos devem ser capturados, como descrito anteriormente.

O módulo de visão determina a localização dos objetos rastreados, fornecendo as posições x e y em relação à imagem adquirida de cada um. O ponto $(0,0)$ encontra-se na extremidade superior esquerda da janela da imagem de vídeo adquirida.

Assim, os objetos são localizados através dos marcadores sobre eles. Cada objeto deve ter, inicialmente, o seu protótipo capturado. Para verificar se um objeto encontrase em uma determinada posição da imagem, uma região quadrada de igual tamanho ao do objeto capturado é analisada. Ela é segmentada através da matriz de segmentação de cores e um vetor histograma dessa região é gerado. Em seguida, compara-se este vetor com o vetor do objeto procurado. Caso os vetores sejam iguais ou semelhantes, considera-se que o objeto em questão está nessa região. A semelhança entre dois vetores histogramas é determinada através do cálculo da diferença entre cada posição do vetor. Se a diferença em cada uma dessas posições for menor que um valor de tolerância arbitrário pré-estabelecido, então os vetores são considerados semelhantes.

O processo de busca na imagem ocorre "irradiando" a região de busca a partir da última posição conhecida do objeto. Assim, a busca ocorre em iterações:

- $1^{a}$ iteração: Busca do protótipo exatamente na última posição conhecida do objeto.

- $2^{\mathrm{a}}$ iteração: Ocorre caso o objeto não seja encontrado na $1^{\mathrm{a}}$ iteração. É realizado um incremento de uma unidade no raio de busca. A Figura A.4 apresenta um exemplo completo desta iteração na busca de um protótipo de tamanho 3 x 3 pixels em uma imagem de 7 x 7 pixels de resolução. No exemplo, esta iteração possui 8 passos. No passo 1, a região de busca (quadrado com a borda preta mais espessa) desloca-se uma posição para a esquerda e uma para cima em relação à última posição conhecida do objeto (quadrado cinza). A seguir, o módulo verifica se o objeto encontra-se ali, através do processo descrito anteriormente. Caso não esteja, ocorre o passo 2, em que a região de busca desloca-se uma posição para a direita. E assim o processo continua até encontrar o objeto ou até terminar o passo 8 .

- $3^{\text {a }}$ iteração: Ocorre caso o objeto não seja encontrado na $2^{\text {a }}$ iteração. É realizado mais um incremento de uma unidade no raio de busca. A Figura A.5 exemplifica os três primeiros passos desta iteração na busca de um protótipo de tamanho $3 \mathrm{x}$ 3 pixels em uma imagem de 9 x 9 pixels de resolução. O processo de busca nesta 
iteração é semelhante ao anterior, ocorrendo, porém, em um raio de distância de duas unidades em relação à última posição conhecida do objeto. Esta iteração termina somente se o objeto for encontrado ou se o último passo for finalizado.

- A busca continua enquanto o objeto não for encontrado. Após a $10^{\mathrm{a}}$ iteração, o raio de busca passa a ser incrementado em duas unidades. E após a $25^{\mathrm{a}}$ iteração, o incremento do raio de busca passa a ser três unidades. A Figura A.6 ilustra de forma simplificada a "irradiação" da área de busca com os sucessivos incrementos do raio.

- Caso toda a imagem seja percorrida e o objeto não seja encontrado, o processo de busca reinicia-se a partir da $1^{\mathrm{a}}$ iteração.

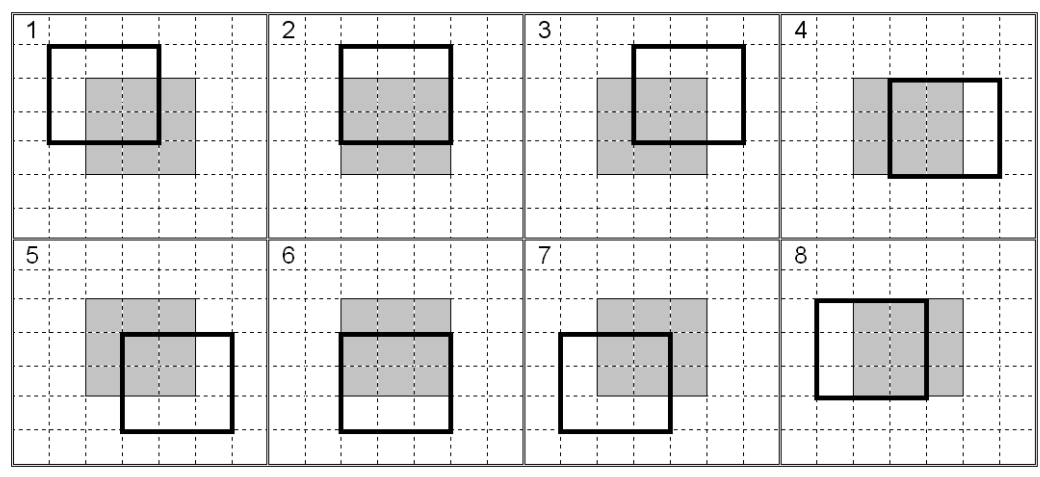

Figura A.4: $2^{\text {a }}$ iteração do processo de busca de um protótipo de tamanho 3 x 3 pixels em uma imagem de $7 \times 7$ pixels.

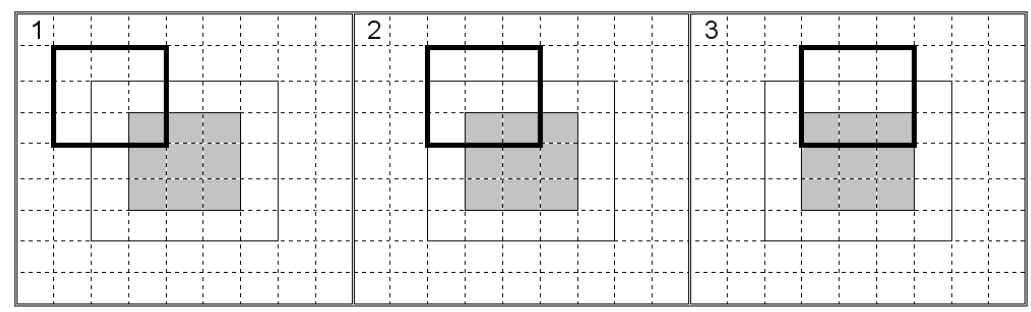

Figura A.5: Os três primeiros passos da $3^{\text {a }}$ iteração do processo de busca de um protótipo de tamanho $3 \times 3$ pixels em uma imagem de $9 \times 9$ pixels.

Um outro ponto importante a ser destacado é em relação a como é realizada a busca de vários objetos ao mesmo tempo. O módulo de visão foi implementado utilizando threads. Assim, para cada objeto a ser rastreado o módulo habilita um thread, que se responsabilizará por sua localização e, no caso dos robôs, também da determinação de sua orientação.

Neste trabalho, o termo "orientação do robô" refere-se ao lado considerado como a frente do robô. Para a determinação da orientação, deve haver um marcador rosa 


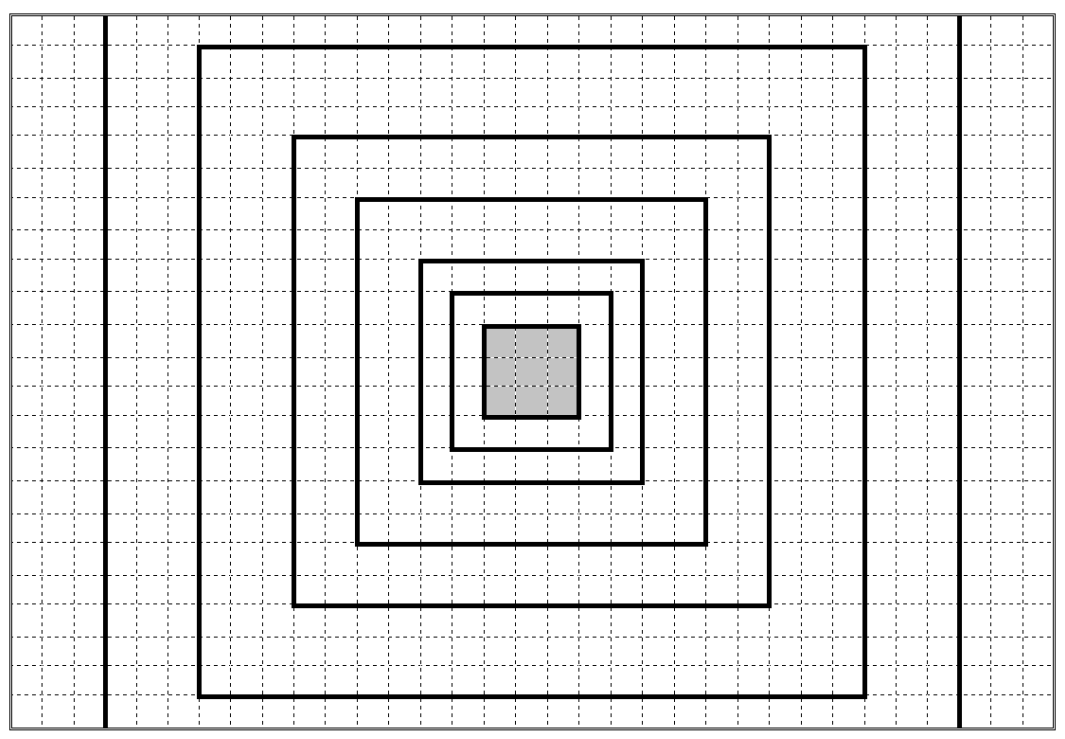

Figura A.6: "Irradiação" da área de busca

sobre o robô, conforme já especificado anteriormente. Foram definidas 16 posições em que o marcador de orientação será procurado ao redor dos marcadores de identificação do robô. A Figura A.13 exibe um exemplo. O quadrado amarelo indica a região de busca pelos marcadores de localização do robô e as setas cinza indicam as 16 posições de busca pelo marcador de orientação. Entre as setas adjacentes, há um ângulo de $22,5^{\circ}$.

Quando a dimensão dos protótipos é definida, o módulo calcula e armazena o deslocamento necessário nos eixos das ordenadas e abscissas para se obter todos os 16 pontos a partir do centro do protótipo. Para isso, considera-se este centro como $(0,0)$ e, com um valor de raio pré-estabelecido, esses pontos são matematicamente calculados. Este procedimento é realizado para reduzir a necessidade de processamento. Assim, quando o processo de rastreamento é iniciado, primeiro o protótipo é localizado e, em seguida, determina-se a orientação somando-se os valores de deslocamento às coordenadas do centro. Os pontos são verificados sequencialmente, um a um, até que o marcador de orientação seja encontrado. Para verificar se o marcador de orientação está em um determinado ponto, uma região de 3 x 3 pixels é considerada. É calculada uma média dos valores de $\mathrm{R}, \mathrm{G}$ e $\mathrm{B}$ dos nove pixels e os valores obtidos são utilizados para consultar a matriz de segmentação de cores para verificar se correspondem à cor do marcador. 


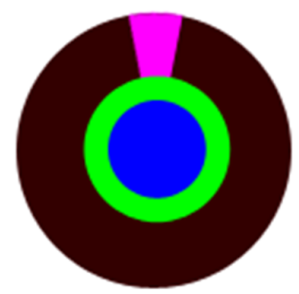

(a)

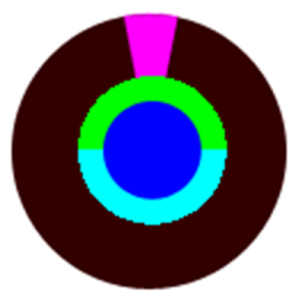

(b)

Figura A.7: Exemplos de marcadores de robôs: (a) com uma cor de identificação verde; (b) com duas cores de identificação - verde e ciano.

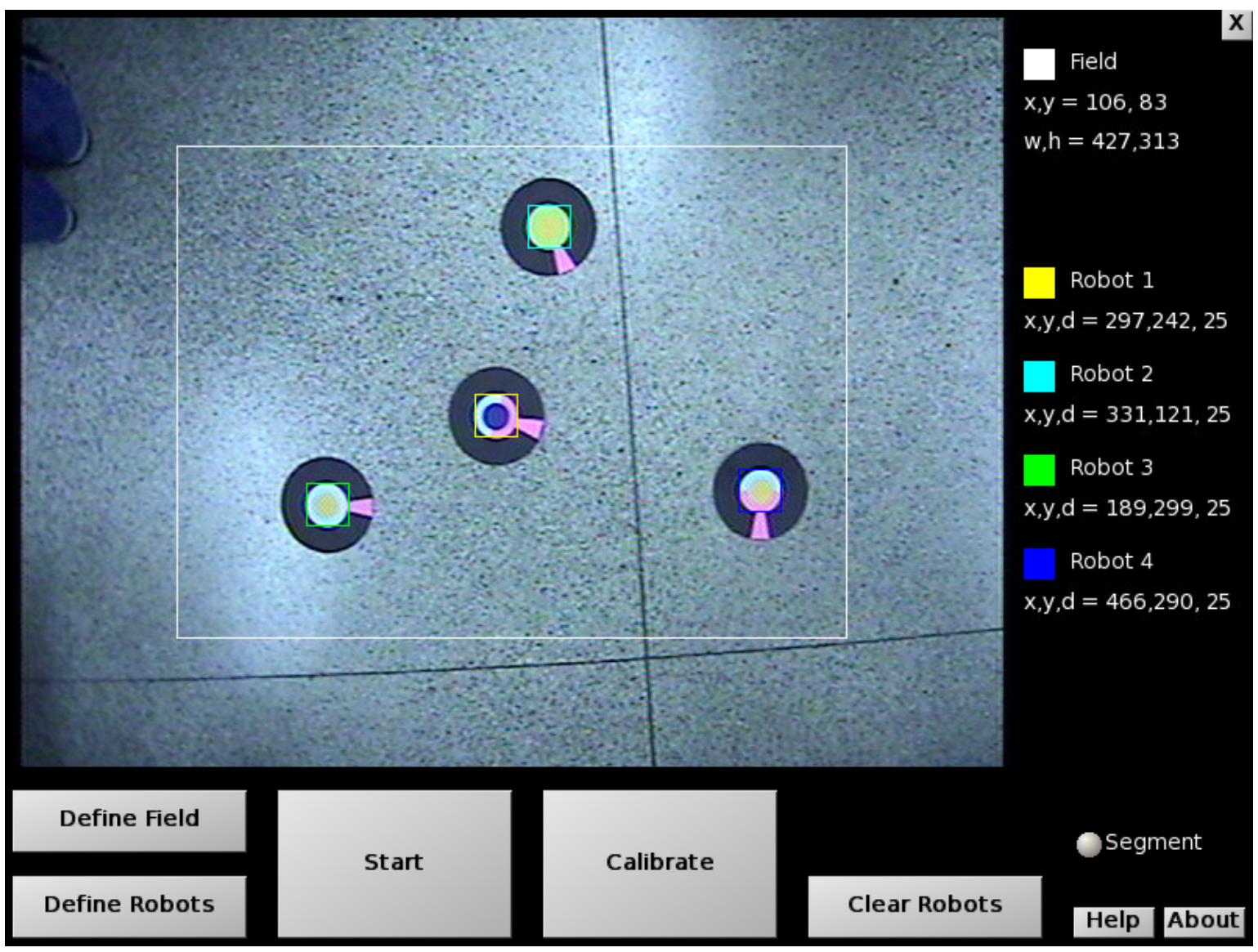

Figura A.8: Tela Principal 


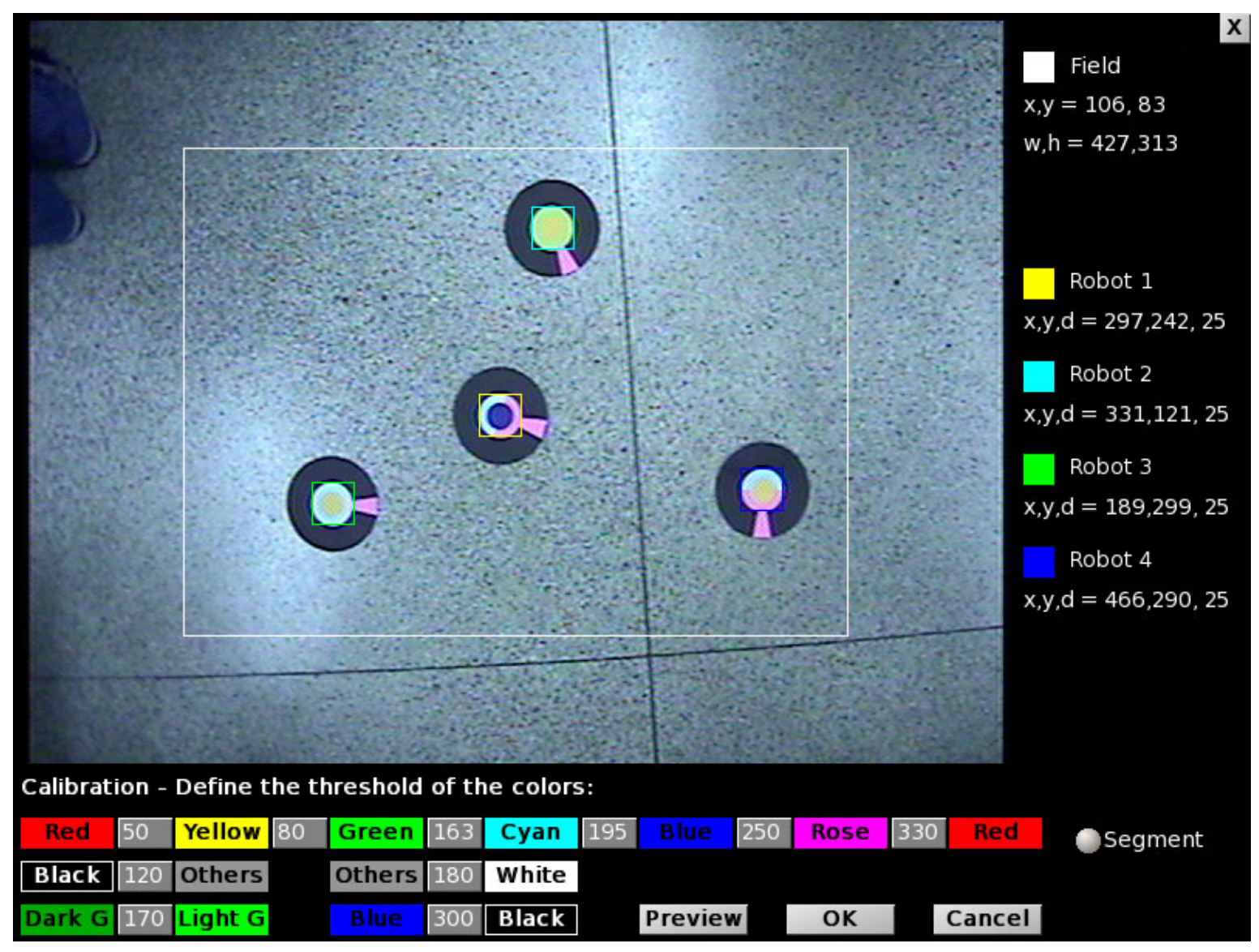

Figura A.9: Tela de Calibração

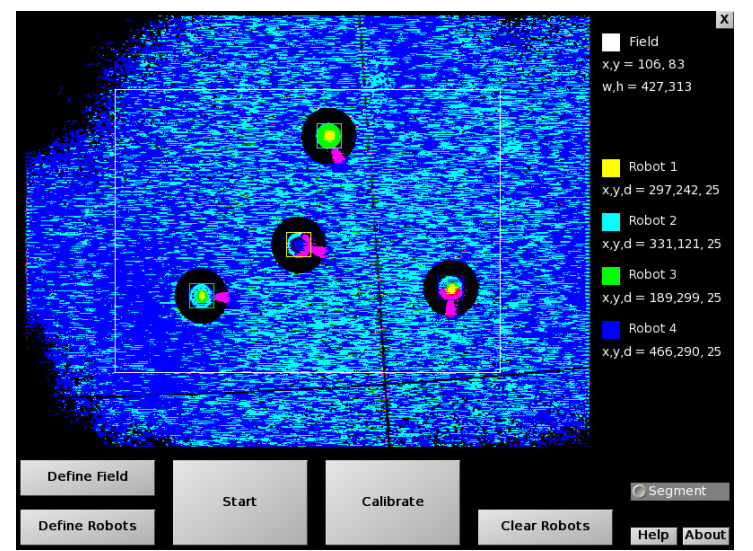

(a)

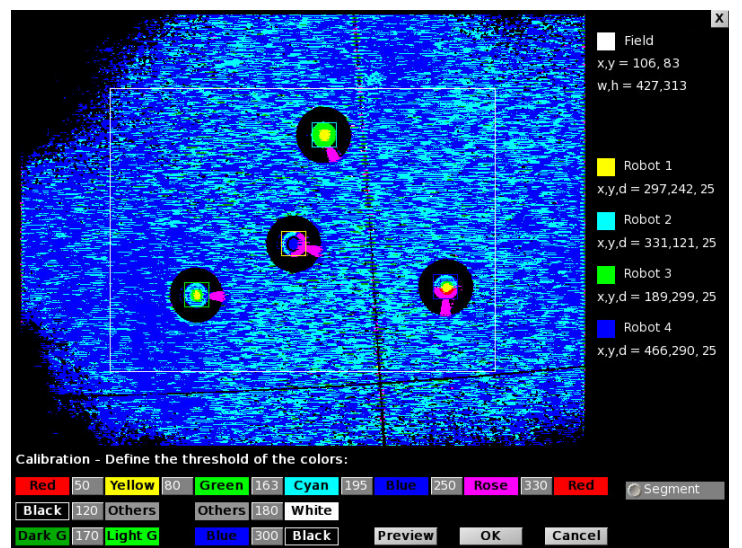

(b)

Figura A.10: Visualização da segmentação de imagens na Tela Principal (a) e na Tela de Calibração (b). 
a)

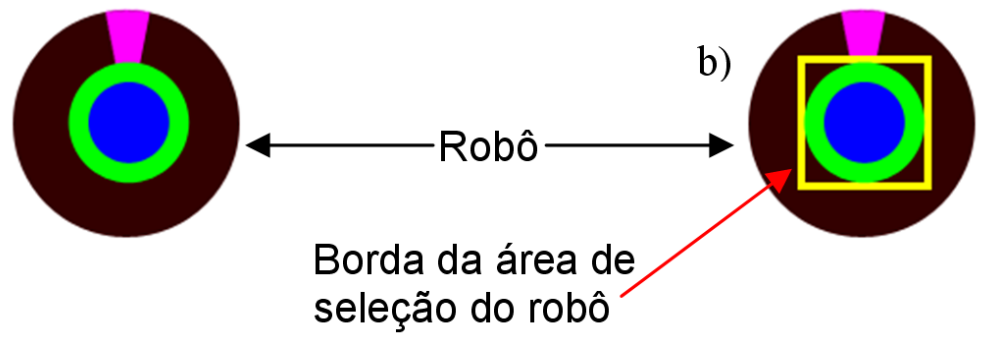

Figura A.11: Seleção do robô para rastreamento: robô antes de ser selecionado (a) e robô após ser selecionado (b).

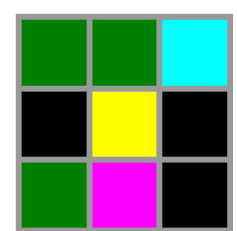

(a)

\begin{tabular}{|l|l|l|l|l|l|l|l|l|}
\hline 0 & 1 & 0 & 1 & 0 & 1 & 3 & 3 & 0 \\
\hline
\end{tabular}

(b)

Figura A.12: Exemplo de protótipo (a) e de vetor histograma (b)

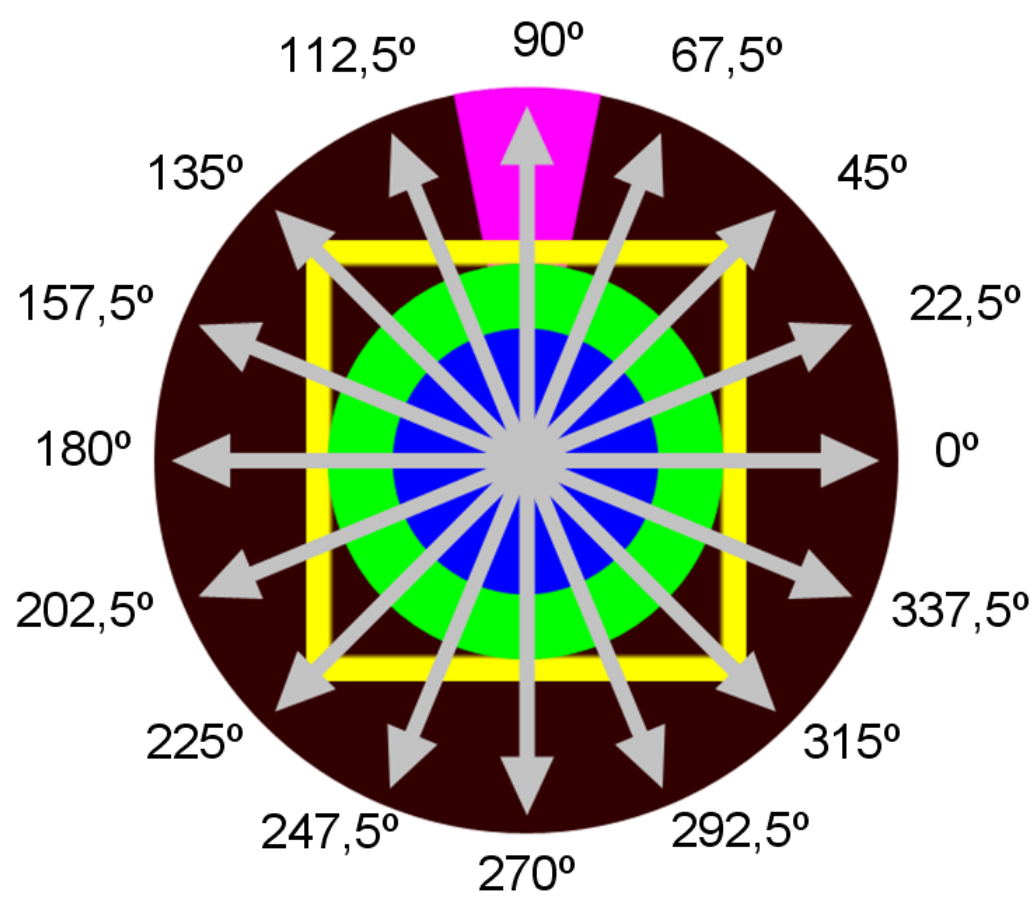

Figura A.13: Exemplo de marcador de robô com as regiões de busca por marcadores de localização e orientação do robô destacadas. 
